\title{
Mars Reconnaissance Orbiter's High Resolution Imaging Science Experiment (HiRISE)
}

\author{
Alfred S. McEwen, ${ }^{1}$ Eric M. Eliason, ${ }^{1}$ James W. Bergstrom, ${ }^{2}$ Nathan T. Bridges, ${ }^{3}$ \\ Candice J. Hansen, ${ }^{3}$ W. Alan Delamere, ${ }^{4}$ John A. Grant, ${ }^{5}$ Virginia C. Gulick, ${ }^{6}$ \\ Kenneth E. Herkenhoff, ${ }^{7}$ Laszlo Keszthelyi, ${ }^{7}$ Randolph L. Kirk, ${ }^{7}$ Michael T. Mellon, ${ }^{8}$ \\ Steven W. Squyres, ${ }^{9}$ Nicolas Thomas, ${ }^{10}$ and Catherine M. Weitz, ${ }^{11}$ \\ Received 9 October 2005; revised 22 May 2006; accepted 5 June 2006; published 17 May 2007.
}

[1] The HiRISE camera features a $0.5 \mathrm{~m}$ diameter primary mirror, $12 \mathrm{~m}$ effective focal

length, and a focal plane system that can acquire images containing up to

$28 \mathrm{~Gb}$ (gigabits) of data in as little as 6 seconds. HiRISE will provide detailed images

( 0.25 to $1.3 \mathrm{~m} / \mathrm{pixel}$ ) covering $\sim 1 \%$ of the Martian surface during the 2-year

Primary Science Phase (PSP) beginning November 2006. Most images will include color

data covering $20 \%$ of the potential field of view. A top priority is to acquire

$\sim 1000$ stereo pairs and apply precision geometric corrections to enable topographic

measurements to better than $25 \mathrm{~cm}$ vertical precision. We expect to return more than

$12 \mathrm{~Tb}$ of HiRISE data during the 2-year PSP, and use pixel binning, conversion from

14 to 8 bit values, and a lossless compression system to increase coverage. HiRISE images

are acquired via $14 \mathrm{CCD}$ detectors, each with 2 output channels, and with multiple choices

for pixel binning and number of Time Delay and Integration lines. HiRISE will

support Mars exploration by locating and characterizing past, present, and future landing sites, unsuccessful landing sites, and past and potentially future rover traverses. We will investigate cratering, volcanism, tectonism, hydrology, sedimentary processes, stratigraphy, aeolian processes, mass wasting, landscape evolution, seasonal processes, climate change, spectrophotometry, glacial and periglacial processes, polar geology, and regolith properties. An Internet Web site (HiWeb) will enable anyone in the world to suggest HiRISE targets on Mars and to easily locate, view, and download HiRISE data products.

Citation: McEwen, A. S., et al. (2007), Mars Reconnaissance Orbiter's High Resolution Imaging Science Experiment (HiRISE), J. Geophys. Res., 112, E05S02, doi:10.1029/2005JE002605.

\section{Introduction}

[2] The High Resolution Imaging Science Experiment (HiRISE) was selected by NASA in November 2001 and the Mars Reconnaissance Orbiter (MRO) was launched on

\footnotetext{
${ }^{1}$ Lunar and Planetary Laboratory, University of Arizona, Tucson, Arizona, USA

${ }^{2}$ Ball Aerospace \& Technologies Corp., Boulder, Colorado, USA.

${ }^{3}$ Jet Propulsion Laboratory, Pasadena, California, USA.

${ }^{4}$ Delamere Support Systems, Boulder, Colorado, USA.

${ }^{5}$ Smithsonian Institution, National Air and Space Museum, Washington, DC, USA.

${ }^{6}$ NASA Ames Research Center and SETI Institute, Moffett Field, California, USA.

${ }^{7}$ U.S. Geological Survey, Flagstaff, Arizona, USA.

${ }^{8}$ Laboratory for Atmospheric and Space Physics, University of Colorado, Boulder, Colorado, USA.

${ }^{9}$ Department of Astronomy, Cornell University, Ithaca, New York, USA.

${ }^{10}$ Physikalisches Institut, University of Bern, Bern, Switzerland.

${ }^{11}$ Planetary Science Institute, Tucson, Arizona, USA.

Copyright 2007 by the American Geophysical Union. 0148-0227/07/2005JE002605
}

12 August 2005 and entered Mars orbit on 10 March 2006. In this paper we describe the experiment in ways that will be useful to scientists who expect to analyze the HiRISE data. This includes a brief description of the hardware and more detailed descriptions of measurement capabilities, sequence planning, calibration plans, and data processing. We discuss our major scientific objectives and expectations for better understanding the many processes that have shaped the surface of Mars. Education and public outreach plans are summarized in a final section.

[3] NASA released an announcement of opportunity (AO) for several MRO science experiments in 2001, including solicitation for a high-resolution imager. Science objectives for the imager were to "Search for sites showing evidence of aqueous and/or hydrothermal activity by... observing the detailed geomorphology and stratigraphy of key locales to identify formation processes of geologic features suggesting the presence of liquid water," "Map and characterize in detail the stratigraphy, geologic structure, and composition of Mars surface features at many globally distributed targeted sites to better understand its complex terrain and to distinguish processes of aeolian and non-aeolian trans- 
port," and "Explore additional ways of identifying sites with a high scientific potential for future Mars landed investigations. "These objectives generally followed from the recommendations of the Mars Exploration Program Analysis Group [Mars Exploration Program Analysis Group, 2001; Greeley et al., 2001; Zurek and Smrekar, 2007].

[4] Originally assuming a $200 \times 400 \mathrm{~km}$ orbit (now $255 \times 320 \mathrm{~km}$ ), the AO specified the following minimum capabilities for the high-resolution imager: "ground resolution" $\leq 30 \mathrm{~cm} /$ pixel from $200 \mathrm{~km}$ altitude, swath width $\geq 3 \mathrm{~km}$ from $200 \mathrm{~km}$, and signal-to-noise ratio (SNR) "adequate for operation in a 3:00 PM local mean solar time orbit." We assumed that the $30 \mathrm{~cm} /$ pixel guideline (which is a ground sampling dimension, not resolution) also required a reasonable Modulation Transfer Function (MTF) for the complete system, such as $\geq 0.1$ at Nyquist ( 2 pixel length scale). Resolution of a surface feature (e.g., enabling measurement of its planimetric dimensions) depends on the contrast of the feature, SNR, and illumination angle, but a useful guideline is that 3 pixels (with $\geq 0.1 \mathrm{MTF}$ and high SNR) are needed across an object to consider it resolved. Fewer pixels may be needed for detection of an object or feature (especially linear features), but may preclude more than an upper limit on dimensions, and may not distinguish between positive and negative relief unless the object is isolated against a uniform background. In essence, our interpretation was that the AO was calling for the capability to measure the dimensions of $\sim 1$ meter scale objects on the Martian surface. We suspect that this requirement metric traced, in part, from an engineering evaluation for the 2001 Mars Surveyor lander (now reborn as the Phoenix lander), that landing on a $0.33 \mathrm{~m}$ high object could be fatal [Golombek et al., 1999], and that an object such as a mostly buried boulder $0.33 \mathrm{~m}$ high would have an exposed diameter of $\sim 1 \mathrm{~m}$. High resolution is also essential for many science studies, but the precise resolution needed varies widely depending on the science objective and characteristics of the surface materials.

[5] We placed a major emphasis on stereo imaging and precision geometric corrections needed to make small-scale topographic measurements, essential both to characterization of candidate landing sites and to quantitative study of surface processes. In addition we added a 3-color capability over $20 \%$ of the swath width, because color images can help resolve ambiguities in image interpretation, such as whether brightness variations are due to topographic shading or the reflectivity of different surface materials, and will enable us to place compositional data from other experiments into more specific geologic and stratigraphic context. We planned a monochromatic swath width of $6 \mathrm{~km}$ at $300 \mathrm{~km}$ altitude as this improves the efficiency of stereo imaging and mapping surface regions of special interest. Also, we set a goal of at least 100:1 SNR as this improves the data for all uses, and is key to detection of small surface units that may have a low contrast with their surroundings.

[6] The orbit of MRO was initially expected to be markedly elliptical with $200 \times 400 \mathrm{~km}$ altitude and with periapse migrating through all latitudes on both the day and night sides. We proposed a camera that would provide $25 \mathrm{~cm} /$ pixel imaging at $200 \mathrm{~km}$ altitude. However, studies by the MRO project in 2002 revealed the need to raise periapse, and the project adapted a $255 \times 320 \mathrm{~km}$ orbit with periapse fixed near the south pole [Zurek and Smrekar, 2007]. At that time we decided to enlarge the telescope structure and increase the effective focal length to $12 \mathrm{~m}$ to achieve an instantaneous field of view (IFOV) of 1 microradian, resulting in 25.5 to $32 \mathrm{~cm} /$ pixel imaging. In this way we preserved meter-scale resolution ( 3 pixels across a meter-scale object) anywhere on Mars, provided highfrequency spacecraft pointing jitter does not significantly smear the images.

[7] A major challenge to high-resolution imaging with a ground track velocity of $\sim 3.2 \mathrm{~km} / \mathrm{sec}$ is how to collect enough photons to make a high-quality image. One option would be to fly a very large telescope, but that is difficult to accommodate on a spacecraft with limited resources. Another option is to slew the spacecraft or instrument or a scanning mirror to slow down the ground velocity of the instrument field of view; slewing the instrument is the strategy used by the Compact Reconnaissance Imaging Spectrometer for Mars, CRISM [Murchie et al., 2007]. We chose to use Time Delay Integration (TDI), in which each small patch of ground is imaged up to 128 times and the signals are summed to increase SNR [Delamere et al., 2003; Dorn et al., 2004; Bergstrom et al., 2004]. The HiRISE charge-coupled device detectors (CCDs) are 2048 pixels wide and 128 pixels high for TDI. We can choose to use all 128 lines, or 64,32 , or 8 lines, depending on the scene brightness, binning level, and tradeoff between SNR and potential smear. TDI imaging requires very precise stability and pointing control by the spacecraft, as described by Lee et al. [2001].

[8] Square pixel binning is available in 6 modes: none $(1 \times 1), 2 \times 2,3 \times 3,4 \times 4,8 \times 8$, and $16 \times 16$. We will use binning when desired to reduce data volume and increase coverage of Mars or to increase SNR. The $8 \times 8$ and $16 \times 16$ binning lead to saturation of well-illuminated scenes and will be most useful for imaging in twilight to extend the seasonal monitoring of polar regions. We have a stepped resolution strategy in which we can image with a subset of CCDs (usually in the center of our FOV) at full resolution, other CCDs with, for example, $4 \times 4$ binning, and then the Context Camera, CTX [Malin et al., 2007] images have a pixel scale twenty times larger than fullresolution HiRISE images and a swath width of $30 \mathrm{~km}$. Thus we can step out by factors of 4 and 5 in pixel scale, covering progressively larger areas at lower resolution for regional context.

[9] In addition to pixel binning, the data can be compressed from 14 to 8 bits and the 8-bit images can be further compressed (without information loss) using the Fast and Efficient Lossless Image Compression System, FELICS [Howard and Vitter, 1993], which is a hardware computer board in the solid-state recorder (SSR) of the spacecraft. We expect FELICS to compress images by factors of 1.5 to 2.0, depending on image characteristics.

[10] Capabilities of the flight instrument are summarized in Table 1 . We met all of our performance goals with three minor exceptions. The read noise in some RED channels will fall short of 100:1 SNR at full resolution over the most challenging required targets, which are low-albedo regions at high latitudes with summertime illumination. This is true for both high northern and high southern latitudes. Although 
Table 1. HiRISE Camera Capabilities at $300 \mathrm{~km}$ Altitude

\begin{tabular}{ll}
\hline \multicolumn{1}{c}{ Parameter } & \multicolumn{1}{c}{ Characteristics } \\
\hline Ground sampling dimension & $30 \mathrm{~cm} /$ pixel $(1 \mu$ rad IFOV) \\
Resolution & $\sim 90 \mathrm{~cm}(3$ pixels across an object) \\
Swath width (RED CCDs) & $6 \mathrm{~km}\left(1.14^{\circ} \mathrm{FOV}\right)$ \\
Color swath width & $1.2 \mathrm{~km}\left(0.23^{\circ} \mathrm{FOV}\right)$ \\
Maximum image size (pixels) & $20,000 \times 63,780(14$-bit data) \\
SNR (anywhere on Mars in the optimal season) & From $90: 1$ to $250: 1$ in RED channels with TDI 128 and full resolution \\
Color band passes (at half maximum of Mars- and & RED: $570-830 \mathrm{~nm} \mathrm{BG:}<580 \mathrm{~nm}$ NIR: $>790 \mathrm{~nm}$ \\
$\quad$ solar-weighted spectral response; see Figure 12) & $\sim 25 \mathrm{~cm}$ vertical over $\sim 1 \mathrm{~m}^{2}$ areas \\
Stereo topographic precision & $8,32,64$, or 128 \\
TDI lines & none $(1 \times 1), 2 \times 2,3 \times 3,4 \times 4,8 \times 8,16 \times 16$ \\
Pixel binning & 14, can be compressed to 8 via look-up tables (LUTs) \\
Bits per pixel & FELICS, compression $>1.6: 1$ \\
Compression (8-bit images only) &
\end{tabular}

Mars is closer to the sun in southern summer (improving $\mathrm{SNR}$ ), the orbit is also lower, which decreases the integration time (worsening SNR), and these two effects are of similar magnitude. The second exception is that the computer processing/memory module (CPMM) for one of the blue-green CCDs (BG13) may not work correctly with 128 or 64 TDI lines, so with no more than 32 TDI lines we must typically apply $4 \times 4$ rather than $2 \times 2$ binning to exceed 100:1 SNR. The third problem is injection of bad data in channel 1 of CCD IR10 when the Focal Plane Electronics (FPE) is relatively cold $\left(<15^{\circ} \mathrm{C}\right)$, a problem discovered after launch. Before the start of the PSP we plan to increase the heater settings to insure that the FPE will be no colder than $\sim 15^{\circ} \mathrm{C}$.

\section{HiRISE Instrument Description}

[11] Here we give a very brief summary of the instrument design and performance, described in more detail by Delamere et al. [2003], Dorn et al. [2004], Bergstrom et al. [2004], and Gallagher et al. [2005]. The HiRISE instrument consists of the telescope and focal plane subsystem (FPS) and two remote electronics boxes, one for the power supply and another for the instrument controller electronics (Figure 1). The telescope (Figures 2 and 3) is a $50 \mathrm{~cm}$ aperture, $\mathrm{f} / 24$ system. The focal plane contains 14 CCD detectors that are operated in Time Delay and Integration (TDI) mode. The mass and orbital average power of the camera are summarized in Table 2.

\subsection{Remote Electronics}

[12] The remote electronics consists of two boxes (Figure 1): the instrument controller and the power supply. The controller consists of the processor board and two boards containing the telemetry and interface components. There are two controllers for complete redundancy. In the standby state, the processor controls and monitors the instrument temperatures, outputs telemetry data to the spacecraft and receives commands from the spacecraft. When an image request is received from the spacecraft the controller sets up the

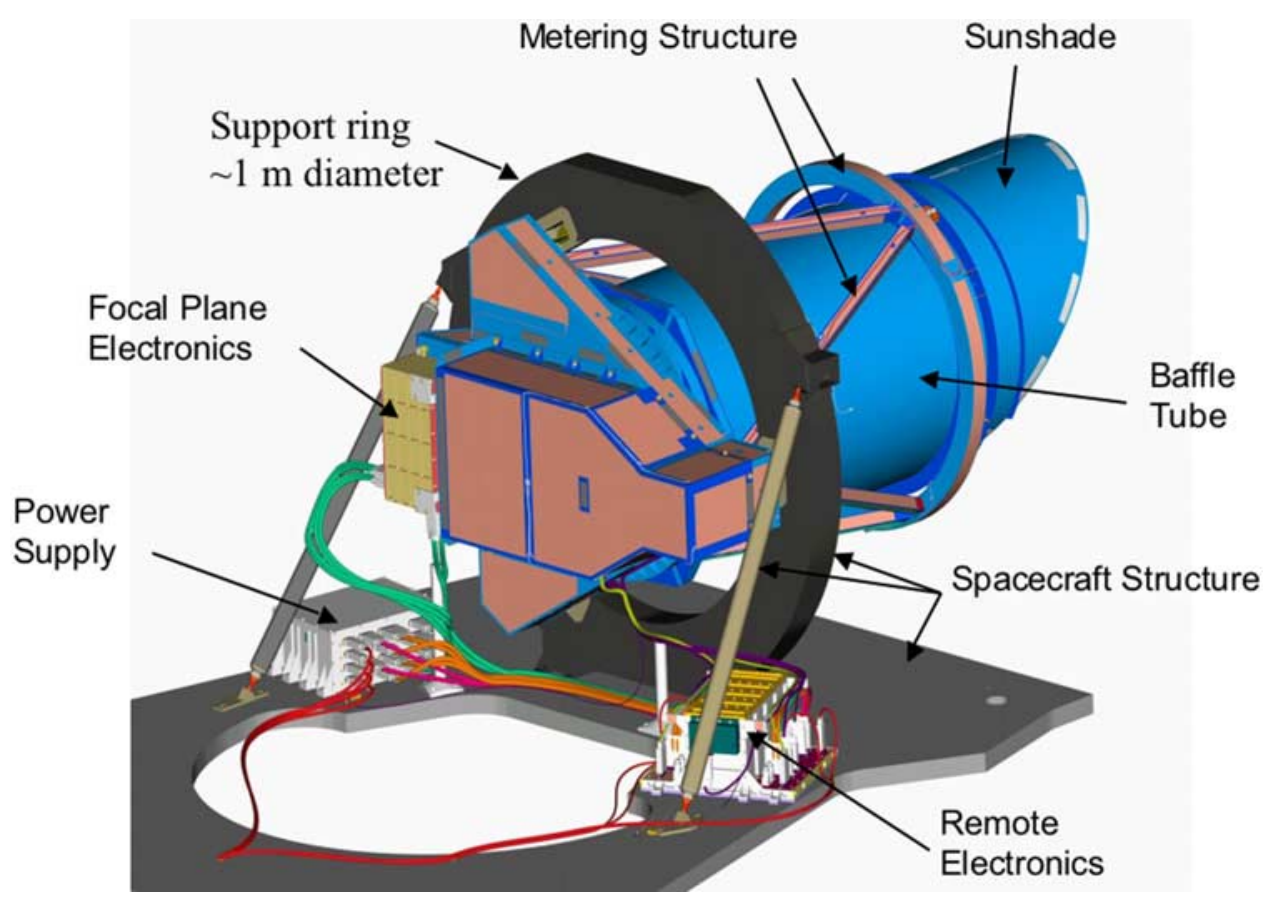

Figure 1. Drawing of the HiRISE imager mounted to spacecraft support ring. The FPS is attached to the back of the telescope. The two separate boxes mounted on the spacecraft structure are the power supply (left) and the instrument controller (right). 


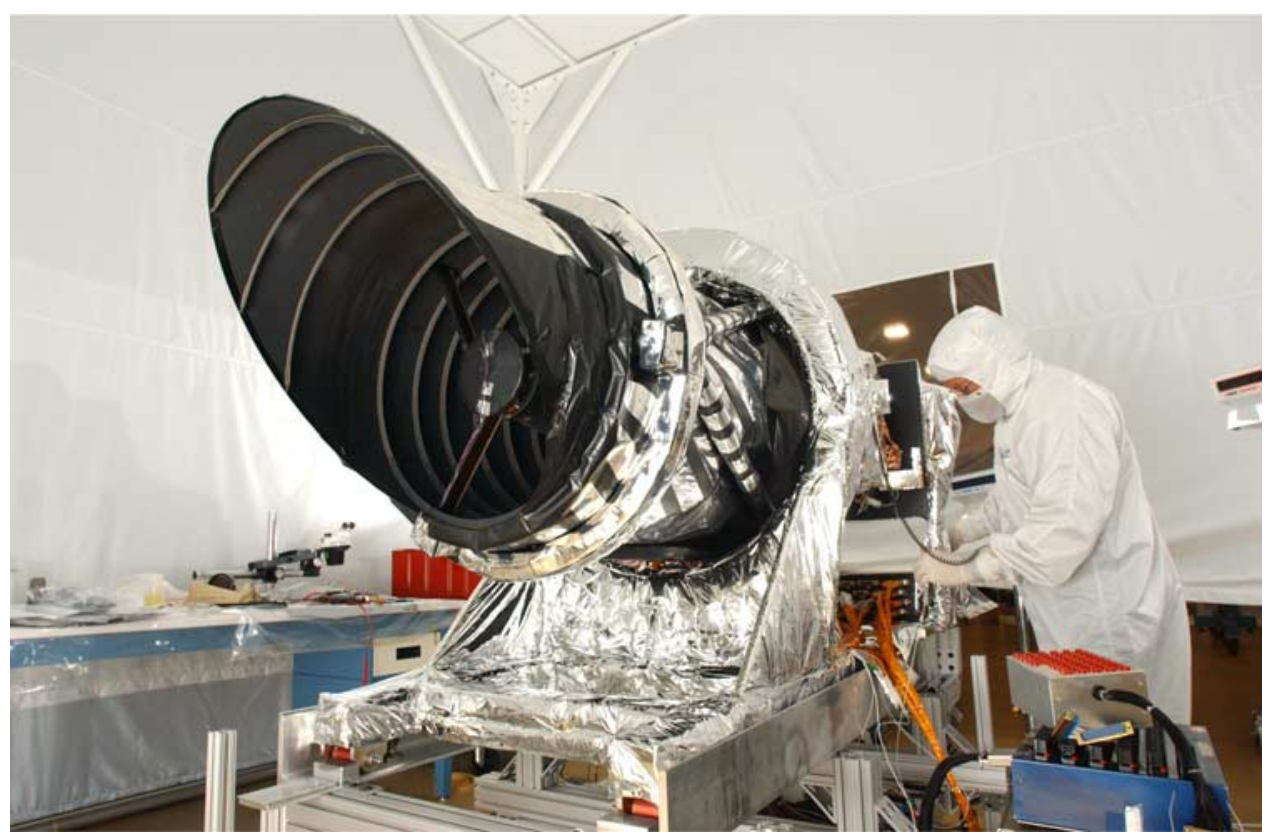

Figure 2. HiRISE instrument inside a clean room tent at Ball Aerospace and Technology Corporation in Boulder, Colorado.

imaging conditions, turns the power on to the camera electronics and sends the image parameters to the CPMMs. No image data is handled by the processor during CPMM memory dump. The controller simply adds header data to the image data as it is transferred to the spacecraft SSR. The power supply is completely redundant and each side consists of two boards, one for the instrument controller and one for the camera electronics. These boards produce all the necessary regulated voltages from the spacecraft $28 \mathrm{~V}$ supply. HiRISE redundant electronic sides A and B are tied to the redundant spacecraft SSR sides 1 and 2, respectively, so we can switch to side B (and return data) only if the spacecraft switches to SSR side 2.

\subsection{Telescope}

[13] The telescope design is an all-reflective three-mirror astigmatic with light-weighted Zerodur optics and a graphitecomposite structure (Figure 3). The Cassegrain objective with relay optic and two fold mirrors is optimized for diffraction-limited performance over the long, narrow

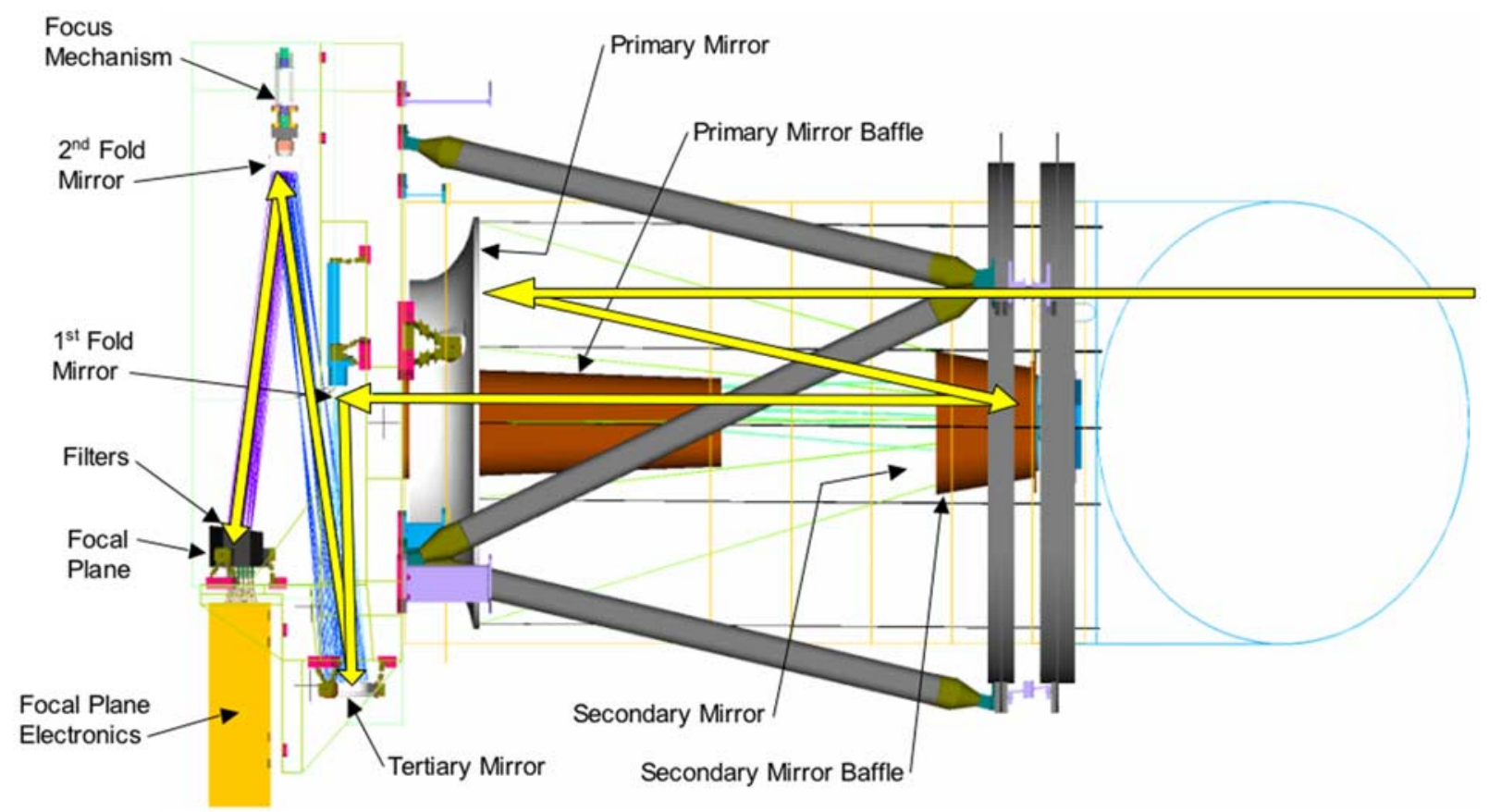

Figure 3. Graphical cut-out representation of HiRISE imager, with a sample of ray traces (yellow). 
Table 2. Mass and Orbital Average Power of HiRISE Camera

\begin{tabular}{lcc}
\hline \multicolumn{1}{c}{ Item } & Mass, kg & $\begin{array}{c}\text { Orbital Average } \\
\text { Power, W }\end{array}$ \\
\hline Thermal control system & 5 & 35 \\
Instrument controller & 8 & 13 \\
FPS & 5 & 5 \\
Power supply & 7 & 7 \\
Optics & 15 & 0 \\
Structure & 19 & 0 \\
Cables & 6 & 0 \\
Totals & $\mathbf{6 5}$ & $\mathbf{6 0}$ \\
\hline
\end{tabular}

field-of-view (FOV) required for "push-broom" imaging. Fold mirror 2 lies on a linear actuator for focus control. The primary mirror has a "dual arch" construction for low mass and high rigidity. The optical system provides a diffraction limited modulation transfer function (MTF) on $12 \mu \mathrm{m}$ pixels for all 14 HiRISE CCDs. Color filters are located $30 \mathrm{~mm}$ from the detectors for all three bands; this distance avoids problems due to stray light and multiple reflections from the filters in the $f / 24$ quasi-collimated beam. A Lyot stop is located between the secondary mirror and the first fold mirror for reduction of stray light. Light Emitting Diodes (LEDs) are mounted inside the Lyot stop, enabling generation of uniformly illuminated images to monitor performance of the instrument. Geometric distortions in the field of view are very small, and the CCDs were positioned to compensate for the slight curvature, so there is one correct spacecraft yaw or slew angle for all 14 CCDs.

[14] The telescope structure is made of graphite-fiberreinforced composite material. This produces a stiff, lightweight structure with low moisture absorption properties and low coefficient of moisture expansion. The negative coefficient of thermal expansion (CTE) of the composite elements, in conjunction with metallic, positive CTE fittings, is tailored to provide temperature compensation. Note that the external support structure (Figures 1 and 2) is the metering system between the primary and secondary mirrors and is temperature controlled with heater mats.

\subsection{Focal Plane Subsystem (FPS)}

[15] The FPS consists of the CCDs, a focal plane substrate of aluminum-graphite composite material, a spectral filter assembly, and CCD processing/memory modules (Figure 4). Each CCD has $204812 \times 12$ um pixels in the cross-scan direction and 128 TDI elements (stages) in the along-track direction. The CCDs are staggered to provide full swath coverage without gaps (Figure 5). There are two CCDs for both the BG and NIR bands and 10 CCDs for the RED band. The staggered CCDs overlap by $48 \pm 5$ pixels with adjacent CCDs in the same color band pass; this provides an effective swath width of $\sim 20,048$ pixels for the RED images and $\sim 4,048$ pixels for the blue-green and NIR images. The BG and NIR channels overlap with the central two RED CCDs to provide 3-color coverage.

[16] TDI increases the effective exposure time, allowing a high SNR in spite of $1 \mu$ radian pixels and a ground speed near $3.2 \mathrm{~km} / \mathrm{s}$. As the spacecraft moves over the surface of Mars, the TDI method integrates the signal by shifting the accumulated electrons into the next row (line) of the CCD at the same rate as the image moves (see Figure 6). The pixel line time for each image is set to match the predicted ground velocity so that charge from one image pixel is sequentially clocked into the next corresponding element in the alongtrack direction. The correct line time is determined by the ground track velocity and spacecraft altitude, corresponding to $74 \mu \mathrm{sec}$ for $238 \mathrm{~km}$ altitude and $110 \mu \mathrm{sec}$ at $320 \mathrm{~km}$ altitude if the surface altitude is near the $0 \mathrm{~km}$ datum. Longer line times are possible, for example for imaging stars, but $74 \mu \mathrm{sec}$ is the minimum allowed by the electronics. Use of line times that are either shorter or longer than the correct value results in downtrack smear. The imager can use $8,32,64$ or 128 TDI stages (detector elements in the along-track direction) to match scene radiance to the $\mathrm{CCD}$ full well capacity, or to the 14-bit limit if pixel binning is used (see Figure 7).

[17] The CCD Processing and Memory Module (CPMM) electronics were designed to minimize the number of active and passive components that contribute to noise. The analog signal processing chain between the CCD output amplifier and the 14 bit analog-to-digital converter adds less random noise than the $\mathrm{CCD}$, while being radiation tolerant and reasonably low power. The digital Correlated Double Sample (CDS) scheme is capable of very high pixel rates, in excess of 16 megapixels per second, while sampling a minimum of twice per pixel. Each of the 14 CPMMs uses a radiation-hard Xilinx Virtex 300E FPGA to perform the control, signal processing, compression through use of look-up tables (LUTs), data storage and maintenance, and external input/output.

\section{Camera Performance}

\subsection{Optics Performance}

[18] Preflight testing showed that the optical performance is excellent in terms of MTF and the point-spread function (PSF). Figure 8 shows an image taken with the HiRISE camera of a 2000 line/inch bar target at the focus of a 30inch collimator. The image was acquired via strobe illumination to "freeze" an image on the CCD without moving the camera relative to the target. Each bar pair would represent a $90 \mathrm{~cm}$ feature (like $90-\mathrm{cm}$ wide grooves) imaged from a range of $300 \mathrm{~km}$. Plots of signal intensity across the bars show that the MTF is $\sim 20 \%$. A typical PSF (Figure 9)

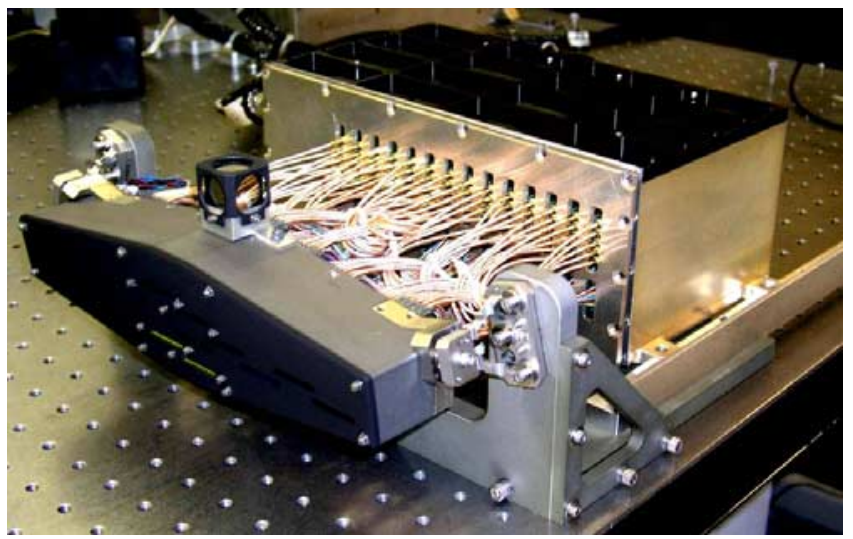

Figure 4. Focal Plane Assembly with optical alignment cube on top of the filter cover over the CCDs. 


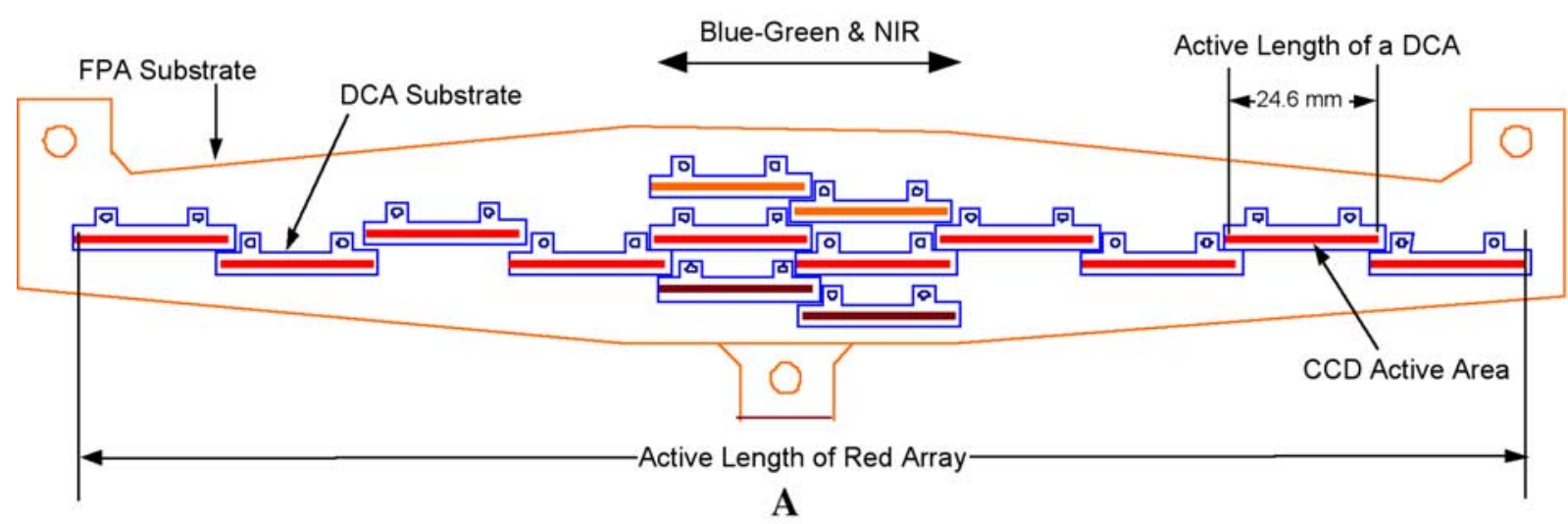

A

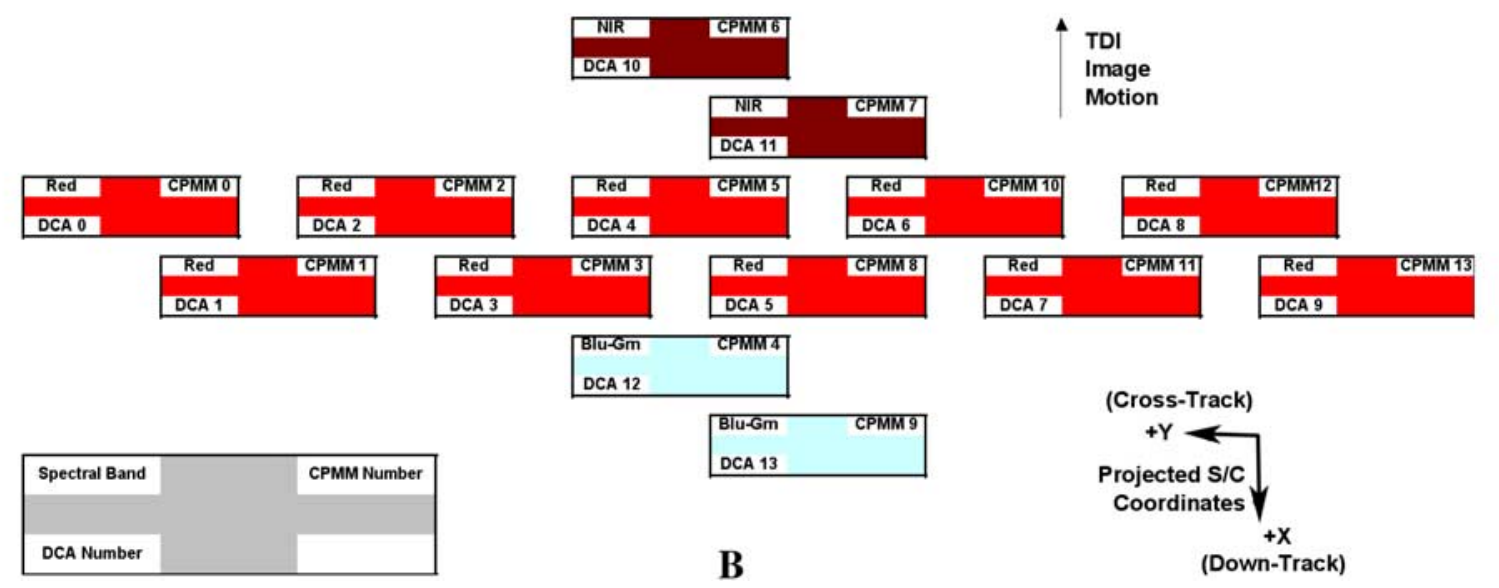

Figure 5. (a) Layout of CCDs on the base plate, approximately to actual scale. (b) Reference data on each Detector Chip Assembly (DCA), which consists of the CCD and CPMM. Spacecraft motion would be down as shown here, although HiRISE will typically image on the ascending side of the orbit.

for a strobe-illumination pinpoint image has a full width at half of maximum (FWHM) PSF of $\sim 1.5$ pixels. Images acquired in flight include down-track and cross-track smearing. The down-track smear should be only $1 / 4$ pixel via the four-phase readout of HiRISE images (the charge in each line is actually read out and transferred four times for each line). The smear due to jitter (down-track and cross-track) and yaw error (cross-track) is expected to be less than 0.5 pixel for the majority of time during high-stability imaging. Therefore a typical PSF of a HiRISE image of Mars will be as wide as $\sim 2$ pixels FWHM with no binning, or $\sim 1$ pixel with $2 \times 2$ binning.

[19] The predicted maximum signal from Mars (sunfacing slope with bright-region albedo) is $\sim 76,000$ electrons for the RED channel at $300 \mathrm{~km}$ with 128 TDI lines and no binning. Figure 10 shows the expected SNR at full resolution as a function of illumination angle and regional albedo for the blue-green, red, and NIR bands. Binning increases the SNR by approximately the square root of number pixels binned, so $2 \times 2$ binning doubles the SNR if the number of TDI lines is unchanged. Actual illumination angles in the PSP orbit will range from $\sim 45^{\circ}$ (or lower at times with the 3 PM local mean solar time) to $90^{\circ}$ (or higher via imaging in twilight), but in the optimal season we can image polar regions down to $\sim 70^{\circ}$ illumination angle. At $70^{\circ}$ illumina- tion angle we fall just short of our 100:1 SNR goal for the darkest terrains for some of the 28 channels of data. Bluegreen and NIR images will usually be binned by at least $2 \times 2$ to achieve $>100: 1$ SNR.

\subsection{FPS Performance}

[20] The random noise is close to the desired values, $\sim 80$ to 120 electrons RMS (root-mean squared). There is also a fixed pattern noise (vertical stripes) that is correctable in

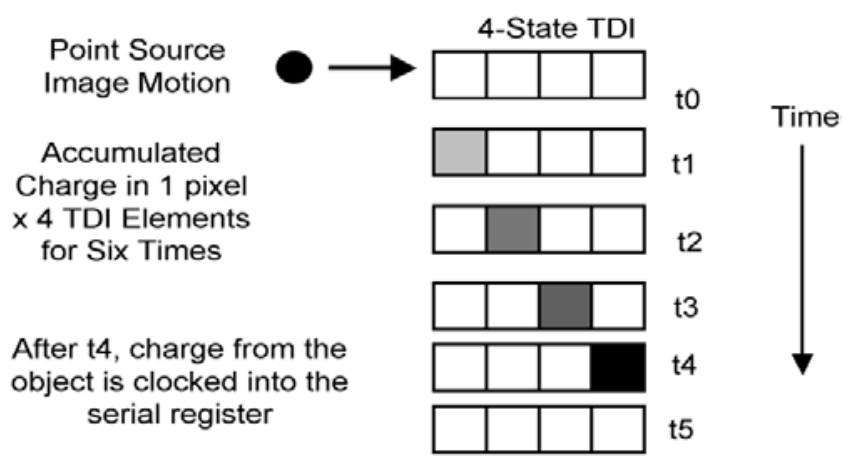

Figure 6. Illustration of 4-line Time Delay and Integration (TDI). HiRISE can use $8,32,64$, or 128 TDI lines. 


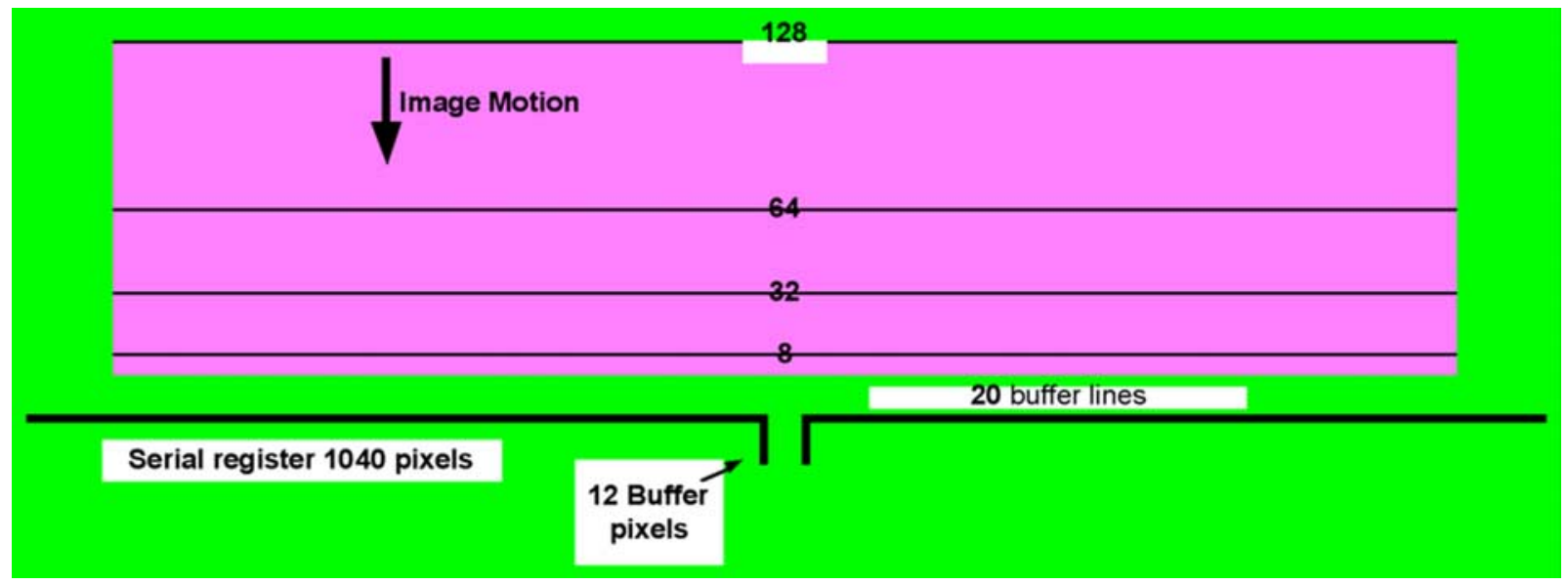

Figure 7. Layout of each HiRISE CCD. There are 4 sections of lines corresponding to the 4 TDI choices, plus 20 buffer lines (read out once at the beginning of each image). The data is read out into 2 channels from a tap in the middle of the array, beginning each line with 12 buffer pixels and ending with 16 masked pixels. Channel 0 is on the right and channel 1 on the left side, as viewed here, so the data from channel 1 must be "mirrored or flipped left to right to restore the proper image orientation. (Note that spacecraft motion is up here, whereas it is down in Figure 5.)

processing. When using mixed bin modes there is also a correctable horizontal fixed pattern. The CCD gain values range from $\sim 20$ to 25 electrons per 14-bit digital number (DN). The CCD is backside illuminated and treated to give an average quantum efficiency greater than $65 \%$ over the wavelength range of 350 to $900 \mathrm{~nm}$. There are selectable parameters for where to sample the analog video waveform for digital conversion. There are 8 possible positions for where to measure the two video waveform samples, and the difference between these two values is proportional to the signal level and determines the DN. We found settings " 5 " and " 4 " to give the best performance (lowest read noise,

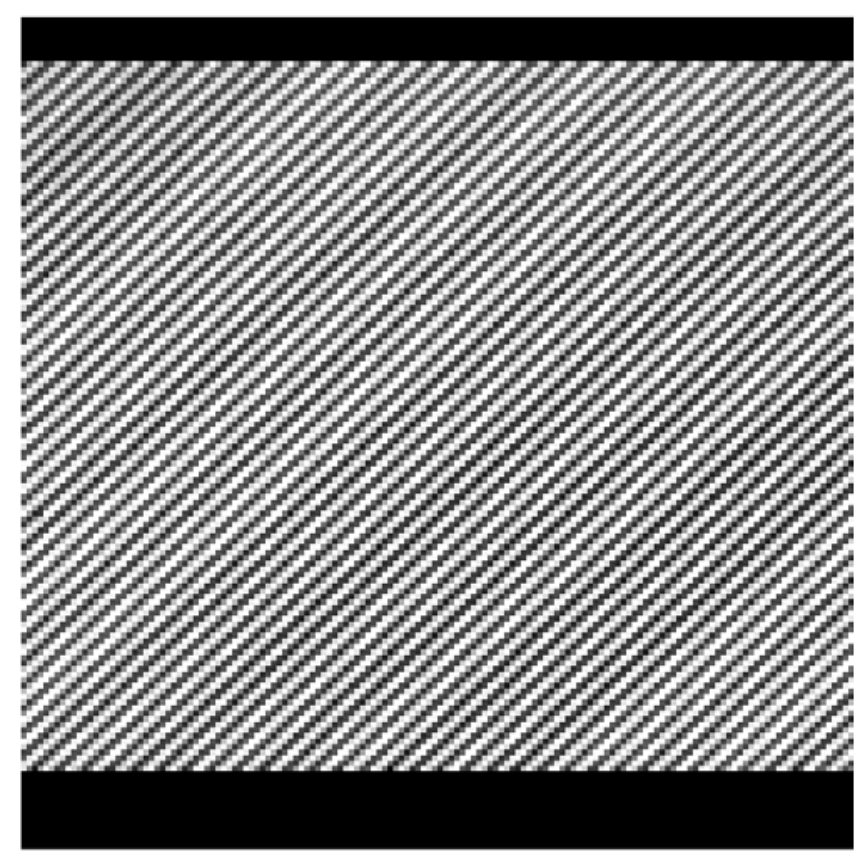

Figure 8. Preflight image of a target with a bright-dark pattern 3 pixels wide, used to verify instrument MTF. highest SNR, and least fixed-pattern noise) for all channels. The 5,4 setting also minimizes the bad data at cold temperatures seen in IR10 channel 1.

\subsection{Thermal Considerations}

[21] There are 14 operational thermal control zones in addition to the 3 survival zones under spacecraft control. We maintain the temperatures of both the FPS and optics to $\sim 20^{\circ} \mathrm{C}$. However, when large quantities of image data are being collected or transmitted to the solid-state recorder, the FPA and FPE will heat up. We model these temperatures as a function of the type and number of images per orbit to prevent excess dark current (thermal noise) and especially to avoid "safing" (power off) of the camera, which occurs if allowable flight temperatures are exceeded. At Mars we will be strongly limited overall by our data volume allocation,

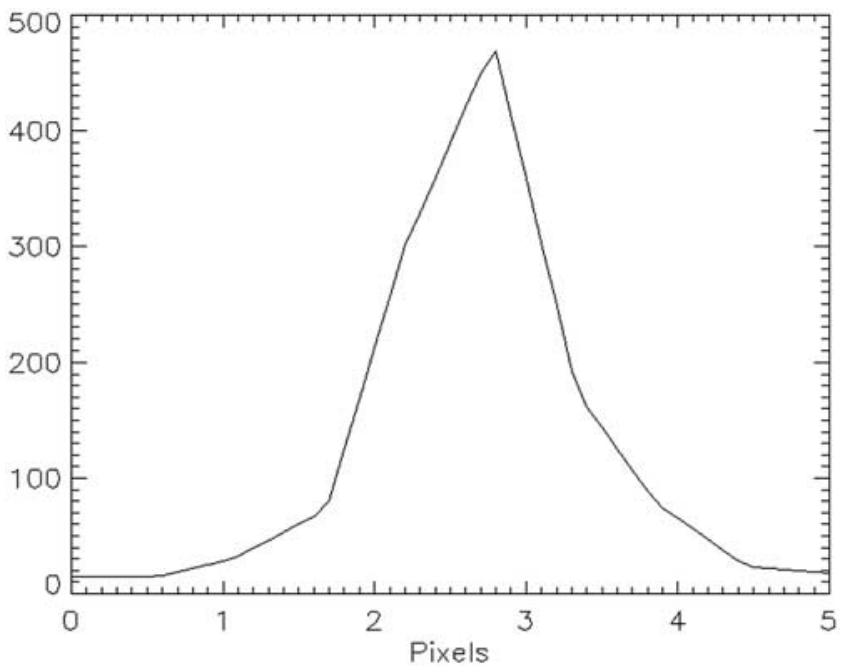

Figure 9. Typical Point-Spread Function (PSF) for a HiRISE pinhole image, acquired at Ball Aerospace with a 30-inch collimator. 

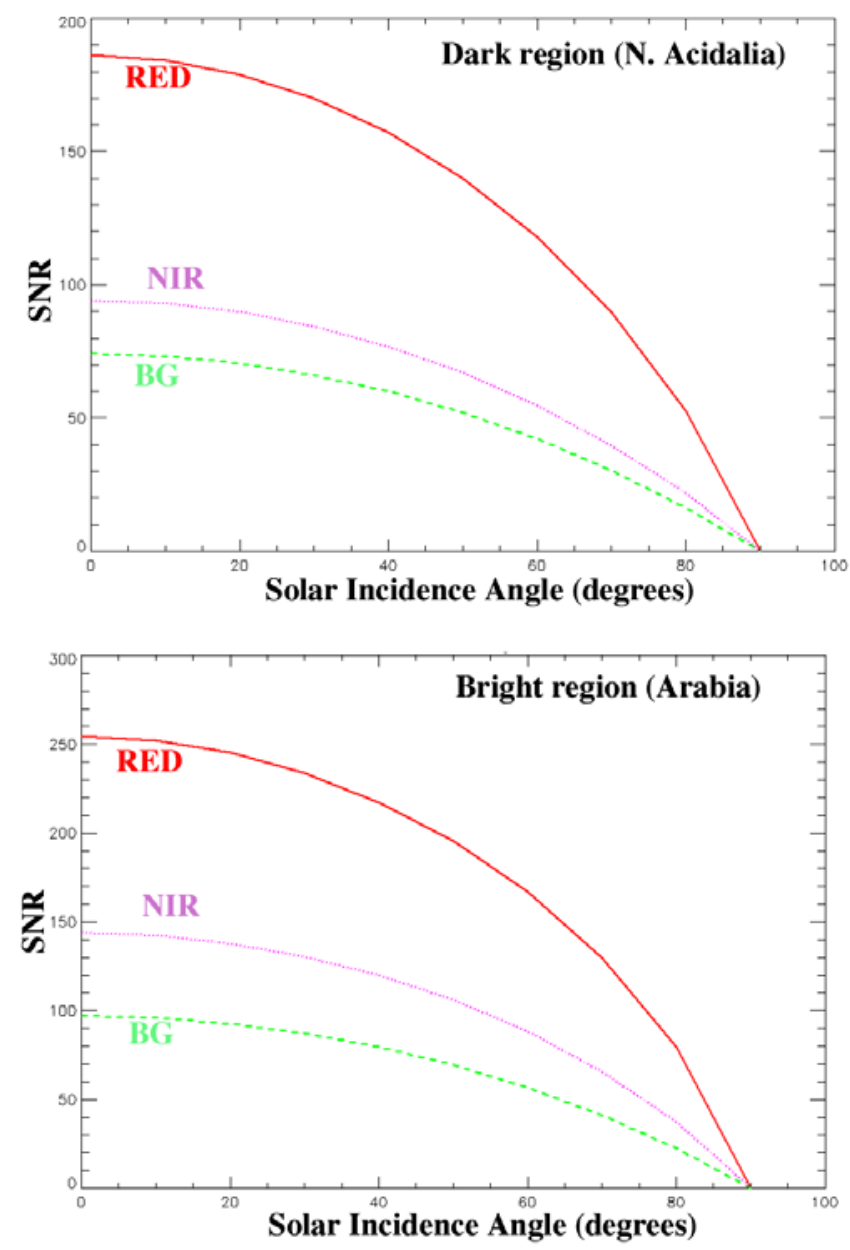

Figure 10. Signal-to-noise ratio (SNR) as a function of illumination angle for bright and dark regions of Mars, assuming 120 electrons of read noise, an inverse gain of 20 electrons/DN, average line time, average Sun-Mars distance, and Lambertian photometry.

but the thermal limits reduce flexibility because we cannot collect more than one large $(>12 \mathrm{~Gb})$ image in a single orbit.

\subsection{Anatomy of HiRISE Image Channels}

[22] When the camera is turned on, it begins in reverseclocking mode, so the charge is transferred "up" to an electron drain rather than "down" to the serial register (Figure 7). This avoids accumulation of change on CCDs. When we switch to forward-clocking mode there is a transition over the number of TDI lines, producing a ramp ranging from zero signal at top to twice the scene signal at the bottom (Figure 11). A "trim" function delays the start of forward clocking for each CCD so that they all begin to collect data over the same starting location in the scene, so the assembled image will have a nearly straight beginning edge (usually the southern edge at Mars since we are in an ascending orbit on the dayside). The trim function is imperfect for mixed-mode images because the ramp size varies with bin and TDI setting. The camera first records 20 masked lines and 20/bin reverse-clocked lines to aid offset calibration and removal of fixed-pattern noise, then records the ramp followed by the desired image. If binning is greater than 1, then the number of reverse-clock and ramp lines are reduced accordingly, but the number of image lines is specifically commanded for each CCD. The ramp length in lines is the number of TDI lines divided by binning, so it can be as much as 128 lines or as little as 1 line (TDI 8 and binning 8 or 16). The number of image pixels in a line for each channel is 1024 divided by the binning level. In addition, we record 12 buffer pixels (offset only) on the left and 16 masked pixels (offset plus dark current) on the right.

\section{Spectrophotometry}

[23] HiRISE includes broad-band color capability. In addition to the red-filter channels extending over the full swath width, the central $20 \%$ of the swath can be imaged with additional CCDs that are covered with blue-green or NIR filters. In Figure 12, the spectral distribution of the signal is shown as a function of wavelength for a typical Mars spectrum. The integrated signal level in the RED channel is $\sim 6 \times 10^{6}$ electron $\mathrm{s}^{-1}$ which, for a minimum integration time of $74 \mu$ secs and a TDI of 128 lines, would give 60,000 electrons per pixel in the highest-resolution mode and SNR 175:1.

[24] The central wavelengths of the filters (weighted by the response function and by a typical Mars spectrum) are given in Table 3. Note that the central wavelength of the "blue-green" channel of HiRISE is close to the $530 \mathrm{~nm}$ central wavelength of the Viking Orbiter green filter. Table 3 also shows the ratio of the expected signal level to that in RED for the two color channels. Binning $2 \times 2$ in the color channels will therefore give comparable SNR at a slightly lower resolution than in the RED channel.

[25] HiRISE has been radiometrically measured with an integrating sphere and its in-flight performance has been checked with standard star and lunar observations. This should allow high-resolution photometric characterization of the Martian surface assuming that atmospheric scattering is minor or can be accurately modeled.

[26] The high-resolution color capability is a novel feature of HiRISE that will be used to assess possible compositional differences in, for example, layers seen in sedimentary deposits and valley and canyon walls. Lucchitta et al. [1992] reviewed some of the results from Viking Orbiter broadband spectral reflectance observations of stratigraphy in the canyon systems. Significant differences between units were noted, even over the relatively limited spectral range of the Viking camera system $(450-590 \mathrm{~nm})$. With the wider spectral range of HiRISE, heterogeneity in composition can be better addressed (detecting color distinctions between, for example, pyroxene-rich and hematite-rich units; Figure 13) and will complement the mineralogic results from CRISM. This capability of HiRISE will also be useful for observations of the polar caps where albedo and color differences possibly resulting from heterogeneity in dust deposition will strongly influence the energy budget. Care in interpretation will be needed, however, because the skylight has a redder color than does direct sunlight. Shadowed regions (illuminated by skylight) will appear relatively red, including subresolution shadows. Thus a rougher unit may have a different color than a smoother exposure of the same materials [Thomas et al., 2000] and 

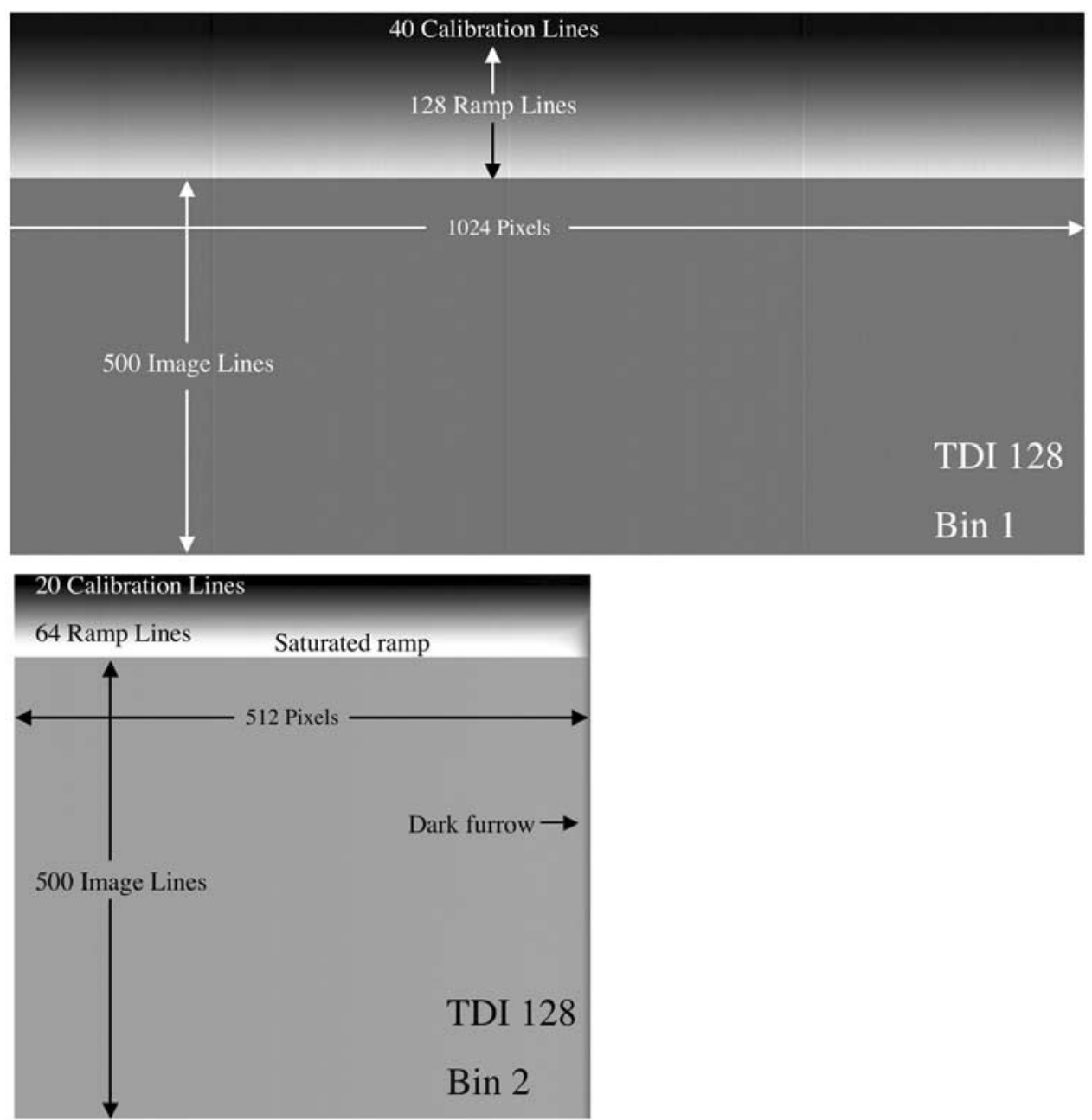

Figure 11. Single-channel images illuminated by internal stimulation lamps (LEDs). (top) RED CCD 4 channel 0, TDI 128, bin 1. (bottom) RED CCD 4 channel 1, TDI 128, bin 2. Note ramp saturation and "furrow" on right edge of channel (middle of CCD). The furrow occurs on the right edge of channel 1 EDRs (after mirroring) and on the left edge for channel 0.

some color differences may be the result of physical differences in surface materials [Christensen and Moore, 1992] rather than compositional differences. Frosts and smallscale high-opacity condensate clouds should be identifiable in the color images.

[27] HiRISE color data will be complementary to that from the Thermal Emission Imaging System (THEMIS) [Christensen et al., 2004] and High Resolution Stereo Camera (HRSC) [Neukum and Jaumann, 2004]. The visible camera of THEMIS provides images in five color band passes from 400 to $900 \mathrm{~nm}$ wavelength and up to $18 \mathrm{~m} /$ pixel scale, but these data contain a stray light component that has been difficult to calibrate [McConnochie et al., 2006]. The HRSC camera on Mars Express has color imaging at a moderately high resolution (up to $\sim 10 \mathrm{~m} /$ pixel). Images through each HRSC band pass are acquired at different emission and phase angles, so photometric corrections are needed to avoid apparent color variations due to the scattering behavior of the atmosphere and different surface materials. HiRISE acquires data in all 3 band passes at identical photometric angles and has excellent stray light rejection (verified by lunar imaging), so color variations due

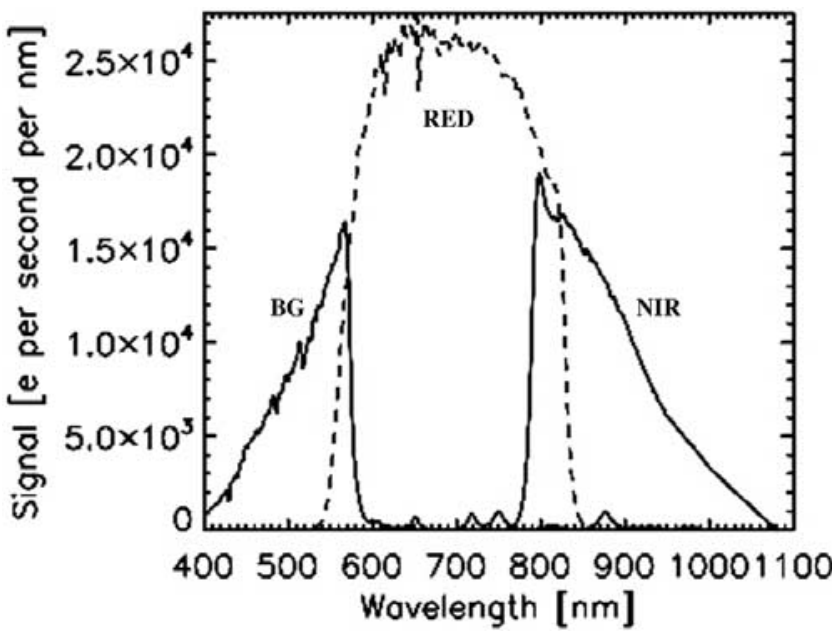

Figure 12. Spectral response (in electrons $/ \mathrm{sec} / \mathrm{nm}$ ) of each HiRISE color channel. Solid curves are blue-green and near-IR channels; RED channel is shown with dashed curve. Simulation assumes average "bright" Mars surface reflectance, observed at solar phase angle $=45^{\circ}$ at $1.5 \mathrm{AU}$ from the Sun. 
Table 3. Central Wavelengths of HiRISE Color Channels Derived by Weighting Predicted Instrument Response in Each Channel by the Solar Spectrum and Bright Mars Surface Reflectance

\begin{tabular}{lcc}
\hline \multicolumn{1}{c}{ Filter } & $\begin{array}{c}\text { Central } \\
\text { Wavelength, nm }\end{array}$ & $\begin{array}{c}\text { Signal Level } \\
\text { (Red }=100 \%)\end{array}$ \\
\hline Red & 694 & $100 \%$ \\
Blue-green & 536 & $23 \%$ \\
NIR & 874 & $39 \%$ \\
\hline
\end{tabular}

to compositional and roughness variations of the surface materials will be measured if atmospheric properties are uniform over the small image areas. However, THEMIS and HRSC color coverage of Mars is much more extensive than that likely from HiRISE.

\section{Instrument Calibration}

\subsection{Preflight Calibration Data}

[28] More than 7,000 images were acquired prior to launch for functional and reliability tests, diagnosing problems with the Xilinx FPGA code that controls the FPS, optical performance tests, and radiometric calibrations. The images include dark frames (no illumination), images illuminated by the internal stimulation lamps (LEDs), unfocused images through the telescope with uniform lighting (integrating sphere or diffuse "flat field" targets), and images acquired through the telescope with a collimator to enable focused images. Due to late changes in the Xilinx FPGA code, only a subset of these images is fully representative of the performance of the camera launched to Mars. The final flight version of the FPGA code was loaded into the camera on 14 May 2005. We are in the process of deriving matrices and procedures for correction of offset, dark current, fixed-pattern noise, gain, and furrows (see Figure 11). Matrices are needed for each of the 28 channels and for each of the 4 TDI settings, with additional corrections as a function of binning mode and FPE temperature. Results of this effort and in-flight calibrations will be described in detail in a future paper.

\subsection{Inflight Calibration}

[29] Inflight calibration observations have been and will continue to be acquired (1) to determine how the instrument's radiometric and geometric calibration has changed in a postlaunch environment, (2) to assess the effects of spacecraft jitter under a range of conditions, (3) to determine the optimum focus position, (4) to measure the PSF (including effects of stray/scattered light), and (5) to determine the boresight alignment between HiRISE, the star trackers, CRISM, and CTX. These calibrations began during cruise and will continue in the transition and primary science phases.

\subsubsection{Cruise Calibrations}

[30] Three observation periods were initially planned during cruise. Star images are mostly uncompressed (14 bits per pixel) with up to 45,000 lines. Slews were at $0.05^{\circ} \mathrm{sec}^{-1}$ or less, necessitating line times of $1.1 \mathrm{msec}$ or more. Inertial Measurement Unit (IMU) data at $200 \mathrm{~Hz}$ and spacecraft pointing information at $10 \mathrm{~Hz}$ was returned. This engineering data was also acquired independent of imaging in order to assess the stability of the spacecraft under various conditions (reaction wheel speed and any

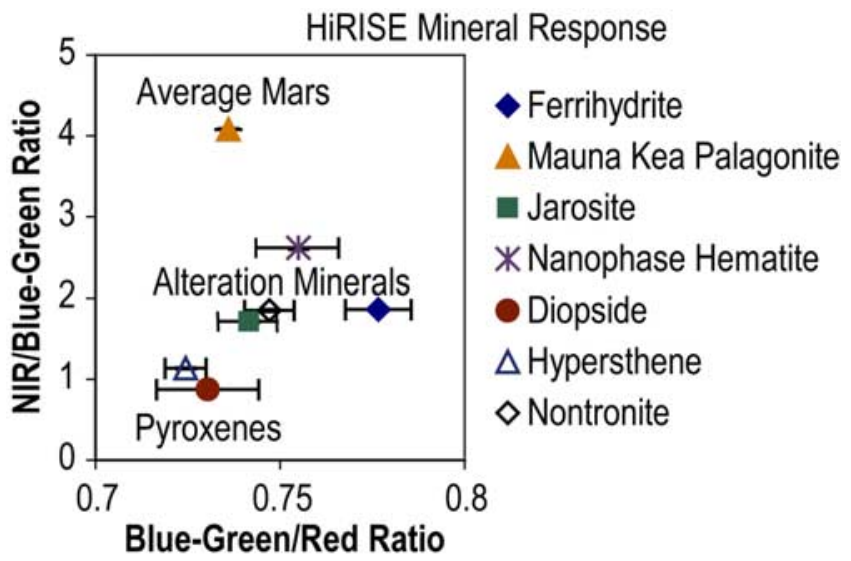

Figure 13. Laboratory spectra for candidate minerals on Mars from http://speclab.cr.usgs.gov/spectral-lib.html [Clark et al., 2003] convolved to HiRISE color band passes and plotted as color ratios. Major classes of minerals (average dusty Mars, alteration minerals, and unaltered volcanic pyroxenes) can be distinguished.

other movements). Images of dark space will be used to assess dark current and offset.

5.2.1.1. Moon and Omega Centauri, 8 September 2005

[31] During this opportunity there were three scans across the Moon at $0.05^{\circ} \mathrm{sec}^{-1}$ to the globular cluster Omega Centauri. These were the first HiRISE images taken in space

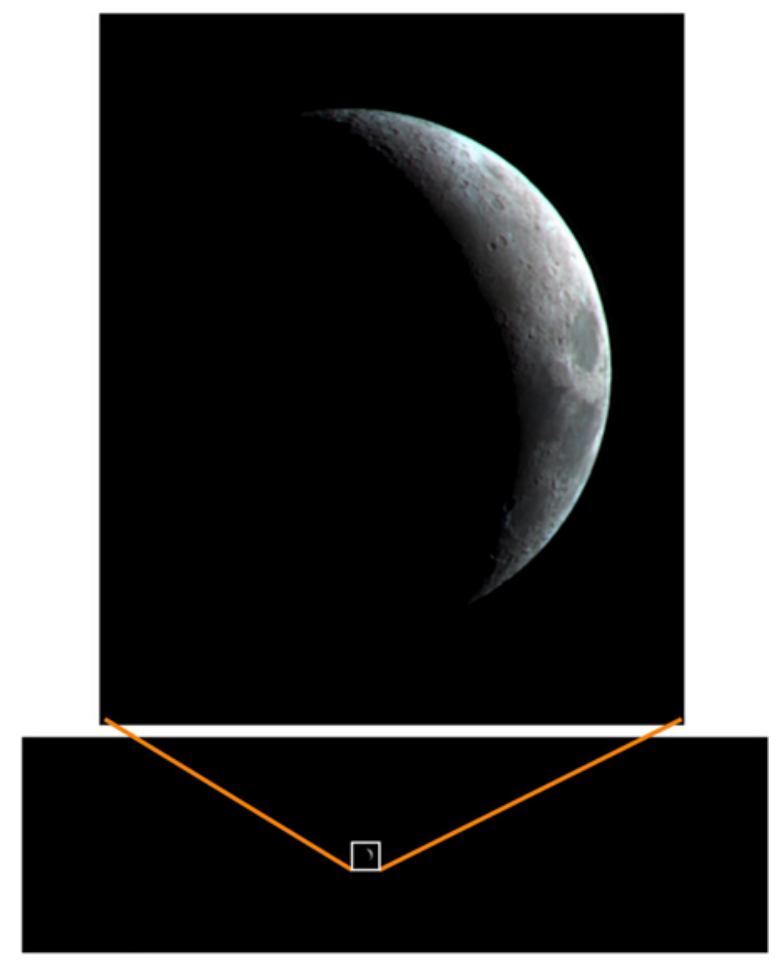

Figure 14. HiRISE image of the Moon acquired 8 September 2005. The bottom image shows the entire red-filter image with 10 CCDs. Image size is $20,048 \times 8,000$ pixels. At top is a blowup of the lunar image in color, $10 \mathrm{~km} / \mathrm{pixel}$. The color variations are lightly enhanced via use of color ratios. Shown is the nearside at $\sim 120^{\circ}$ phase angle; Mare Crisium is the dark circular region near right center. 


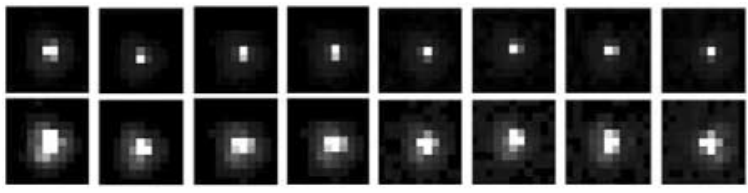

Figure 15. Small $(15 \times 15$ pixel $)$ images of 8 bright stars seen in the Omega Centauri image. Top row shows images with the brightest pixel in each image stretched to white; bottom row shows hard stretch to show low-intensity wings of the PSFs.

while the spacecraft was slewing. Each scan was at a different focus position, with one of the scans at the predicted best focus and the other two offset from this on either side. The inner CCDs, including color, were set at 32 or 64 TDI lines, full resolution, 14 bits/pixel, to best acquire lunar radiometric data. The other CCDs were binned $4 \times 4$ to provide scattered light information. All CCDs were used to image Omega Centauri at TDI 128, except for bluegreen CCD 13, which must be limited to TDI 32. Comparison of star radiance in the HiRISE images to stellar spectrophotometry will be useful as a check on absolute radiometric calibration. The images were acquired during a major solar flare and contain many cosmic-ray "hits" or noise spikes.

[32] This was the first attempt at precision slewing of the spacecraft relative to the HiRISE TDI columns and the first attempt to match the HiRISE line time to the spacecraft slew rate, and the results were excellent (Figures 14 and 15). The focus position in the best-focus image was within a few motor steps of optimal.

\subsubsection{Star Tracker-to-HiRISE and Star Calibrations, 6 October 2005}

[33] During this opportunity, HiRISE made three scans across the Wild Duck (M11) open cluster at different focus positions. Based on analysis of the Omega Centauri image we elected to use a slew rate of $0.01^{\circ} \mathrm{sec}^{-1}$; this enabled detection of many more stars but also worsened the geometric distortions and smear. The timing and position of stars imaged by HiRISE and the Star Tracker were determined to calibrate their boresights. We also acquired a set of internal images (dark frames and flat images illuminated by the LEDs).

\subsubsection{Star Calibrations in December 2005}

[34] These calibrations viewed the Jewel Box (NGC 4755) open cluster in Crux. Images were acquired to tweak the determination of best focus position and to assess geometric distortions, PSF, and jitter. The jitter tests were intended to involve the activation of some of the components that are designed to move in Mars orbit (CRISM cryocooler and gimbal, Mars Climate Sounder (MCS) gimbal, and reaction wheels at different speeds) to build up a matrix of noise sources. Problems with the spacecraft software or procedures led to success of only the jitter test with the CRISM cryocooler, which appears to be a minor source of jitter. See McCleese et al. [2007] and Murchie et al. [2007] for detailed descriptions of MCS and CRISM, respectively.

[35] A large set of internal calibration images were also acquired in December. Concerns about bad data at cold temperatures in IR10 channel 1 led to an additional set of internal images in January 2006, repeating the first 55 images of the December test but with different video signal sampling positions. The IR10 noise was significantly worse at these settings, and subsequent investigation at Ball Aerospace with the Engineering Model FPS confirmed that these settings worsen the anomaly.

\subsubsection{Post-MOI Imaging, March 2006}

[36] After Mars Orbital Insertion (MOI) on 10 March, HiRISE acquired a few Mars observations on 23 and 25 March, before the start of the aerobraking phase. Four images were acquired on orbit P10 and another four images on P11. The last P11 image was acquired on the dark side of the terminator and is of little value; the other 7 images are posted at http://marsoweb.nas.nasa.gov/hirise, http://hiroc. lpl.arizona.edu/first_images/, and http://photojournal.jpl.nasa. gov/. These images are being evaluated during the 6 months of aerobraking, to develop, test, and refine calibration and image-processing techniques. An error in the spacecraft yaw compensation algorithm created twist errors of up to $3^{\circ}$ and cross-track smear up to 5 pixels. The images on orbit P11 were designed to test the effects of MCS gimbal motions on pointing stability. The first HiRISE image of Mars is shown in Figure 16, and the color portion is shown in Figure 17.

\subsubsection{Transition Phase Calibrations,}

September-November 2006

[37] The transition phase follows aerobraking, and after some initial adjustments the orbits are expected to be the standard $255 \times 320 \mathrm{~km}$ orbits like in the PSP. This time will be used for a series of deployments, tests, and calibrations, except during solar conjunction. Primary HiRISE goals are to (1) test our imaging capability in various modes, (2) test procedures to acquire interactive observations such as off-nadir pointing and/or high-stability imaging, (3) refine the boresight alignment with CTX and CRISM, (4) assess spacecraft jitter in the final orbital environment, and (5) acquire additional radiometric calibrations. The jitter tests will involve a variety of noise sources while imaging at line times appropriate to the PSP orbit (74 to $110 \mu \mathrm{sec}$ rather than the $1.1 \mathrm{msec}$ or longer used in cruise or the $0.5 \mathrm{msec}$ or longer used for post-MOI imaging). Radiometric calibrations will include "flatfield" images acquired by rotating the spacecraft $90^{\circ}$ in the yaw axis to image Mars.

\subsubsection{Primary Science Phase Calibrations}

[38] Ideally, all major in-flight calibrations will be achieved before the start of the PSP, but jitter calibration is expected to be an ongoing task and all calibrations must be monitored for changes over time. All HiRISE images (other than internal calibration images) will be associated with simultaneous $200 \mathrm{~Hz}$ IMU and $10 \mathrm{~Hz}$ quaternion ancillary data. This information, combined with analysis of pixel displacement in the CCD overlap regions, will be used to assess geometric distortions and smear due to pointing jitter and yaw errors. Observations with the LEDs turned on will be acquired on the dark side of Mars in order to monitor relative changes of the instrument. Dark current will be monitored by imaging the night side. Geometric, PSF, and focus tests using stars will be conducted once or twice per year, generally using the same star clusters as in cruise. Radiometric and stray light calibrations of Phobos and Deimos will be conducted as opportunities warrant. 


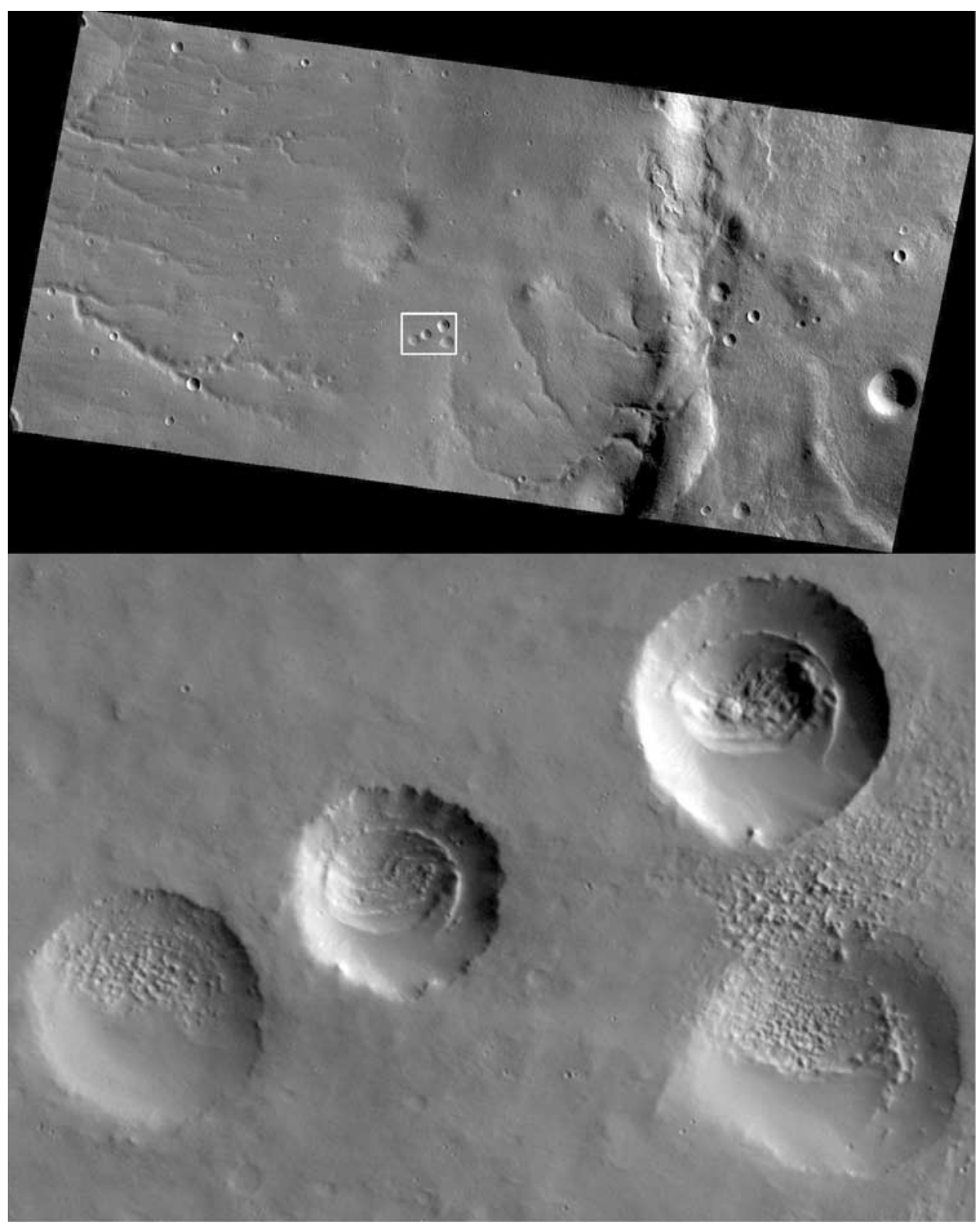

Figure 16. First monochromatic HiRISE image of Mars, equirectangular projection. White box shows location of full-scale $(2.48 \mathrm{~m} / \mathrm{pixel})$ sample at bottom, width $2.6 \mathrm{~km}$. In the mapping orbit a HiRISE image at this latitude would have a scale of $\sim 0.28 \mathrm{~m} /$ pixel and cover a swath width $\sim 9$ times narrower than that covered here (from an altitude of $2480 \mathrm{~km}$ ).

While in orbit about Mars, simultaneous observations with the Hubble Space Telescope (HST) and ground-based observations may be planned. Comparison between HiRISE and HST imaging will achieve absolute radiometric calibration within $20 \%$. Simultaneous observations with CTX and CRISM will also provide information on radiometric performance.

\section{Science and Sequence Planning}

\subsection{Science Team}

[39] The HiRISE science team is an integral part of operations. Each Co-Investigator (Co-I) is responsible for one or more specific science themes and/or objectives (Table 4), which includes prioritization of suggested obser- vations; participation in observation planning to ensure that the observational goals of each theme are achieved; and leadership in papers, workshops, and presentations related to their theme. Science themes will be subdivided or expanded as appropriate with the addition of postdoctoral researchers and Participating Scientists. We have an expanded list of topics for use in HiWeb (described below).

[40] An important function will be that of the "Co-I of the Pay Period" (CIPP), whose duties will be to lead the science image acquisition for two weeks of operations. His/her work will cover 3 or 4 weeks of uplink planning, 2 weeks of sequence execution (one week overlap with uplink planning), and 2 weeks or more to validate science objectives and help with daily captioned image releases (some overlap with 

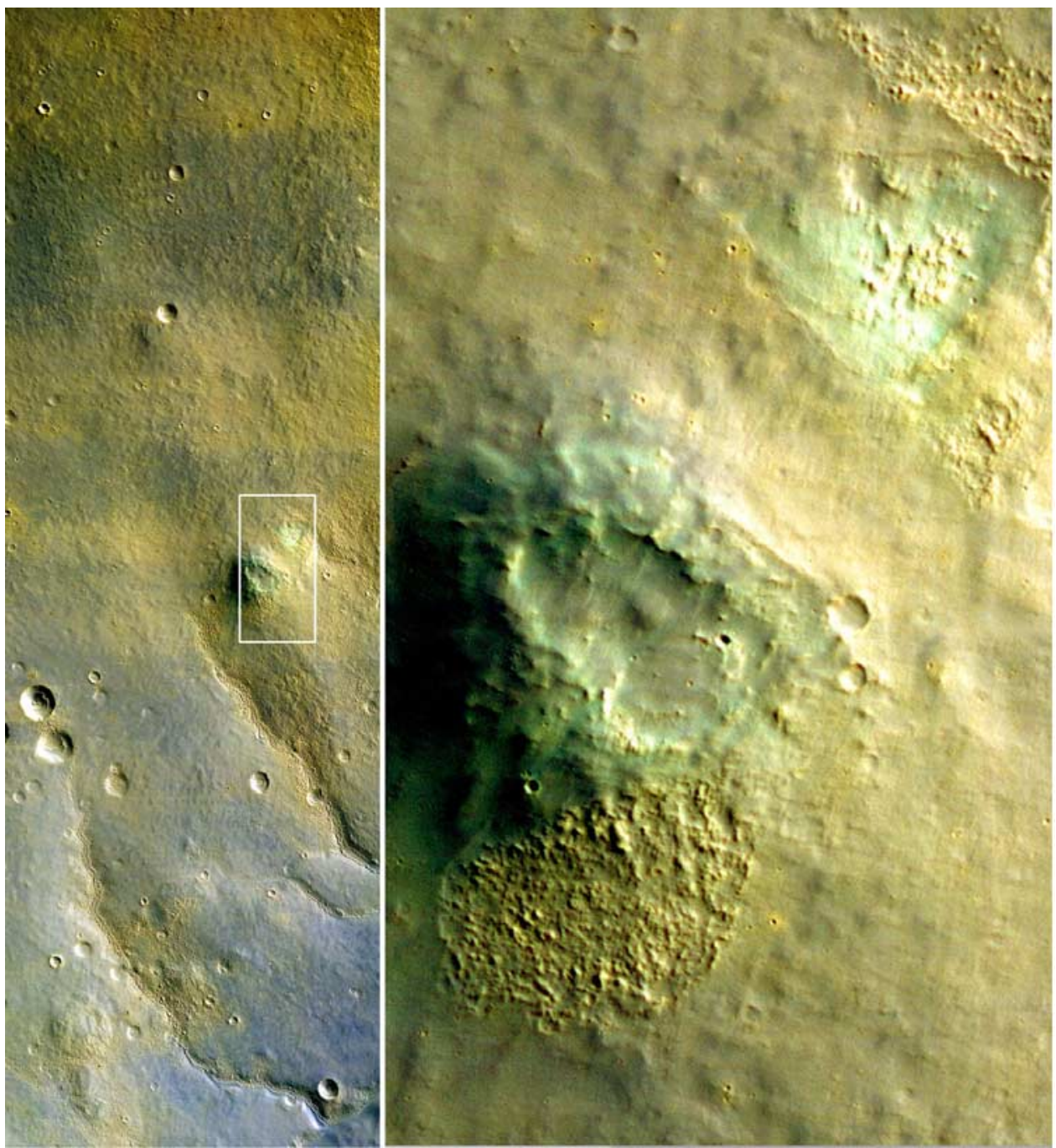

Figure 17. First false-color HiRISE image of Mars (center portion of full image in Figure 16, but not map-projected). Color is composed of NIR image displayed in red, RED in green, and BG in blue; each band was stretched to increase contrast. White box outlines subscene shown at full resolution at right. Channel 1 of IR10 contained bad data for this first (cold FPE) image, so this color product is 3 channels wide rather than four. The two "greenish" spots highlighted here have an unusually low IR/RED ratio compared with the rest of this scene.

Table 4. Science Team Roles and Responsibilities

\begin{tabular}{lll}
\hline Team Member & \multicolumn{1}{c}{ Role/Responsibility/Science Theme ${ }^{\mathrm{a}}$} & Institution \\
\hline Alfred McEwen & Principal Investigator/CIPP/Cratering & LPL, University of Arizona \\
Candice Hansen & Deputy PI/Uplink Design/CIPP/Seasonal Processes & JPL \\
Alan Delamere & Engineering Support/Radiometric calibration & Delamere Support Systems \\
Eric Eliason & Manager of HiROC/GDS Design/PDS & LPL \\
Virginia Gulick & E/PO and HiWeb Lead/CIPP/Fluvial and hydrothermal processes/ & NASA Ames/SETI Institute \\
Ken Herkenhoff & Radiometric Calibration/CIPP/Polar geology & USGS \\
Nick Thomas & European Operations/CIPP/Spectrophotometry & U. Bern \\
Randolph Kirk & Geodesy and DEM production/Geometric calibration & USGS \\
John Grant & MSL Landing Sites/CIPP/Landscape evolution & Smithsonian Institution \\
Laszlo Keszthelyi & Observation Planning Process/CIPP/Volcanism & USGS \\
Mike Mellon & Coordination with Phoenix Mission/CIPP/Periglacial, glacial, and regolith processes & University of Colorado \\
Steve Squyres & MER landing sites/CIPP/Future exploration & Cornell University \\
Cathy Weitz & CRISM coordination/CIPP/Layering processes and stratigraphy & Planetary Science Institute \\
Nathan Bridges & JPL Investigation Scientist/CIPP/Aeolian processes & JPL \\
\hline
\end{tabular}

${ }^{\mathrm{a}} \mathrm{CIPP}$, Co-I of the pay period. 
execution), for a total of about six weeks. The CIPPs work closely with the HiRISE team, HiRISE Operation Center (HiROC) staff, MRO personnel at JPL, and other MRO science experiments (especially CRISM and CTX) to make/coordinate science decisions.

\subsection{Science Planning}

[41] The planning of science data acquisition by the MRO project will be a multistage process and will involve a broad swath of the Mars science community [Eliason et al., 2003]. Special emphasis will be given to examination of potential landing sites for future Mars missions such as Phoenix and Mars Science Laboratory (MSL). The HiRISE science planning process can be divided into 2 main activities. The first process involves selecting locations on Mars that should be imaged by HiRISE and is independent of operational constraints. The second is a time-dependent process and involves creating orbit-by-orbit sequences to acquire specific images.

[42] Suggestions for locations on Mars to image (with a specific science rationale) can be input into our database at any time via HiWeb (http://marsoweb.nas.nasa.gov/HiRISE/ hiweb/ or http://hirise.lpl.arizona.edu/HiRISE/hiweb/). The HiRISE team and/or MRO project will hold workshops in conjunction with major scientific meetings in order to foster input from the planetary community. By combining these workshops with opportunities to share the latest science results from HiRISE, we hope to maximize the community's understanding of the capabilities and limitations of HiRISE.

[43] The suggestion of locations on Mars that HiRISE should image is considered a time independent process that can occur weeks to years before the target is observed. Finding the key locations on Mars is essential to the success of HiRISE. During the PSP we expect to image $1 \%-2 \%$ of Mars at better than $\sim 1.2 \mathrm{~m} /$ pixel (up to $4 \times 4$ binning), $0.1 \%-0.2 \%$ at full resolution, and $\sim 0.05 \%$ in stereo. Finding the type localities and key exposures that can provide major new insights is a major challenge, and this is one reason why we are encouraging input from the entire Mars science community. HiWeb will assist users in formulating and submitting image suggestions. Users will have the capability to browse existing images and other data sets from past and current Mars orbiter missions including Viking, MGS, Mars Odyssey, Mars Express, and MRO. The latest USGS Mars Digital Image Maps (MDIMs), and maps produced from the Thermal Emission Spectrometer (TES), Mars Orbiter Laser Altimeter (MOLA), THEMIS, Gamma Ray Spectrometer (GRS), and MOC as well as available data from Mars Express and MRO will be accessible from HiWeb. Users will be able to compare these data sets and pan and zoom on the data map to desired regions of interest.

[44] After browsing desired data sets, HiWeb users will specify a suggested image or Region of Interest (ROI) along with suggested image parameters and a brief science justification. HiRISE team members will select the final image modes based on the data and timeline constraints, SNR, atmospheric conditions, and thermal limits of the instrument. After any image is acquired, it will be automatically posted to the HiWeb site when processing is complete. Typically we will retire any suggestion or ROI that overlaps with an acquired image of high quality, but new suggestions may be entered at any time. The general public and students will also use HiWeb to identify potential observations, as described in the E/PO section of this paper. Candidate images that have been carefully considered and have specific objectives and justifications will be the most likely to be acquired.

\subsection{Observation Sequence Planning}

[45] The MRO project at JPL will command the spacecraft via 28-day background sequences that control the communication of the spacecraft with the Earth. The DSN coverage will be firm at the start of the planning cycle for a background sequence 4 to 7 weeks before execution. There will be two 14-day planning cycles within the 28-day background sequence.

[46] Observations may be acquired that are interactive (IO), which requires coordination with other instrument and spacecraft teams, or noninteractive (NIO). One form of interaction is that the spacecraft may be turned up to $30^{\circ}$ off nadir, to the left or right of the direction of motion, to ensure imaging of high priority targets and for optimal stereo geometry. We cannot turn off nadir at will, as that may conflict with the desires of other MRO experiments or requirements. For example, the project will select nadir-only orbits for CRISM global mapping and atmospheric surveys and a set of polar passes by SHARAD [Seu et al., 2004, 2007], and there are guidelines about the spacing and frequency of off-nadir turns designed to avoid large gaps in the MCS data. Off-nadir turns larger than $\sim 10^{\circ}$ create significant gaps in the global monitoring of MCS. We expect most of our off-nadir requests to be less than $10^{\circ}$ from nadir, except for stereo imaging in which one of each pair of images must be greater than $10^{\circ}$ off nadir to achieve a good base-to-height ratio. Another form of IO is a highstability observation, in which the motions of MCS and the solar arrays are paused for HiRISE imaging, to reduce pointing jitter. High-stability mode can be used for both nadir-looking and off-nadir observations. IOs must be planned a week or more in advance of execution whereas NIOs (nadir-looking and not high stability) can be planned a few days in advance.

[47] Observations will also be classified as (1) "coordinated," (2) "stand-alone," or (3) "ride-along." The coordinated observations are all IOs whereas the stand-alone and ride-along observations may or may not be interactive. Stand-alone observations do not require any science coordination with other instruments, but they may require interaction for off-nadir turns or use of the high-stability mode. Most of the stand-alone and coordinated observations will include a standard-size $(\sim 30 \mathrm{~km}$ wide $\times 50 \mathrm{~km}$ long $)$ CTX image for regional context; an observation is considered coordinated with CTX if they have a special interest in the observation. CRISM and CTX can choose to ride along with any of our observations, and we can choose to ride along with any of theirs. HiRISE can use high-stability mode for ridealongs that are planned before the IO deadline. Coordinated observations are aimed at locations where the synergism between HiRISE and/or CRISM and/or CTX is expected to be key to addressing a science question. We expect to coordinate many stereo targets with CTX and to coordinate imaging of regions with diverse and interesting compositions and morphologies with CRISM. Ride-along 
HiRISE observations may be substantial high-stability images, effectively resulting in a late coordinated observation, or are relatively small images taken when another instrument is observing. NIOs where we desire CTX coverage will typically be acquired in areas previously imaged by CTX or as ridealongs with CTX. CTX has sufficient data volume and compression capability to cover much of Mars in the PSP, and they will of course favor the more interesting regions and optimal viewing conditions.

[48] Coordinated observations with CRISM and CTX are expected to constitute a significant percentage of the HiRISE data volume. Aqueous mineralogies are present over many areas on Mars [Bibring et al., 2005] and mark sites of high interest for future exploration. Furthermore, we expect the combination of HiRISE and CRISM data at high spatial and spectral resolution to be especially powerful for detailed studies. HiRISE stereo may be of particular value to such studies, but we expect to acquire only $\sim 1000$ stereo pairs in the PSP so many coordinated targets will lack HiRISE stereo. Topographic data may prove crucial to compositional interpretations on slopes, where bedrock is most often exposed. We expect to coordinate with CTX on many stereo observations; CTX acquires stereo coverage over large areas (typically $\sim 30 \times \sim 100 \mathrm{~km}$ ) at $\sim 6 \mathrm{~m} /$ pixel scale.

[49] The individual observations are combined to create the HiRISE observation sequence. HiRISE imaging plans are constrained by trade-offs between key limited resources such as (1) what is visible on the surface, (2) storage space on the SSR, (3) available downlink, (4) timeline constraints, and (5) thermal constraints. We must avoid conflicts in the timeline, manage the SSR and computer resources, and assure a full load for downlink. It only takes seconds to acquire a HiRISE image, minutes to clear the camera buffer, but hours to "packetize" and play back the data. Thus the camera has a low average duty cycle. Each large $(>10 \mathrm{~Gb})$ image causes significant heating of the FPS, so we must allow cool-off time between large images to avoid violation of temperature limits, which results in shutting off the instrument and loss of some subsequent images.

[50] The observation scenarios will vary with the downlink volume. During relatively low data rate periods, we expect to take a small number of large images of the most important science sites along with small images of other sites. We expect to acquire many small images early in the PSP (a low data-rate period) to sample different terrains at HiRISE resolution. This is essential to learn what is most informative at these scales so we can intelligently select the small area of Mars to image at highest resolution. During high data rate periods we expect to take larger images to fill the downlink without greatly increasing the number of images. As a baseline, we expect to acquire $\sim 10,000$ standalone or coordinated HiRISE images in the PSP, and perhaps another 2,000 small ride-along images.

[51] About 2000 of the off-nadir images will be components of $\sim 1000$ stereo pairs. These stereo images will usually be moderate to large (several $\mathrm{Gb}$ ), and are expected to comprise as much as $40 \%$ of our data volume allocation. The binning mode used will depend on spacecraft jitter characteristics, data volume margins, surface geology, scene albedo and illumination, and other factors. A strawman estimate is that of the 2000 anticipated stereo observations, about half will consist of unbinned RED CCDs and the other half will use RED CCDs with $2 \times 2$ binning. Bluegreen and NIR images (almost always binned to achieve $>100$ :1 SNR) will typically be added for the color information, but also to fill potential gaps in the center RED CCDs and to improve the precision geometric corrections. Given the greater probability of significant pointing jitter for the NIOs, most or all of these will be binned up to $4 \times 4(8 \times 8$ and $16 \times 16$ binning can usually only be used under dim illumination, to avoid saturation).

[52] The optimum geometry for topographic measurements requires stereo baseline angles of $15-25^{\circ}$. In most cases stereo observations will require one component $>10^{\circ}$ off nadir; it will be rare for both images to be greater than $10^{\circ}$ or both less than $10^{\circ}$. For optimal correlations between image points we will favor phase angles between $\sim 30^{\circ}$ and $80^{\circ}$. Therefore, at equatorial latitudes we will try to have the emission angle of the 1st component of each stereo pair be small and looking either east or west, with the 2nd component being larger and looking west. At polar latitudes, the roll angles of the two images of a stereo pair become more similar, and viewing from different ground azimuths becomes an increasingly important factor in generating stereo convergence. The difference in spacecraft azimuth, which makes stereo possible, is accompanied by a difference in sun azimuth, which hinders the ability to match the images to one another. Sun azimuth difference, rather than phase angle or cardinal direction, is thus the main constraint on stereo imaging at very high latitudes.

\subsection{HiRISE Image Modes}

[53] HiRISE imaging is extremely flexible because the camera has 14 independently commanded CCDs, and each can have a different choice of binning, TDI, number of lines, and choice of LUT. The line time must be the same for all CCDs in an image because it is set to match the ground track speed. Since MRO is in an elliptical orbit the line time will vary from image-to-image. Also, when using FELICS compression (the great majority of Mars images), the data from all CCDs must first be LUT-compressed to 8 bits.

\subsubsection{Precision Geometric Corrections}

[54] One constraint on mixed binning modes is that we need certain combinations of three adjacent RED CCDs to derive precision geometric corrections. The spacecraft pointing is not perfectly stable, and while very high frequency errors result in smear, lower-frequency errors result in geometric distortions. Correcting these distortions is essential for production of meter-scale DEMs, for subpixel registration of color images, and for precise planimetric measurements. The spacecraft engineering data is inadequate to provide the information we need to make these corrections at high frequencies, but we can extract such information from our overlapping CCDs. We need relative pointing information on timescales comparable to line time multiplied by number of TDI lines. This means we need the vertical offset of the overlapping CCDs to be $\sim 128$ lines or less for TDI 128 and $\sim 32$ lines or less for TDI 32. However, the physical housing of the CCDs precludes a vertical offset of less than $\sim 750$ lines. The solution is to use 3 CCDs (call them A, B, and C) and two overlap distances, so that, for example while the overlap between A and B is 750 lines and that between $\mathrm{B}$ and $\mathrm{C}$ is 775 lines, we can use both overlaps 
Table 5. Standard HiRISE Binning Combinations and Typical TDI Settings

\begin{tabular}{|c|c|c|c|c|c|c|c|}
\hline Name & Description & $\begin{array}{l}\text { RED } \\
4-5-6 \\
\end{array}$ & $\begin{array}{l}\text { Other } 7 \\
\text { REDs }\end{array}$ & NIR & BG12 & BG13 & $\begin{array}{c}\mathrm{Gb} / 10 \mathrm{~K} \text { bin } 1 \\
\text { Lines }\end{array}$ \\
\hline 1 & & bin 1 & bin1 & bin 2 & $\operatorname{bin} 2$ & bin4 & \multirow{3}{*}{1.16} \\
\hline Bin1A & \multirow[t]{2}{*}{ Highest res at >100:1 SNR; stereo } & 128 & 128 & 128 & 128 & 32 & \\
\hline 2 & & bin 1 & bin 1 & bin4 & bin4 & bin 432 & \\
\hline Bin1 & \multirow[t]{2}{*}{ bin 1 full FOV RED, $4 \times 4$ color } & 128 & 128 & 32 & 64 & 32 & \multirow[t]{2}{*}{1.10} \\
\hline 3 & & bin1 & bin2 & bin 2 & $\operatorname{bin} 2$ & bin4 & \\
\hline Bin1-2A & \multirow[t]{2}{*}{ Bin1 RED4-6; others bin 2} & 128 & 64 & 128 & 128 & 32 & \multirow[t]{2}{*}{0.58} \\
\hline 4 & & bin 1 & $\operatorname{bin} 2$ & bin4 & bin4 & bin4 & \\
\hline Bin 1-2 & \multirow{2}{*}{ Bin1 RED4-6; others bin 2} & 128 & 64 & 32 & 64 & 32 & \multirow[t]{2}{*}{0.52} \\
\hline 5 & & bin 1 & bin 4 & bin 2 & bin 2 & bin 4 & \\
\hline Mohawk1A & \multirow{2}{*}{ high-res sample, bin 2 color } & 128 & 32 & 128 & 128 & 32 & \multirow[t]{2}{*}{0.46} \\
\hline 6 & & bin 1 & bin 432 & bin4 & bin4 & bin4 & \\
\hline Mohawk1 & \multirow{2}{*}{ high-res sample. bin4 color } & 128 & 32 & 32 & 64 & 32 & \multirow[t]{2}{*}{0.40} \\
\hline 7 & & bin 2 & $\operatorname{bin} 2$ & bin2 & bin 2 & bin4 & \\
\hline $\operatorname{Bin} 2 \mathrm{~A}$ & \multirow[t]{2}{*}{ bin 2 full FOV RED; stereo } & 64 & 64 & 128 & 128 & 32 & \multirow[t]{2}{*}{0.36} \\
\hline 8 & & bin 2 & $\operatorname{bin} 2$ & bin4 & bin4 & bin4 & \\
\hline $\operatorname{Bin} 2$ & \multirow[t]{2}{*}{ bin 2 full FOV RED, $4 \times 4$ color } & 64 & 64 & 32 & 64 & 32 & \multirow[t]{2}{*}{0.30} \\
\hline 9 & & bin 2 & bin 4 & bin 2 & $\operatorname{bin} 2$ & bin4 & \\
\hline Mohawk2A & \multirow[t]{2}{*}{ bin2 sample, bin2 color } & 64 & 32 & 128 & 64 & 32 & \multirow[t]{2}{*}{0.22} \\
\hline 10 & & bin 2 & bin4 & bin4 & bin4 & bin4 & \\
\hline Mohawk2 & \multirow[t]{2}{*}{ bin 2 sample, bin 4 color } & 64 & 32 & 32 & 64 & 32 & \multirow[t]{2}{*}{0.16} \\
\hline 11 & & bin4 & & bin4 & bin4 & bin4 & \\
\hline Color-14 & \multirow[t]{2}{*}{ High SNR color (14-bit) } & 32 & - & 32 & 64 & 32 & \multirow[t]{2}{*}{0.16} \\
\hline 12 & & bin4 & bin4 & bin4 & bin4 & bin4 & \\
\hline Bin4 & \multirow[t]{2}{*}{ bin 4 everything (E/PO) } & 32 & 32 & 32 & 64 & 32 & \multirow[t]{2}{*}{0.10} \\
\hline 13 & & bin8 & bin8 & bin8 & bin 8 & bin8 & \\
\hline Bin8 & Bin 8 imaging in twilight & 32 & 32 & 128 & 128 & 32 & 0.02 \\
\hline Name & Description & REDs & & NIR & BG12 & BG13 & \\
\hline 14 & & bin1, any & & & & & \\
\hline RED-solo & bin $1 \mathrm{CTX}$ ridealong & single RED & TDI 128 & - & - & - & 0.11 \\
\hline 15 & & RED 012, 234, & & & & & \\
\hline 3RED-bin 2 & bin 2 CTX ridealong & 456,678 , or 789 & TDI 64 & - & - & - & 0.08 \\
\hline 16 & & RED 012, 234, & & & & & \\
\hline 3RED-bin4 & bin 4 CTX ridealong & 456,678 , or 789 & TDI 32 & - & - & - & 0.02 \\
\hline 17 & & RED 0-5, 1-6, & & & & & \\
\hline 6RED-bin4 & bin 4 CTX ridealong & $2-7,3-8$, or $4-9$ & TDI 32 & - & - & - & 0.04 \\
\hline 18 & & & RED $1-8$ & bin4 & bin 4 & bin4 & \\
\hline Split & Compare stratigraphic profiles & RED 0,9 bin $1 / 128$ & bin $4 / 32$ & 32 & 64 & 32 & 0.30 \\
\hline Name & Description & RED 2-3-4 & Other REDs & NIR & BG12 & BG13 & \\
\hline 19 & RED234 high res, low noise & $\operatorname{bin} 1 / 128$ & - & - & - & - & 0.32 \\
\hline RED234-solo & & & & & & & \\
\hline 20 & RED only with high res 234 & bin $1 / 128$ & $\operatorname{bin} 4 / 32$ & - & - & - & 0.37 \\
\hline RED234 & & & & & & & \\
\hline
\end{tabular}

to measure the 25-line offset between $\mathrm{A}$ and $\mathrm{C}$. Thus, rather than perfectly aligning 5 RED CCDs in a top row and 5 in a bottom row (see Figure 5), three CCDs were offset a bit more to provide the following 3-CCD solutions: 012 (31.5 pixels offset), 234 (45 pixels), 456 (17 pixels), 678 (12 pixels), and 789 (17 pixels). In addition to these frequencies (12 to 45 lines multiplied by the line time) we can use any of the 2-CCD overlaps for $\sim 750$ line solutions, data from a NIR CCD to that from a corresponding RED CCD for $\sim 1500$ line solutions, and data from NIR and BG CCDs for $\sim 3000$ line solutions. We will also use the spacecraft IMU (Inertial Measurement Unit) and Star Tracker data. How to reduce and merge all of these data sets to correct the pointing information is a research project that lies ahead.

\subsubsection{Binning Combinations}

[55] There are hundreds of possible HiRISE binning mode combinations, but we need a more limited set of standard combinations, at least initially, to simplify observation planning and data processing. Table 5 lists the types of standard images that HiRISE currently expects to collect. These choices are explained below.

[56] We expect to use all 10 RED CCDs at either $1 \times 1$ or $2 \times 2$ binning for stereo observations, coverage of landing/ roving sites, and other very high-priority observations. However, the data volume per image is large so the number of such images will be limited. For many science targets we may wish to sample with only a few CCDs in bin 1 or bin 2, thus the Bin1-2 and four "Mohawk" modes.

[57] Our 3-color coverage includes RED CCDs 4 and 5, in the middle of the RED FOV. Since we would like to merge lower-resolution BG and NIR data with higherresolution RED data, we want to favor CCDs 4 and 5 for higher resolution. However, the $3-\mathrm{CCD}$ precision geometry solution will be limited by the lowest resolution among the triplet, so we plan CCDs 4, 5, and 6 together for standard image modes with color (Table 5). If we are not using the NIR and blue-green CCDs (for example over a bland dustcovered scene) then we can favor other triplets. 
Table 6a. Average Signal Expected for a Bright Scene: Solar Incidence Angle $45^{\circ}$, Bright-Region Spectrum ${ }^{\mathrm{a}}$

\begin{tabular}{clccc}
\hline Bin & TDI & \# Ke- RED & \# Ke- NIR & \# Ke- BG \\
\hline 1 & 128 & 59 & 23 & 13 \\
2 & 128 & 236 & 92 & 52 \\
2 & 64 & 118 & 46 & 26 \\
2 & 32 & 59 & 23 & 13 \\
3 & 128 & 531 & 207 & 117 \\
3 & 64 & 266 & 104 & 59 \\
3 & 32 & 133 & 52 & 29 \\
3 & 8 & 33 & 13 & 7 \\
4 & 128 & 944 & 368 & 208 \\
4 & 64 & 472 & 184 & 104 \\
4 & 32 & 236 & 92 & 52 \\
4 & 8 & 59 & 23 & 13 \\
8 & 32 & 472 & 184 & 104 \\
8 & 8 & 236 & 92 & 52 \\
\hline
\end{tabular}

${ }^{\text {a }}$ Signal is $\times 10^{3}$ electrons. The most favorable range, to achieve a high SNR but without saturation, is from $\sim 18$ to $\sim 125 \mathrm{Ke}^{-}$.

[58] Bin-3 mode is not expected to be used often as it is messy in two ways. First, the "trim" function does not work properly with bin 3 . The trim function delays the start of image collection from each CCD so that they all line up with respect to the target, so a complete HiRISE image of Mars has a straight top or bottom edge rather than squarewave edge. This does not work perfectly for mixed modes because the number of ramp lines varies with binning and TDI. By choosing the correct number of lines for each $\mathrm{CCD}$, the other end (top or bottom) lines up. In bin 3 mode the Trim function divides by 4 rather than 3 (this is an FPGA code limitation) so it under-trims. The other reason bin 3 is messy is that 1024 (number of pixels in a channel) does not divide evenly into 3 so a column of data is effectively lost, averaged into the dark pixels. In general use of either bin 2 or 4 should be acceptable and bin 3 is not needed. The exception may be for NIOs, where bin 2 images may be excessively smeared but bin 3 is OK and returns the best images.

[59] A couple of modes have specialized purposes. The Bin8 mode is for imaging polar regions in twilight to extend seasonal monitoring. We do not plan to use bin 16 since bin 8 is already highly compressed in data volume and is less likely to saturate. The Split mode, full resolution in the end RED CCDs ( 0 and 9$)$ with $4 \times 4$ binning in the other $\mathrm{CCDs}$, is to acquire stratigraphic profiles separated by 5 to $6 \mathrm{~km}$ to study lateral changes. Color 14, the only mode that does not usually include conversion of the data to 8 bits and FELICS compression, is for targets where color data at the highest possible SNR is considered essential. For targets suggested by the general public we expect to use one of the small color image modes such as Bin4; these modes will also be useful for many science targets. We prefer to image with all 14 CCDs when color is included, because the fixed pattern noise changes and the IR10 channel 1 anomaly is worse when the power level drops. (The power level on an "unused" CCD drops after 120 lines have been recorded.) The only exception is Color14, to save data volume.

[60] For CTX ride-along observations we will often use small images with a limited set of CCDs, but the specific CCDs can be selected in order to tweak the crosstrack targeting of features of particular interest (e.g., modes 14-17 and 19-20 in Table 5). Any other image mode could also be used in ride-along mode.

[61] The last two modes in Table 5 favor RED CCDs 2, 3, and 4, for use where high SNR is key but color is not important. One channel of CCD 5 has a higher read noise, so the CCD triplet 2-3-4 may be preferable.

\subsubsection{Selecting Number of Lines}

[62] In addition to binning modes we must choose the number of lines, which will be determined to best match the downtrack extent of the target of interest plus the timing uncertainty, expected to be equivalent to $\sim 500 \mathrm{~m}$. Although we can choose a different number of lines for each CCD, we prefer to keep this constant, normalized for binning level and trim, so we acquire nearly rectangular images with straight edges. We will face tradeoffs between down-track coverage and data volume, and with occasional conflicts in the timeline. Sometimes the number of lines will be limited by thermal constraints.

\subsubsection{TDI Selection}

[63] The best choice of TDI lines $(8,32,64$, or 128) will depend on binning, spacecraft jitter characteristics, and the intensity of the scene through each filter. An increase in binning often requires a corresponding decrease in TDI to avoid saturation; Table 5 lists the most common TDI settings we expect to use with each bin mode. The HiRISE Photometric Program (HIPHOP) is used to optimize the choice of TDI lines for each binning mode over a given predicted scene intensity histogram. Tables $6 \mathrm{a}$ and $6 \mathrm{~b}$ show the expected average signal as a function of TDI and binning for typical bright and dark scenes on Mars. Our goal is to keep the average signal greater than $\sim 18 \mathrm{~K}$ electrons ( 100:1 SNR) and less than $\sim 125 \mathrm{~K}$ electrons ( DN 6250, to avoid saturation of sunlit slopes or clouds and to avoid the formation of "furrows" in bright portions of the image, when the signal exceeds 8000 DN; Figure 11). We want to favor fewer TDI lines, especially for NIOs, as that minimizes the smear in the event of significant pointing jitter. When imaging through poor atmospheric conditions due to dust or condensate haze we need an especially high SNR to get good images of surface features, so we

Table 6b. Signal Expected for a Dark Scene: Solar Incidence Angle $70^{\circ}$, Dark-Region Spectrum ${ }^{\mathrm{a}}$

\begin{tabular}{clccc}
\hline Bin & TDI & \# Ke- RED & \# Ke- NIR & \# Ke- BG \\
\hline 1 & 128 & 17 & 6 & 4.5 \\
2 & 128 & 68 & 24 & 18 \\
2 & 64 & 34 & 12 & 9 \\
2 & 32 & 17 & 6 & 4.5 \\
3 & 128 & 153 & 54 & 40 \\
3 & 64 & 76 & 26 & 20 \\
3 & 32 & 38 & 13 & 10 \\
3 & 8 & 10 & 3 & 2.5 \\
4 & 128 & 272 & 96 & 72 \\
4 & 64 & 136 & 48 & 36 \\
4 & 32 & 68 & 24 & 18 \\
4 & 8 & 17 & 6 & 4.5 \\
8 & 64 & 544 & 192 & 144 \\
8 & 32 & 272 & 96 & 72 \\
8 & 8 & 68 & 24 & 18 \\
\hline
\end{tabular}

\footnotetext{
${ }^{\mathrm{a}}$ Signal is $\times 10^{3}$ electrons.
} 
Table 7. Offset Levels and Max Signal Levels Defining the 28 Stored LUTs $^{\mathrm{a}}$

\begin{tabular}{cccccccc}
\hline & \multicolumn{7}{c}{ Highest DN } \\
\cline { 2 - 8 } Lowest dark DN & 16383 & $13457-14057$ & $11076-11676$ & $8695-9295$ & $6552-7152$ & $4648-5248$ & $2743-3343$ \\
\hline 600 & 0 & 1 & 2 & 3 & 4 & 5 & 6 \\
800 & 7 & 8 & 9 & 10 & 11 & 12 & 13 \\
1000 & 14 & 15 & 16 & 17 & 18 & 19 & 20 \\
1200 & 21 & 22 & 23 & 24 & 25 & 26 & 27 \\
\hline
\end{tabular}

${ }^{a}$ Numbered from 0 to 27 . A range of values is given for the highest DN because it varies with the offset level.

will try to reach $100-250 \mathrm{~K}$ electrons and accept possible furrows, which are easy to calibrate over uniform scenes.

\subsubsection{LUT Selection}

[64] All but a small percent of HiRISE images will be converted from 14 to 8 bits per pixel via onboard lookup tables (LUTs), because use of LUT plus FELICS compression can increase coverage of Mars by as much as a factor of four. It is anticipated that only small 14-bit images will be returned to preserve the maximum SNRs and avoid potential LUT saturation, for color imaging or for scenes where the dynamic range is especially large or not well understood.

[65] HiROC personnel will run HIPHOP to predict the image histogram as a function of various input parameters. (This module also predicts the SNR in each color with various TDI-bin combinations.) The predict histogram is needed to choose the optimal LUT for conversion of the data from 14 to 8 bits per pixel. Although we can easily pass minimum and maximum $\mathrm{DN}$ values for each $\mathrm{CCD}$ to produce linear LUTs (calculated in the Instrument Controller), the stored LUTs are nonlinear and have several advantages. First, we preserve the dark DNs in the calibration lines at the top of the image and in the columns on the edges, as these values need an adequate precision for radiometric calibrations. Second, the quantization is nonlinear, designed to balance quantization noise with electronic noise such that the root-sum square noise is minimized and
SNR is optimized. Third, the LUTs designed for high signal levels, which we expect to use for images acquired during hazy or dusty atmospheric conditions, have been further modified to minimize quantization noise for the $\mathrm{DN}$ values expected to be most abundant in the image histogram. In other words, the stored LUTs have been designed to optimize overall SNR in the processed images. New or modified LUTs can be uploaded in flight.

[66] The stored LUTs will be the default for use when imaging Mars. There are 28 stored LUTs representing 4 offset levels and 7 signal levels (Table 7 and Figure 18). Each CCD will have offset values that best fit one of the 4 categories at normal operating temperatures (Table 8). Although we do not currently expect to use offset level $600 \mathrm{DN}$, we might need that if we decide to switch to different analog/digital sampling positions for some channels. The photometry program will predict the max signal level, and the sequence planner can influence this by predicting the roughness and presence/absence of frost or other bright material. We will usually select the LUT with the max signal level that is greater than but closest to the maximum predicted histogram value plus safety margin. The lowest-signal LUTs $(6,13,20$, and 27) are nearly lossless (preserving 96\% of the 14-bit SNR) for all DN levels because the quantization noise is much smaller than the electronic noise; these are the LUTs we will use most

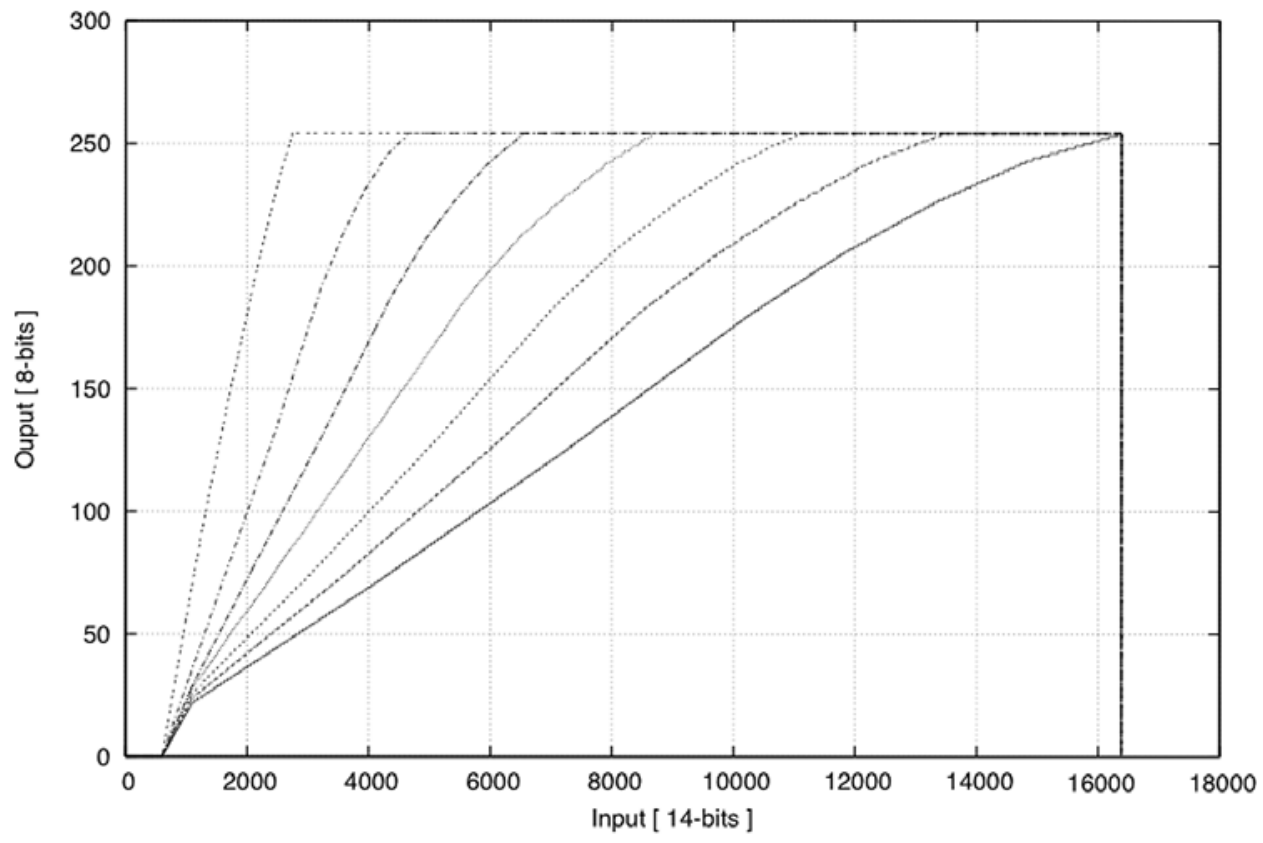

Figure 18. Plot of look-up table (LUT) conversion from 8 to 14 bits for the seven signal levels for one of the four offset levels (600 DN). 
Table 8. Measured Offset Values

\begin{tabular}{lcl}
\hline CCD & $\begin{array}{c}\text { Average Offsets (ch0, ch1) } \\
\text { at FPE }=21^{\circ} \mathrm{C}\end{array}$ & $\begin{array}{c}\text { Lowest DN Category } \\
\text { for Stored LUT }\end{array}$ \\
\hline 0 & 1333,1434 & 1200 \\
1 & 1116,1191 & 1000 \\
2 & 1250,1161 & 1000 \\
3 & 1125,1253 & 1000 \\
4 & 1159,1139 & 1000 \\
5 & 1214,1408 & 1000 or 1200 \\
6 & 1052,1239 & 800 or 1000 \\
7 & 1124,1426 & 1000 \\
8 & 1320,1452 & 1200 \\
9 & 1165,1323 & 1000 \\
10 & 1208,1103 & 1000 \\
11 & 1226,1218 & 1000 or 1200 \\
12 & 1060,1230 & 800 or 1000 \\
13 & 1094,1062 & 800 or 1000 \\
\hline
\end{tabular}

often for full-resolution images. New stored LUTs can be uploaded in flight as a software "patch".

\section{Ground Data System (GDS) Design and Data Products}

[67] The HiRISE Operations Center (HiROC) is located at the Lunar and Planetary Laboratory at the University of Arizona, Tucson. Observational timelines and camera commands are developed at HiROC. The project has furnished a secure line, a Science Operations and Planning Computer (SOPC) and software for transfer of instrument commands to JPL for radiation to the spacecraft. Likewise data is transmitted from JPL to HiROC for data processing. The HiRISE team is responsible for delivery of archival quality data to the Planetary Data System (PDS) and HiROC will house the PDS HiRISE Data Node. The HiRISE team is responsible for monitoring the health and performance of the instrument. Ground Data System (GDS) functions are illustrated in Figure 19.

\subsection{Downlink Processes}

[68] The objective of the HiRISE downlink process is to retrieve data from the MRO operations center at JPL, then produce and validate the products to be shared with users (the HiRISE science team, other MRO investigators, the Mars Exploration Program, the Mars science community, and the general public). The data processing begins when the downlink organizer (HiDOg) detects (sniffs out) and retrieves science data from the project's Raw Science Data Server (RSDS) at JPL and registers them in the catalog and database (HiCat). The data on the RSDS will be stored as files that organize the data by channel (up to 28 channels per observation). HiROC will use automated processing to create raw and processed HiRISE images based on information in our database.

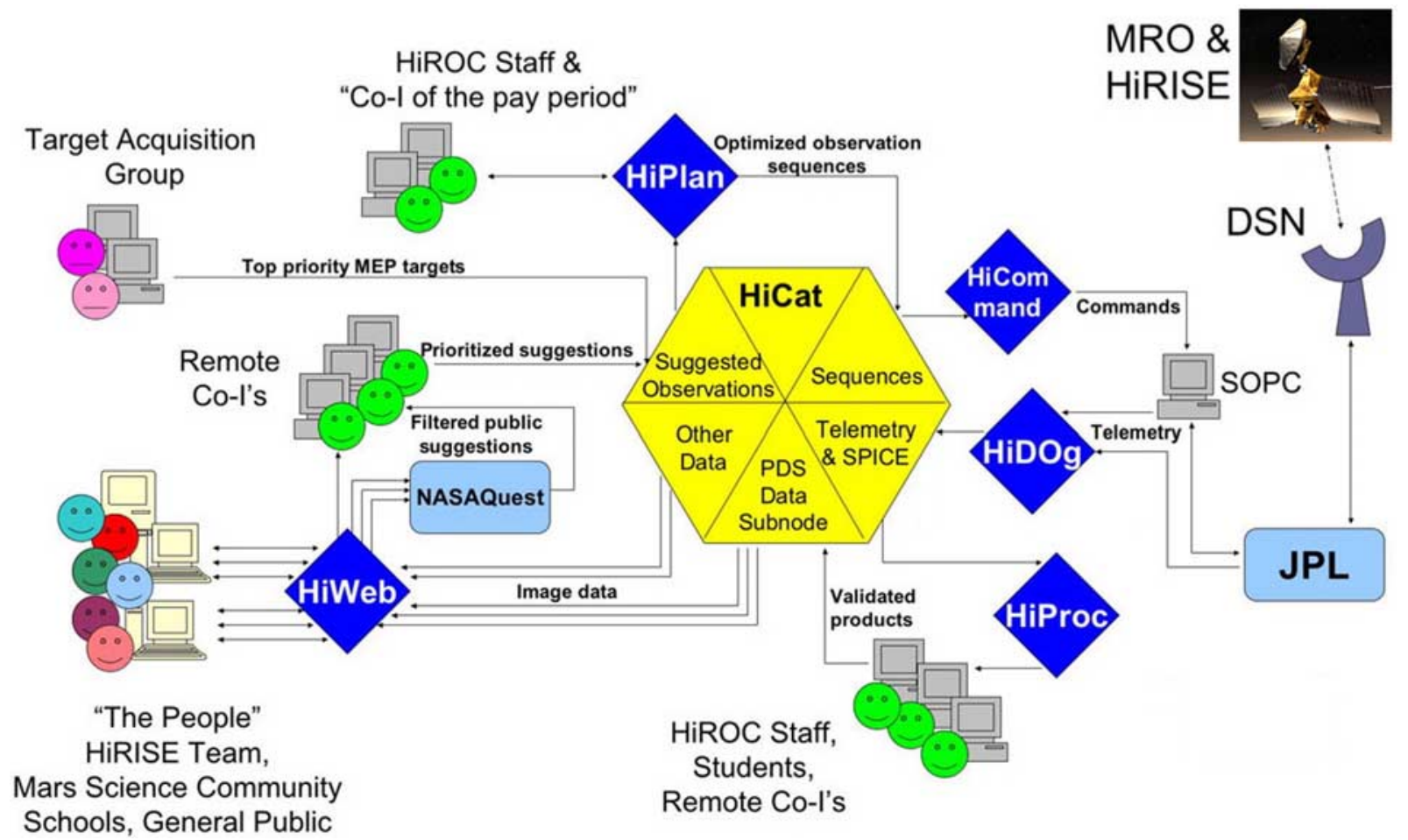

Figure 19. HiRISE Ground Data System. Targets can be suggested and viewed by anyone via a userfriendly Web interface (HiWeb). Suggestions from the project-level Target Acquisition Group will go directly to HiCat, whereas others will be prioritized by the HiRISE team (Co-Is). The distributed Co-Is will assist the HiROC staff in planning the actual observation sequences with HiPlan, and instrument commands will be sent to the secure SOPC. Images returned from the spacecraft will be retrieved by HiDOg from JPL and inserted into HiCat through a dedicated line. The images are processed via automated procedures (HiProc) and checked by HiROC staff, students, and others to validate the results prior to PDS release. 
Table 9. HiRISE PDS Data Products ${ }^{\mathrm{a}}$

\begin{tabular}{lcc}
\hline \multicolumn{1}{c}{ Product } & Number of Products & Data Volume, Gb \\
\hline EDR: Raw images (losslessly recompressed) & 12,000 & 17,500 \\
Panchromatic RDRs (JPEG2000) & 12,000 & 74,500 \\
Binned color RDRs (JPEG2000) & 10,000 & 9,500 \\
Digital Elevation Models (DEMs) & $\sim 20$ & 100 \\
EDR Ground Calibration ("safed") & $\sim 1,000$ & 100 \\
EDR Cruise Calibration ("safed") & $\sim 1,000$ & 100 \\
Full-resolution merged color RDR & 4,000 & 40,000 \\
\hline
\end{tabular}

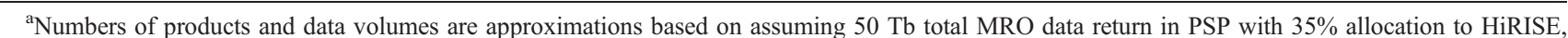
rough estimates of percent data volume for each type of image (Table 5), FELICS compression factor 1.7, and JPEG2000 compression estimates for each image type.

\subsection{Standard Data Products}

[69] After downloading the raw science data file for an observation, the data are then handed to the automated processing system (HiProc [Schaller, 2006]) to produce two basic products: EDRs (PDS-labeled Experiment Data Records or "raw" images) and RDRs (Reduced Data Records or processed images). EDR generation includes (1) image decompression (of FELICS) and accommodating data gaps, (2) organizing the image data by CCD channel, (3) extraction of information needed for the PDS labels, and (4) storing additional metadata in PDS label objects within the EDR file. Since each CCD is read out into two channels via the center, channel 1 (left side) data is mirrored or flipped left-right in the telemetry. We flip the channel 1 image lines back to the correct orientation, separate from the buffer and dark pixels at the ends of each line. All EDR data products will contain a single CCD channel data sequence, whereas a complete observation is composed of up to 28 channel data files.

[70] For RDR production, the processing steps include (1) radiometric correction, (2) geometric transformation to standard map projections, (3) formatting data to PDS standards, and (4) preparation of data products with lossless JPEG2000 compression. Generation of the RDRs requires the incorporation of reconstructed SPICE (Spacecraft and Planet ephemerides, Instrument, Camera-matrix, and Event) kernels generated by the MRO navigation team, typically available within a few weeks after data acquisition.

[71] Two levels of processing are planned resulting in binned color and full-resolution RDR products. Both types of products will be radiometrically corrected and reprojected to a standard map projection. The binned color products will be at least $2 \times 2$ averaged, as this minimizes apparent geometric distortions and misregistration of the color band passes. A research and development effort will be needed to sufficiently understand the spacecraft jitter and develop processing techniques before we can create the best full-resolution RDR products. We will need data acquired at Mars to characterize the jitter, so the final full-resolution or precision-corrected RDRs may not be released for up to a year. However, we will more quickly release full-resolution EDRs, reduced-resolution color RDRs, and interim fullresolution RED-filter RDRs.

[72] The standard map projection scheme to be used by both HiRISE and CRISM is Equirectangular or Polar Stereographic in Planetocentric coordinates tied to MOLA. Equirectangular is Simple Cylindrical but with a longitudinal compression factor that varies with 5 degree latitude bins (see Figure 16). This is similar in concept to the
Sinusoidal Equal-Area projection, except that the degrees/ pixel scale is held constant within each 5 degree latitude range. The Equirectangular format will be used for all of Mars except the polar regions above $\pm 85^{\circ}$ latitude, where we switch to Polar Stereographic. The Mapmaker software from USGS in Flagstaff will be available to rapidly convert and mosaic Equirectangular quadrangles or convert to and from Simple Cylindrical map products.

[73] We plan to reproject the great majority of RED-filter images to scales of either 25 or $50 \mathrm{~cm} /$ pixel, normalizing the scale of images with mixed bin modes. Reprojection always reduces resolution at least a little, but this is minimized by reprojecting to a slightly smaller scale for most of the bin 1 data (originally 25 to $33 \mathrm{~cm} /$ pixel) and using cubic deconvolution. The loss of resolution in bin 1 images is minor because the PSF is broader than 1 pixel, but bin 2 and higher images could be more severely degraded. For this reason we will reproject bin 2 data to $25 \mathrm{~cm} /$ pixel and bin 4 data to 25 or $50 \mathrm{~cm} /$ pixel. Images with bin 4 in all RED CCDs would be reprojected to $50 \mathrm{~cm} /$ pixel. The rare twilight bin 8 images will be reprojected to $100 \mathrm{~cm} /$ pixel. The NIR and BG data will be processed along with the center RED CCDs at two scales. Initially the RED images will be reduced to the scale of the least-binned NIR and BG images, to hide the color fringes produced by geometric distortions. Once the precision geometric corrections are available, we plan, on a best-effort basis, to reprocess the color data to the scale of the RED RDRs, usually 25 or $50 \mathrm{~cm} /$ pixel. We will also reprocess the RED RDR stereo pairs with precision geometry, and other RED RDRs on a best-effort basis.

[74] Once an RDR has been produced, it will be losslessly compressed using JPEG2000 [Wu et al., 2000]. This will reduce our data storage needs and greatly facilitate distribution of the data over the Web. We are developing a HiRISE image viewer module (HiView) using JPEG2000 and incorporating simple tools like pan/zoom and image stretching to facilitate efficient exploration of these gigantic images. HiView will be available via HiWeb and PDS.

[75] The data products will be validated by both automated procedures and inspection by team members (Figure 19). Immediately after validation of the binned RDR products, the EDR and completed RDR products will be made available via HiWeb as well as PDS Web sites. The HiRISE team will also produce and release smaller volumes of more highly processed data products, including stereo anaglyphs, a few Digital Elevation Models (DEMs), and five images per week with captions.

[76] HiRISE PDS data products are identified in Table 9. Since HiROC is serving as a PDS data node, we can release 
image products as soon as possible, hopefully well before the formal delivery deadlines ( 6 months after acquisition for EDRs and end of mission for RDRs).

\subsection{Image Processing}

[77] The Integrated Software for Imagers and Spectrometers (ISIS) system will be used by the Science Team, and the HiROC automated processing procedures for creating standard data products. ISIS (see http://wwwflag.wr.usgs. gov/isis-bin/isis.cgi) will be adapted to handle the instrument specific requirements of HiRISE for radiometric correction and geometric processing. ISIS-2 supports processing for data sets from past and present Mars missions including Mars Odyssey, MGS, Mars Pathfinder, Viking, and Mariner 9. HiRISE will rely on ISIS-3, a 64-bit architecture that can process the large images. The ISIS components directly applicable to HiRISE include map projection transformation, image mosaicking, camera pointing correction, and general image enhancement, display, and analysis tools. The HiRISE processing capabilities added to ISIS will be freely available to the science community through the USGS. Scientists will be able to perform specialized cartographic and image processing of HiRISE data at their home institutions by becoming registered ISIS users.

\subsection{Public and Project Access to HiRISE Data Products}

[78] All users, including the public, will be able to access all released HiRISE images through HiWeb or PDS (http:// www-pdsimage.jpl.nasa.gov/PDS/public/). The HiRISE team goal is to release images within weeks of image acquisition. The same map-based browser tools in HiWeb used to suggest images will also identify the localities of available HiRISE images. Clicking on the image outline will bring up the HiRISE image viewer. Users will be able to rapidly pan across and zoom into the large HiRISE images. This will allow users to download only the portion of the image at the resolution that is of interest. Users will be able to download portions of a HiRISE image in a variety of popular image formats (tiff, jpeg, jpeg2000, gif, and PDS). Basic image processing adjustments (e.g., histogram display and equalization, manual contrast/brightnessstretching, zooming, cropping, and edge enhancement) will also be available. These on-line tools obviate the need for most casual users to download entire (very large) images. In addition, the top-level HiRISE Web site will feature a captioned "image of the day".

\subsection{DEM Production}

[79] Digital elevation models (DEMs) and derived products will be produced by the U. S. Geological Survey (Planetary Geomatics Group of the Astrogeology Team). Techniques for digital (softcopy) mapping were developed in the late 1990s and have been applied to a wide variety of data sets, including those from the Mars Pathfinder [Kirk et al., 1999] and Mars Exploration Rovers [Herkenhoff et al., 2006] missions, Mars Global Surveyor/MOC [Kirk et al., 2003], Viking Orbiter [Rosiek et al., 2005], and Mars Express HRSC [Kirk et al., 2005].

[80] The essence of the USGS approach to planetary stereomapping is the synergistic use of the in-house image processing and planetary cartography system ISIS and
BAE Systems' commercial digital photogrammetric software SOCET SET (SOftCopy Exploitation ToolSET) [Miller and Walker, 1993, 1995]. ISIS is used for "twodimensional" image-processing steps such as map projection and mosaicking and particularly for mission-specific processing such as ingestion and radiometric calibration of images. Development of ISIS in-house ensures that these steps can be tailored to specific mission needs. SOCET SET is used for intrinsically "three-dimensional" steps. The most important of these are DEM production by automatic image matching and DEM quality control and interactive editing involving overlay of DEM data (points, mesh, or contours) on the images in an optoelectronic stereo display and user input via a three-dimensional hand controller. SOCET SET also provides tools for automatic and manual selection of control points and bundle-adjustment to refine image pointing data based on these points, as well as manipulation of DEM data such as contouring, relief-shading, and orthorectification (parallax removal) of images based on the DEM. Other software packages such as ESRI ArcView GIS and Adobe Illustrator may be used to produce finished map products with grids, scales, and appropriate annotation from the DEMs and rectified images.

[81] The capabilities of the stereomatching software, along with the geometric properties and scene content of the images, determine the precision and resolution of the output DEMs. The performance of Automatic Terrain Extraction (ATE) is comparable to that of other stereomatching software. It incorporates an area-based matcher and performs multiple passes working generally from resampled, reduced-resolution versions of the images toward full resolution and from coarse DEM post spacing to fine. The matching window in the final pass is typically $5 \times 5$ or $3 \times 3$ pixels, and, although posts can be spaced as closely as desired, they will not resolve topographic features smaller than this final window size. We plan to produce HiRISE DEMs with a post spacing of $1 \mathrm{~m}$ (3 to 4 pixels) for full-resolution images. A larger post spacing will be used for images obtained with binned pixels, and may also be appropriate for full-resolution images in which the pointspread function was degraded by spacecraft jitter. The vertical precision of the measurements depends on the convergence angle of the images, the image resolution, and the matching error. A widely used estimate of stereo matching error for many types of images is 0.2 pixels. Our experience with several types of planetary images for which we have been able to quantify matching errors [Kirk et al., $1999,2003,2004$ ] indicates that 0.2 pixel is commonly obtained with ATE. For a stereopair containing one vertical image and one with an emission angle of $20^{\circ}$ the expected vertical precision (EP) is equal to the scale of about 0.5 pixel. Increasing the obliquity of one or both images will improve (reduce) the EP statistic but image matching could fail if the images are too oblique (so that slopes are severely foreshortened or even hidden) or the phase-angle difference between the images becomes too large. Given that EP is already substantially less than the effective horizontal resolution of the DEMs and further improvement only exacerbates this mismatch, a convergence angle of $20^{\circ}$ is likely to be near-optimal for most stereo imaging with 
HiRISE. Extremely flat terrains like candidate landing sites might benefit from larger convergence angles.

[82] The resulting expected vertical precision of HiRISE DEMs will be $0.1-0.2 \mathrm{~m}$. The absolute accuracy, however, will be limited by our ability to tie the stereomodels to ground control. The ultimate source of both horizontal and vertical control is MOLA, which has absolute accuracy $\leq 1 \mathrm{~m}$ vertically but $\sim 100 \mathrm{~m}$ horizontally [Neumann et al., 2001], 300-m spot spacing along tracks, and numerous gaps $\geq 1 \mathrm{~km}$ between adjacent tracks. Because of the low horizontal resolution of the MOLA data set compared to HiRISE images, vertical accuracy will likely be governed by the difference between localized topographic features and the broader-scale relief as measured by the altimetry, and may be several meters. The resolution mismatch between the two data sets is likely to make direct use of MOLA for horizontal control almost impossible. Our approach is to control lower-resolution images to a shaded relief product generated from MOLA data gridded at $1 / 256^{\circ}$ or $\sim 231 \mathrm{~m} / \mathrm{pixel}$, then to transfer control from these images to the high-resolution stereopair. Both Viking Orbiter and MGS MOC wide-angle data cover Mars globally at $200-300 \mathrm{~m} /$ pixel, and the utility of the MOLA-controlled global Viking mosaic MDIM 2.1 for controlling stereopairs is well established [Rosiek et al., 2005]. THEMIS coverage will be available for most of Mars at $100 \mathrm{~m} /$ pixel (in the thermal IR) and for substantial regions at $18-36 \mathrm{~m} /$ pixel (visible), and individual images or MOLA-controlled THEMIS mosaics are also likely to be used in the control process, as are MRO CTX images at $\sim 6-12 \mathrm{~m} /$ pixel. The absolute horizontal accuracy of DEMs controlled in this manner will probably be between $100 \mathrm{~m}$ (the accuracy of MOLA) and $200 \mathrm{~m}$.

[83] Experience with MOC-NA data [Kirk et al., 2003] has shown that spacecraft motions ("jitter") can have a significant impact on the quality of DEMs produced from high-resolution scanner images, and can even make stereo data collection impossible. Jitter could be an even more serious issue for HiRISE, with its five times smaller IFOV, although the MRO spacecraft is expected to be more stable than MGS. The geometrical effects of jitter are twofold. Most obviously, spacecraft motions in the direction of the stereo baseline (i.e., across-track or roll variations) mimic stereo parallax and lead to artifacts in the recovered DTM. These artifacts take the form of a "washboard" pattern of high and low stripes extending across the field of view of a given CCD, superimposed on the actual topography. If the spacecraft motion occurs mainly at particular frequencies, it may be possible to remove these artifacts by spatial filtering of the DEM as has been done for MOC data. Motion in the direction orthogonal to the stereo baseline (along-track or pitch variations) can be tolerated up to a point, but if geometric distortions in this direction exceed a few pixels, they can prevent matching of the stereo images at full resolution. It will still be possible to produce a lowerresolution DEM from images that have been pixel-averaged so that the jitter is negligible in a relative sense. The preferred approach to dealing with jitter, however, is to estimate the spacecraft motions based on image correlations in the overlap areas between the CCDs as well as data from the MRO Attitude Control System. The images can then be resampled to correct the geometric distortions caused by jitter, prior to combining the data from multiple CCDs into RDRs and performing stereoanalysis. Jitter can also have a third effect on HiRISE images that has no analog in our MOC experience: motions that occur during TDI will result in blurring in addition to geometric distortion. This effect degrades image resolution and interpretability, but it is not expected to have a severe impact on stereo DEM production because the precision of image matching is subpixel and will not be degraded by moderate image blur. However, high-frequency geometric distortions may not be correctable and would degrade the DEM.

[84] It is interesting to note that the USGS global DEM of Mars, which required over 10 years work to produce with the older, hardcopy stereomapping technology, contains about the same number of posts as three HiRISE DEMs. Considering that the global DEM was produced by interpolating relatively sparse contour data, it actually contains less real stereo-derived elevation information than a single HiRISE DEM. DEM production from HiRISE images will initially involve mapping of limited subareas of a relatively large number of stereopairs taken under different conditions, in order to understand the camera modes and observation geometries that give the best results and the processing approaches that maximize efficiency and DEM quality. Subsequent processing will likely result in a limited number (10-20) of DEMs covering entire stereopairs, with the balance of the $\sim 1000$ pairs obtained during the mission constituting a legacy to future users such as landing site selection/validation working groups, postmission mapping programs, and individual researchers. We expect many other researchers to produce DEMs or extract point-to-point measurements with these released images, perhaps typically over small areas of interest. The DEM production effort at USGS will lead to improvements in precision geometric corrections, including camera calibration parameters as well as jitter collections, which will be applied to all HiRISE stereo images.

\section{Scientific Objectives and Expectations}

[85] HiRISE will address a very broad range and number of scientific studies: anything for which observing the surface is important. Our investigation builds most directly on the spectacular successes of the MOC investigation [Malin et al., 1992], which has truly revolutionized our understanding of the Martian surface. Some of the science to be pursued via HiRISE is described below.

\subsection{Cratering Studies}

[86] Impact craters are ubiquitous on Mars, ranging from the Hellas basin ( $1800 \mathrm{~km}$ diameter) down to a crater only $10 \mathrm{~cm}$ diameter imaged by MER Opportunity (http:// www.nasa.gov/vision/universe/solarsystem/mer-0427 2005.html) [Grant et al., 2006]. HiRISE observations of impact craters can achieve several science objectives by measuring meter-scale structures. While fresh impact craters often expose the bedrock of the region, useful for regional stratigraphic studies, and provide traps or settings for sand dunes, gullies, etc., here we focus on studies more directly related to cratering. Below we discuss three broad topics: what craters might be able to tell us about subsurface water, how they reflect impact processes and target material 
properties, and how they can be used to constrain the ages of planetary surfaces.

[87] Craters with fluidized ejecta morphologies have long been of interest because they are thought by many investigators to indicate the presence of ground ice [e.g., Carr et al., 1977a; Stewart et al., 2004], and crater morphometry has been used to map out variations in depth to ground ice and to constrain ice abundance over time [e.g., MouginisMark, 1979; Costard, 1989; Barlow, 2004]. However, evidence for fluids in ejecta emplacement, such as boulders transported by water or channels suggestive of dewatering of the ejecta flow, has not been confirmed in MOC images according to Williams and Edgett [2004]. It is possible that the resolution, SNR, and topographic information of HiRISE images will lead to detection of such features.

[88] Subsurface ice abundances can also be investigated from viscous relaxation of topography [Squyres, 1989; Squyres and Carr, 1986]. Small craters are convenient for such studies because we have some idea of their original form [e.g., Melosh, 1989]. Ice-rich permafrost is quite mobile under current Martian conditions; for example, E. M. Turtle and A. V. Pathare (Numerical modeling of crater relaxation on Mars: Implications for sub-surface ice content, submitted to Geophysical Research Letters, 2006) predict the complete relaxation of a $2-\mathrm{km}$ diameter crater in ice-rich ground near Mars' equator in just $10^{4}$ to $10^{5} \mathrm{yrs}$, whereas a $20 \mathrm{~m}$ diameter crater would require $10^{8}$ yrs to relax. HiRISE DEMs of multiple small craters on potentially ice-rich terrains could be used to constrain the subsurface ice abundance, stratigraphy, and history, complementary to observations from the Shallow Radar (SHARAD) experiment on MRO [Seu et al., 2004, 2007]. Studies of viscous relaxation of craters in icy terrains may also provide constraints on age estimates [Pathare et al., 2005].

[89] The size-frequency and spatial distributions of blocks in impact ejecta and of secondary craters are important to understanding crater excavation processes and properties of the target material [Melosh, 1989], including tests of the hypothesis that Martian meteorites originate from spallation [Melosh, 1984]. Bart and Melosh [2005] measured blocks and boulders around lunar and Martian craters, and found that the size-frequency distribution (SFD) is approximated by a cumulative power law slope of -4 . This means that a factor of five increase in spatial resolution (roughly the HiRISE to MOC ratio) would result in resolution of 625 times as many boulders per unit area. However, most rock distributions roll over and become shallower (smaller negative power law exponent) at smaller sizes [Golombek et al., 2003b]. Given the number of blocks ( $\geq 5 \mathrm{~m}$ diameter) resolved by MOC, we can expect HiRISE to resolve much greater numbers of 1-5 m diameter blocks and boulders. The SFD of boulders, for example in a stratigraphic layer, may enable us to deduce whether or not the layer was emplaced as impact ejecta. The observed abundance and distribution of large ejecta blocks can also reflect the amount of gradation a crater has undergone since formation as well as providing clues (e.g., burial by aeolian drift) to responsible processes [Grant et al., 2006].

[90] Another potential use for small craters is for estimating the ages of planetary surfaces or their modification [e.g., Hartmann and Neukum, 2001]. However, it has been suggested that the majority of small $(<300 \mathrm{~m}$ diameter) craters on Mars are secondary craters, and that the production function for small primary craters is poorly known [McEwen et al., 2005; McEwen and Bierhaus, 2006]. Millions of secondaries form essentially simultaneously and cannot be assumed to be random independent events like primary craters, so crater counts for age dating may be meaningless if secondaries dominate the statistics. Although some secondaries have distinctive morphologies, distant secondaries are expected to be more circular and isolated, thus difficult to distinguish from primaries. Furthermore, attempts to distinguish primaries from secondaries (which are generally shallower) are complicated by aeolian erosion and infilling. Nevertheless, there may be morphologic differences that can be recognized in higher-resolution images and DEMs. At a minimum, HiRISE images should reveal whether or not a crater is pristine by detecting the rock distribution of the ejecta blanket [Grant et al., 2006] (see section 8.8) or distinctive color properties of the ejecta, as is the case for the image in Figure 17. We can then study the morphologies of pristine secondary craters (using DEMs whenever possible) as a function of range from the primary (where identifiable), to develop quantitative criteria for identification of secondary craters. Counts of small primary craters, if we can confidently identify them as such, would be of great value for dating young surfaces where large craters are infrequent. There are issues of great interest to understanding the geologic evolution of Mars, such as whether there has been any recent volcanic and/or fluvial activity and how much Amazonian climate change may have occurred, for which chronology is key. HiRISE data may also show a clear "rollover" in the abundances of craters smaller than a few meters diameter, from the influence of the atmosphere [Chappelow and Sharpton, 2005].

\subsection{Volcanology}

[91] Mars is fundamentally a volcanic planet. It is home to the largest volcanoes in the Solar System and the majority of the surrounding plains were once covered with lava flows [e.g., Carr, 1973; Carr et al., 1977b; Greeley and Spudis, 1981; Greeley and Schneid, 1991; Keszthelyi and McEwen, 2007]. All the Martian meteorites are igneous rocks and the surface is dominated by mafic (basaltic to andesitic) compositions [e.g., Nyquist et al., 2001; Christensen et al., 2001], but more evolved compositions may be present locally [Christensen et al., 2005]. Volcanic exhalations would have entered the Martian hydrologic cycle with a mix of sulfur, halides, and other volcanic volatiles [e.g., Settle, 1979; Craddock and Greeley, 1995]. The heat from magmatic activity is likely to have caused major (local or regional) perturbations of the cryosphere, perhaps even triggering catastrophic aqueous floods [e.g., McKenzie and Nimmo, 1999; Head et al., 2003a]. Volcanological studies conducted with HiRISE will aim to (1) better understand both effusive and explosive examples of this fundamental geologic process and (2) investigate the interactions between volcanism and water.

[92] For effusive volcanism, a prime focus will be on imaging locations where lava flows can be seen in crosssection. HiRISE images hold out the promise of being able to detect vertical variations in lava flow structures. Of 


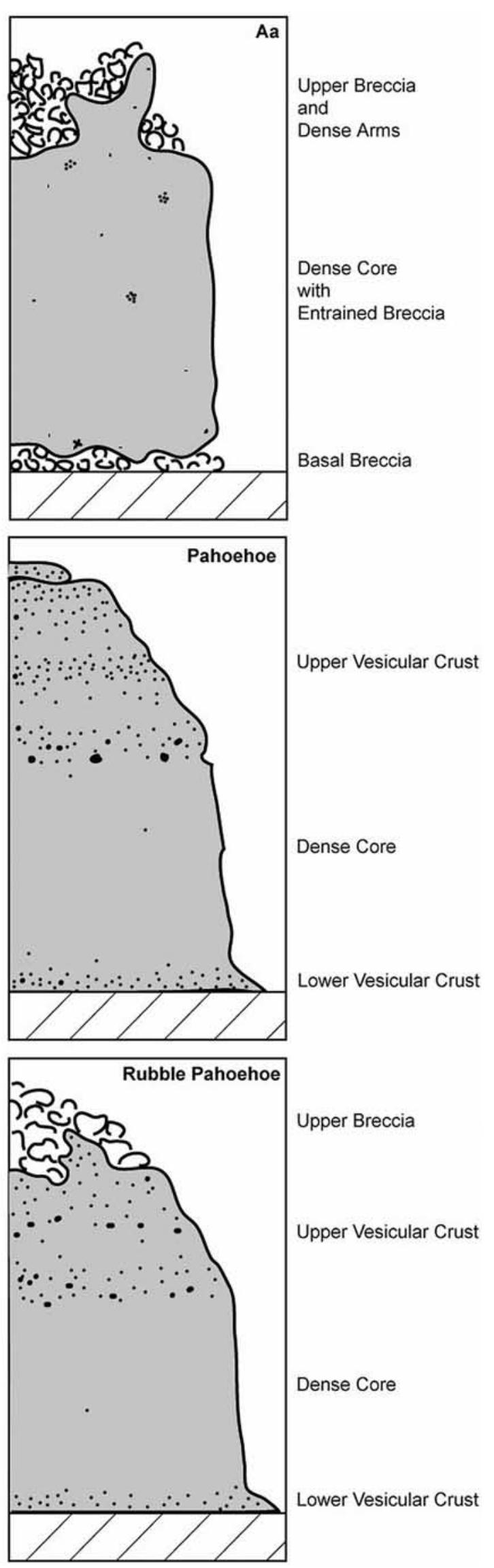

particular interest would be morphologies related to variations in vesicularity, which can be related to the style of emplacement (Figure 20). While HiRISE cannot resolve vesicles from orbit, terrestrial experience shows that the more vesicular portions of lava flows erode more easily. The increased porosity usually results in higher permeability, perhaps leading to color variations due to hydrothermal alteration being visibly more pervasive in the vesicular portions of lava flows. The layering seen in MOC images from some canyon walls are similar to the stacks of lava flows seen in flood basalt provinces [McEwen et al., 1999]. However, MOC resolution has been inadequate to allow quantitative measurements of parameters such as the thickness of the upper vesicular crust and dense core of individual lava flows. These kinds of measurements should allow estimates of eruption duration and eruption rates, via the method used to study terrestrial flood basalt eruptions [Thordarson, 1995; Thordarson and Self, 1998]. Variations in the style of eruptions with time and location could help constrain the thermal and chemical evolution of the mantle. Sampling cliffs cutting lava flows of diverse ages in a wide variety of locations with the full HiRISE spatial resolution (and color) will be a high priority.

[93] Another focus for effusive volcanism will be lava surface features that are near or below the MOC resolution limit. Examples would include lava balls in open channels, inflation cracks in tumuli, and plates on lava lakes. These meter-scale features may be obscured by thick mantles of dust, so imaging will strongly favor young (or recently exhumed) surfaces. The plan is to begin by sampling lava surfaces with a variety of morphologies seen at the MOC/ THEMIS scales. The best examples of each type of meterscale and larger features, as seen in the early HiRISE images, will be targeted for stereo observations, to allow detailed quantitative comparisons with terrestrial features.

[94] The role of explosive eruptions in mafic volcanism is often under-appreciated. However, both terrestrial experience and physical models indicate that Martian pyroclastics are likely to be very voluminous. For example, the largest historical basaltic eruption on Earth, the 1783-1784 Laki eruption in Iceland, produced about $15 \mathrm{~km}^{3}$ of lava flows and close to $1 \mathrm{~km}^{3}$ of pyroclastics that were detected as far as Venice, Italy [Thordarson and Self, 1993]. On Earth, the basaltic explosive eruptions are most often relatively mild (i.e., "hawaiian" fountains or "strombolian" bubble bursts) [e.g., Wilson and Head, 1994]. However, the lower atmospheric density on Mars should enhance the production of pyroclastics [e.g., Wilson and Head, 1994; Fagents and Wilson, 1996]. In fact, some models predict explosivities similar to plinian eruptions on Earth [e.g., Hort and Weitz,

Figure 20. Idealized stratigraphic sections through the three main types of lava flows expected on Mars. Sections produced using terrestrial observations of active flows, older flows exposed in outcrop, and drill cores [e.g., Macdonald, 1953; Hon et al., 1994; Thordarson and Self, 1998; Coffin et al., 2000; Keszthelyi, 2002]. Note that pahoehoe and aa flows have three major sections, while rubbly pahoehoe has four. The relative thicknesses of these sections provide key constraints on eruption duration and other emplacement parameters [e.g., Thordarson, 1995; Keszthelyi et al., 2004]. 


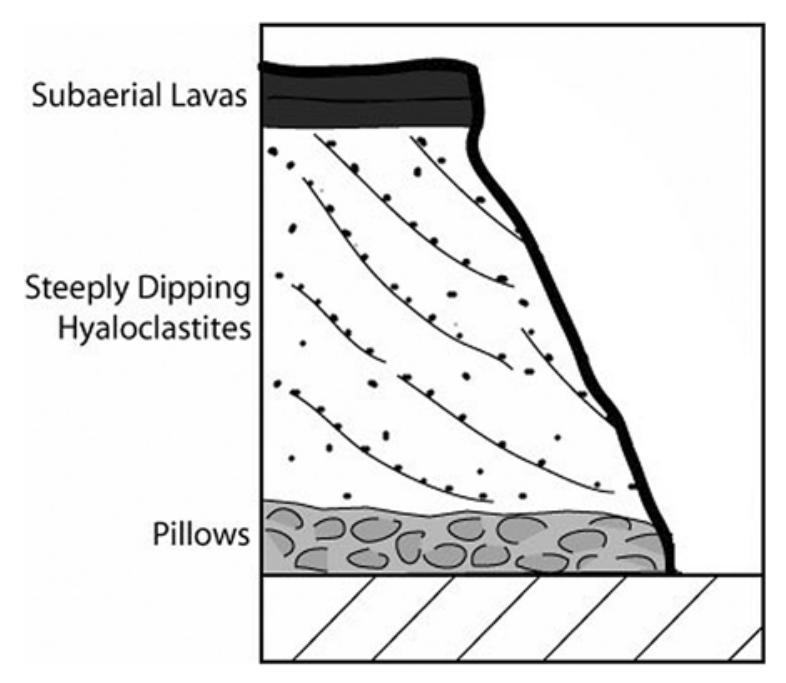

Figure 21. Idealized stratigraphic section through a tuya formed by eruption of lava under water or ice. Pillow lavas typically grade into steeply dipping hyaloclastites as water depth decreases. If the lavas build out of the water, the stack will be capped by resistant subaerial lavas.

2001; Hynek et al., 2003]. Indeed, some of the older volcanoes, including Hadriaca and Tyrrhena Paterae, are thought to have large volumes of pyroclastics within the edifices [e.g., Crown and Greeley, 1993; Gregg and Williams, 1996]. The enigmatic Medusae Fossae Formation may be a more recent example of a large deposit of pyroclastic materials [e.g., Edgett et al., 1997; Keszthelyi et al., 2000]. While we will study these hypothesized pyroclastic deposits, it is likely that they have been significantly modified (altered, eroded and/or redeposited). The study of these deposits may provide more information on sedimentary processes than volcanic eruption processes. As such, these deposits are discussed in more detail under "Layering and Stratigraphy".

[95] A focus for HiRISE studies of explosive volcanic eruptions will be to compare the size and shape of the bestpreserved vents to predictions from theoretical models. Key model parameters that should be observable by HiRISE include (1) radius of welding/agglutination of large pyroclastics, (2) ellipticity of the vent nozzle, (3) flare of the vent nozzle, and (4) constraints on the spatial distribution of pyroclast sizes. The most promising locations will be identified using all the current Mars data sets [e.g., MouginisMark and Christensen, 2005]. Those that look the best preserved in the initial HiRISE imaging will be retargeted to obtain stereo elevation data.

[96] Interactions between water and hot lava are of interest; there are many well-documented features that are diagnostic of water-lava interaction on Earth. These include pillow lavas, hyaloclastites, entablature jointing, rootless cones, and maar craters. We plan to use HiRISE to search for each of these on Mars. However, HiRISE is not particularly well suited to examine entablature jointing (10-cm scale features) or in the search for maar craters (kilometer scale features).

[97] On Earth, pillow basalts are considered diagnostic of subaqueous eruptions. They will be near the limits of HiRISE resolution, unless pillows are larger on Mars because of the lower gravity and/or higher viscosity lavas. Except under water pressures corresponding to the Earth's seafloor, pillow lavas are commonly associated with hyaloclastite deltas, where the rapidly cooling lava fractures. These deltas are often characterized by extensive palagonitization and steep bedding. When the lava pile emerges from the water, it can be capped by subaerial lava flows, forming a tuya or "table mountain" (Figure 21). Several mesas on Mars have been interpreted to be tuyas [e.g., Hodges and Moore, 1978; Allen, 1979; Lucchitta et al., 1994; Chapman, 2003; Chapman and Tanaka, 2001]. Testing these interpretations with HiRISE's combination of high spatial resolution, stereo, and color imaging is a top priority.

[98] The other hydrovolcanic landform that has been claimed to exist on Mars are rootless cones [e.g., Allen, 1979; Greeley and Fagents, 2001; Lanagan et al., 2001]. Rootless cones (aka pseudocraters) form when a lava flow moves over a wet substrate and the resulting steam creates a sustained explosive vent [e.g., Thordarson, 2000]. The gentle escape of steam can produce spiracles, which are much more subtle in their surface expression. Some features that could be rootless cones have also been suggested to be sedimentary or periglacial features such as pingos and kettle holes [Rice et al., 2002; Gaidos and Marion, 2003; Burr et $a l ., 2005]$. The increased spatial resolution of HiRISE may provide new evidence to help resolve this debate: rootless cones would be constructed of agglutinated spatter capable of standing at well beyond the angle of repose, mud volcanoes would be dominated by fluid flows, and pingos would have no emanations except perhaps water along the margins.

\subsection{Tectonism}

[99] The surface of Mars is not sculpted by active plate tectonics. Instead, a different style of tectonism operates, one dominated by volcanic loading of the lithosphere and by a hemispheric dichotomy of thicker crust in the south and thinner crust in the north [e.g., Zuber et al., 2000]. In the absence of a thin mobile lithosphere, Martian volcanoes such as Olympus Mons have grown to enormous proportions. Tharsis, the largest volcanic province on Mars, is so massive that its formation likely shifted the spin axis of the planet [Schultz and Lutz, 1988; Zuber and Smith, 1997]. Such tremendous loading of the lithosphere produces a tectonic signature with effects seen across much of the globe. The tectonism associated with lithospheric loading is manifest both directly as graben, wrinkle-ridges, pit-crater chains, fissures, etc. and indirectly as a major factor in controlling the locations and orientations of other landforms (e.g., Valles Marineris). Tharsis circumferential compressive stresses may have decreased in the Late Hesperian to Early Amazonian, producing strike-slip faulting [Okubo and Schultz, 2006]. Tectonism and volcanism are linked in another manner: buoyant magma can exert a force (cf. hydrostatic head) large enough to fracture overlying rock, and many of the fractures that crisscross Mars are suspected of having had such a volcanic component to their origin.

[100] Nonvolcanic processes influence Martian tectonism as well. The hemispheric dichotomy between the relatively young northern lowlands and the old and cratered southern highlands is the most notable of these. The dichotomy is 
demarcated by a topographic scarp that reflects a decrease in crustal thickness from the southern to the northern hemisphere. Counter-intuitively, tectonic features associated with the dichotomy are observed to be compressive on the southern side and tensile on the northern side. It is postulated that these features may have formed in response to northward lower-crustal flow as the boundary readjusts toward a more equilibrium state [Nimmo, 2005].

[101] Faults in porous sedimentary rocks are of particular interest as they play an important role in controlling volatile migration pathways, acting as either barriers or conduits [Okubo and Schultz, 2005]. The high-resolution images and topographic measurements of HiRISE will allow predictions of volatile pathways, which may help focus future surface exploration [Okubo, 2005].

[102] Although much is known about global- and regionalscale tectonics on Mars, many questions remain. Comparatively little is known about local-scale tectonics; these may hold the key to answering some outstanding questions. One of the basic axioms of structural geology is Pumpelly's Rule, which can be summarized as "a cumulative look at small-scale structures of a given generation and over a given region can reveal the large-scale deformation history." HiRISE will image structures at the meter to decameter scale with the intent of unraveling tectonic processes that may have remained ambiguous when studied at larger scales. Another focus will be to build upon the capability born from MOC and MOLA for using the elevations of thin marker beds on opposite sides of a structure to measure the offset [Beyer and McEwen, 2005]. HiRISE stereo observations will provide new precision in Mars elevation maps, allowing fault offset and other forms of local strain to be evaluated.

\subsection{Fluvial and Hydrothermal Processes}

[103] The major issues involving the formation of fluvial landforms on Mars relate to the water source, the erosional mechanism, and the ultimate fate of the water. Which mechanisms and processes combined to erode and modify the surface, ultimately forming deep integrated valley systems, catastrophic flood channels and recent gullies? While similar fluvial features form on Earth, Mars is a planet whose present climate is not conducive to rainfall and in which liquid water is highly unstable. Although the spatial distribution, overall morphology, and source regions of these landforms differ from their terrestrial counterparts [Carr, 1996; Gulick, 1993, 2001a], water was available periodically throughout Mars' geological history in sufficient quantities over the required duration to provide a full suite of fluvial landforms. Many of the features employed by terrestrial geomorphologists to study and characterize fluvial processes are at the meter scale and finer and thus have been unreachable by previous orbital imagery of Mars.

[104] Perhaps the most puzzling fluvial features on the planet are the geologically young gullies eroding into the flanks of midlatitude craters and valley walls [Malin and Edgett, 2000a]. Numerous formation processes have been hypothesized including surface snowmelt, eruptions of liquid $\mathrm{CO}_{2}$, wind erosion, seepage from subsurface aquifers [see Heldmann and Mellon, 2004, and references therein], or even hydrothermal outflow from smaller localized heat sources such as a small dike, sill intrusion, a recent impact, or tectonic movement along a fault or fracture [Gulick, 2001b]. (There are also dry mass-wasting features on angleof-repose slopes on Mars that have been referred to as "gullies. ") While liquid water erosion or wet debris flows remain the most likely explanations, the source of water remains a mystery. Indeed, the diverse geologic contexts in which gullies are found suggests more than one type of source may be likely. Because of their young geologic age, the prospects of recently active surface water on the surface is of key importance to the exploration of Mars.

[105] HiRISE images will enable us to examine as yet unresolved characteristics of gully morphology that may shed light on their history and the specific source of erosion. Alcove regions at the head of the gullies tend to be associated with exposed subsurface layers. High-resolution morphology and color variations within these layers may implicate a particular layer as the source. Mantled deposits have been eroded by many gullies and have been suggested to be dirty snow deposits [Mustard et al., 2001; Christensen, 2003]. These mantles can be examined for subsurface layering and evidence of sublimation or melting. Gully channels are the most suggestive of liquid water as the eroding agent [Malin and Edgett, 2000a]. HiRISE will enable close inspection of channel levees, as well as tributary and cross cutting relationships indicative of multiple flood episodes. HiRISE stereo will aid in interpretive modeling of fluid flow by providing morphological dimensions and slopes [e.g., Mangold et al., 2003]. Topographic data may also prove key to testing hypotheses of gully formation by snowmelt [e.g., Clow, 1987; Christensen, 2003]. Deposition aprons at the base of each gully system can be examined for distributary characteristics indicative of sediment load, color variations suggestive of salt deposition from brine flows, boulders suggesting dense debris flow, and evidence of subaqueous or subaerial depositional environments.

[106] The formation of the outflow channels remains an enigma. Although the formation by catastrophic floods continues to be the leading hypothesis [Baker et al., 1992], debate persists [e.g., Leovy, 2000; Leverington, 2004] and it is still not clear exactly how such vast deluges of groundwater required to form the channels (on the order of $10^{7} \mathrm{~m}^{3} / \mathrm{s}$ for both the Channeled Scablands and Altai floods terrestrial analogs [Baker et al., 1993]) were abruptly released onto the surface. Other scenarios for Mars such as glacial erosion, mudflows, debris flows, mass wasting, ice rafting, etc., have been proposed in an effort to reduce the magnitude of flood volumes and discharges required to erode the surface and carve the enormous channels. Detailed imaging of the stratigraphy, boulders and bedforms within the channel, including channel bars, mega current ripples (a.k.a., gravel wave trains, diluvial dunes and antidunes, etc.), areas of scour, and potential high-water indicators should enable a clearer understanding of outflow channel formation.

[107] MOC was expected to help resolve debates about the origin(s) of outflow channels; Malin et al. [1992, p. 7702] wrote the following:

MOC will provide a means of testing these alternative ideas and, perhaps more importantly, allow quantitative evaluation of fluvial 
models. These tests derive principally from differences between the hydraulic relationships for ice, air, lava, and water. These differences are most obviously manifested in the quantity and size of the debris transported by each of these fluids. Ice can carry very large loads, both in size and quantity, and these are usually angular and unsorted. Lava rarely carries debris, and when it does, the debris is often coated with spatter and not recognizable as a separate rock type. Debris flows transport considerable material, unsorted, but with distinctive size/ frequency characteristics that depend on the rheology of the fluid phase. Water transports less debris, but is much more efficient in sorting and rounding; bedforms are created that reflect the flow regime of the fluid. Wind is most effective at sorting, but cannot carry large particles. Examination of the beds, banks, and mouths of the major Martian channel systems at meter-scales will provide a means of judging the nature of the debris transported by the channel-forming process and an evaluation of the mechanisms responsible.

[108] However, basic questions about formation of outflow channels remain unanswered. Perhaps MOC images are too low in spatial resolution to identify fluvially transported boulders. MOC detects many blocks that are larger than $5 \mathrm{~m}$ diameter, usually located very close to the source region such as impact craters or exposed bedrock layers just uphill from the blocks. It is rare on Earth for a block larger than $5 \mathrm{~m}$ to be transported for any significant distance (kilometers); there are a few examples in the Ephrata fan of the channeled scabland, but would just look like isolated bumps in a MOC image, not a clear boulder deposit. Many of the rocks on Mars originate from flood lavas; such lavas on Earth tend to have a joint spacing of 1-2 meters due to cooling and contraction, which break into boulders $\sim 1-2 \mathrm{~m}$ diameter when transported for a significant distance by water, mud, ice, or even just gravity. This idea is supported by observations in the outer slopes of Valles Marineris, where blocks are resolved by MOC only close to the outcrops or on landslide lobes, but not in the talus several $\mathrm{km}$ from the nearest apparent source region [Beyer and McEwen, 2005]. HiRISE will target those locations where transported debris is suspected, and where we expect the sediment load to be deposited such as upstream of channel constrictions. For example, HiRISE will target the only location known so far where a type of fluvial bedform known as mega-current ripples or subaqueous dunes has perhaps been detected, in Athabasca Valles [Burr et al., 2002, 2004].

[109] Since they were first recognized on Mariner 9 images, the Martian valley networks have continued to engender substantial debate. To this day, the formation mechanism(s) for valleys formed throughout Mars' geologic history, from those on the ancient heavily cratered terrain to those on the flanks of young volcanoes, remains uncertain. As with the fluvial features seen at other scales, the principle questions surround the water source(s) and cycling mechanism(s), the prevailing climate in which the valleys formed, the role of overland vs. subsurface flow and other flow processes, and the ultimate fate of the fluid. Unlike the outflow channels that could form under current climatic conditions, the fluvial valleys may have required a warmer, denser atmosphere and thus may provide a record of past climatic conditions [Carr, 1979; Mars Channel Working Group, 1983; Gulick and Baker, 1989, 1990; Baker et al., 1992; Craddock and Howard, 2002]. The extensive valley network development on the ancient heavily cratered terrains, Hesperian-age terrains such as in Valles Marineris [Quantin et al., 2005; Williams et al., 2005], and on the flanks of some younger volcanoes implies that water was cycled through the surface and atmosphere over prolonged periods [Gulick and Baker, 1989, 1990; Gulick, 1998, 2001a]. An Earth-like hydrologic cycle has often been invoked to provide a recycling mechanism for the ancient valley networks. However, regional or localized hydrothermal groundwater outflow [e.g., Brakenridge et al., 1985; Gulick and Baker, 1989, 1990; Gulick, 1998; Squyres, 1989; Squyres and Kasting, 1994] or combined snow accumulation and subsequent melting in hydrothermal areas have also been suggested for the younger valleys [Gulick, 1997, 1998, 2001a].

[110] Distinguishing between these different formation mechanisms may be aided by high-resolution imagery and stereo coverage of the headwater regions and valley walls. Do the headwater regions of the valleys start abruptly fullborne, transition into incipient piping or gully development, undercut certain layers or do they taper and blend in gradually with the surrounding terrain? Are there zones of mineral alteration or color changes associated with valley heads or walls? HiRISE's color and stereo capability combined with CRISM data may provide additional clues. However, the valley networks are old and heavily modified, so finding exposures that reveal primary meter-scale structures will be a major challenge [Carr and Malin, 2000].

[111] HiRISE will also search for evidence of hydrothermal outflow associated with fluvial and other geologic features. Alteration zones that commonly accompany regions of terrestrial hydrothermal outflow may be recognizable in HiRISE color imagery. Plausible hydrothermal regions, particularly in the headwaters of valleys, channels and perhaps even gullies that originate near volcanoes, vents, intrusions, large impact craters, maar-like craters, collapse zones and linear structures (e.g., faults and other tectonic features), will be high-priority targets for coordinated observations with CRISM. However, some morphologies associated with hydrothermal systems tend to be fragile and may not be well preserved.

[112] Perhaps the largest-scale controversy about the history of water on Mars is whether or not there have been oceans, and if so, when. Baker et al. [1991] proposed this controversial hypothesis to explain a variety of geomorphological features including the formation of valley networks, glacial features, possible ice sheets and other features that on Earth would require long-term hydrological cycling. These "oceans," Baker et al. [1991] argued, would have inevitably formed in the Northern Plains from the large volumes of water required to form the outflow channels. In addition, Parker et al. [1989, 1993] presented evidence for the existence of what he interpreted as shorelines delineating such oceans. This controversy was reviewed by Carr and Head [2003], who concluded that the best evidence for the presence of a large water body on the northern plains may come from the Vastitas Borealis Formation (VBF), which they interpreted as an Upper Hesperian sublimation residue from the ponded outflow channel effluents. However, Tanaka et al. [2003] interpreted the origin of the VBF as from a variety of processes involving ground volatiles, postdating potential oceans. Hopefully HiRISE data can better constrain the origin of the VBF, perhaps by revealing distinctive distributions of boulders or small-scale morphologies. Geomorphic evidence for shorelines has also been 


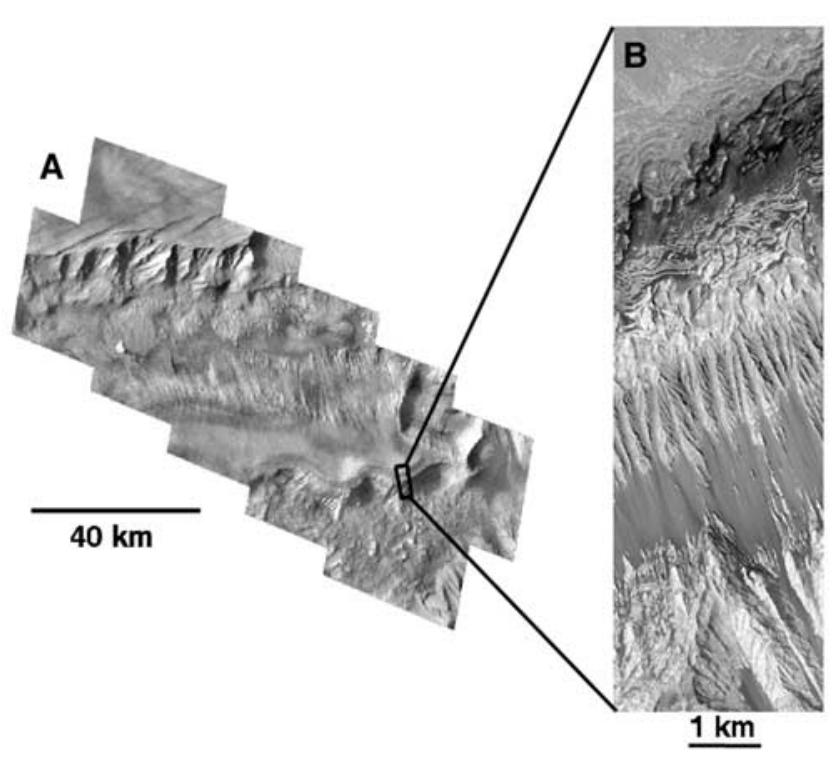

Figure 22. (a) Viking mosaic of a portion of Hebes Chasma and the interior layered deposit unit contained within the chasma. (b) Portion of MOC image M0900284 at $4.3 \mathrm{~m} /$ pixel scale showing a cliff face along the interior layered deposits. The kilometer-scale light and dark banding which had been interpreted as layers in the Viking image actually reflects differences in the amount of dark talus accumulated along the slopes of the unit. The MOC image does reveal meter-scale layering that was not resolved in the Viking images.

controversial, with several workers concluding that Noachianage features would no longer be recognizable. However, geomorphic evidence persists for a Noachian-age paleolake at the headwaters of Ma'adim Vallis [Irwin et al., 2004].

[113] Persistent surface water is important to habitable environments; the discovery of meandering channels in a fan-shaped sequence provided important geomorphic evidence for persistent water [Malin and Edgett, 2003; Moore and Howard, 2005; Bhattacharya et al., 2005]. HiRISE will follow up on this discovery and perhaps find additional evidence for persistent surface water. The evaporite sequences discovered by MER [Squyres et al., 2004a, 2004b] and Mars Express [Bibring et al., 2005] will also be studied in greater detail by HiRISE and CRISM, as discussed in the next section.

\subsection{Layering and Stratigraphy}

[114] Interior layered deposits in the canyons of Valles Marineris [McCauley, 1978; Lucchitta et al., 1992] were identified from Viking and Mariner images as alternating light-dark banding on the scale of hundreds of meters (Figure 22). MOC images showed that this apparent layering was due to relatively flat surfaces covered by dark debris and steeper slopes that appeared brighter due to no accumulation of this dark debris [Weitz et al., 2001]. However, a finer, meter-scale layering became apparent in MOC images of the interior layered deposits (Figure 22b). The two favored origins for the layering are deposition of material in standing bodies of water [e.g., Nedell et al., 1987; Malin and Edgett, 2000b] or volcanism [e.g., Chapman and Tanaka, 2001; Komatsu et al., 2004]. Light-toned meter-scale layering is seen in many impact craters (Figure 23) and terrains elsewhere on Mars [Malin and Edgett, 2000b], suggesting that whatever process(es) emplaced the layered terrain occurred widely in the Martian past.

[115] Even higher-resolution images from HiRISE could reveal finer-scale layering in these light-toned layered units, as well as geologic contacts that could help decipher the processes that emplaced the layered rocks. The close association between sulfates as detected by the OMEGA instrument for several of these layered deposits [Gendrin et al., 2005; Bibring et al., 2005] suggests that both CRISM and HiRISE may further reveal why some light-toned layered deposits have sulfate signatures while others do not. Color images taken by HiRISE could also reveal compositional differences in the layering that could help us decipher their origin. Stereo images could be used to determine the thicknesses and absolute heights of different layers, which will show if layers follow a specific elevation

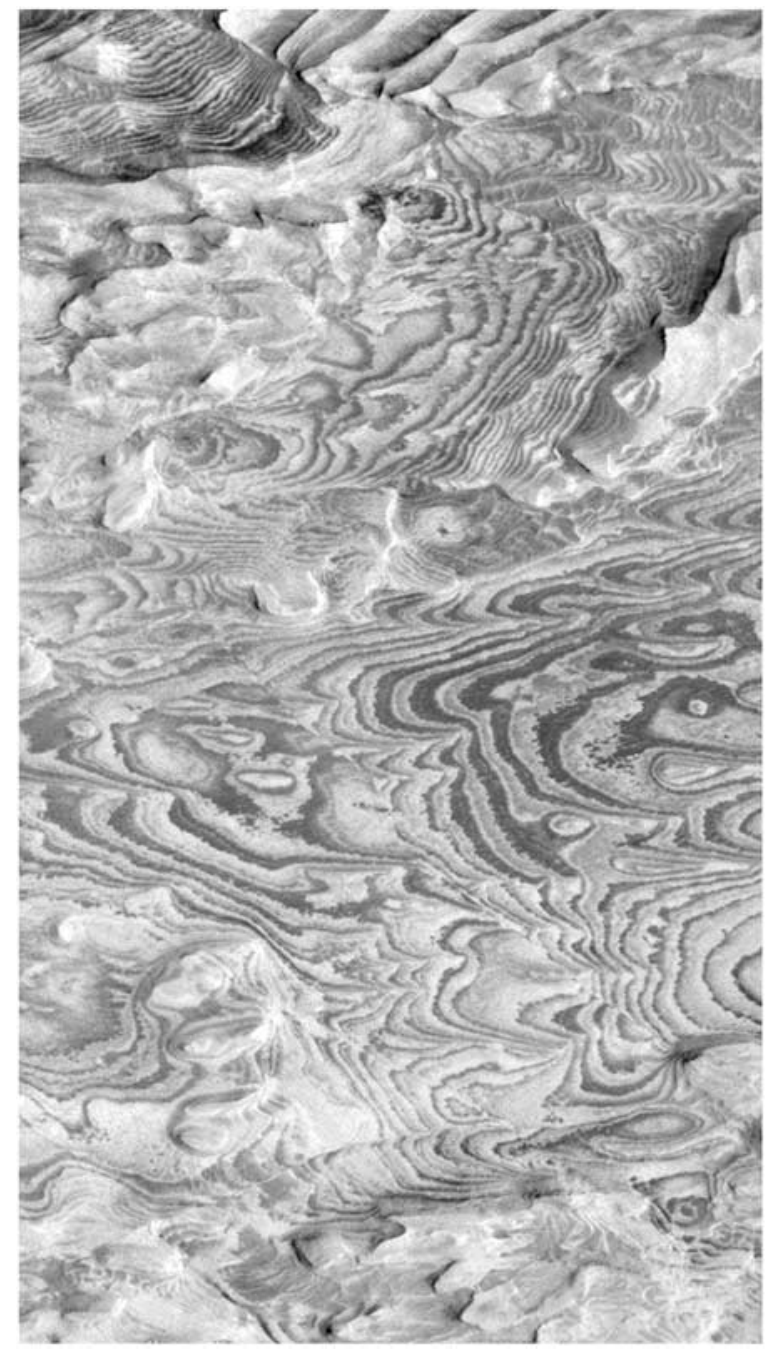

Figure 23. Portion of MOC image R1800383 of layers in Becquerel crater $\left(21.6^{\circ} \mathrm{N}, 8.3^{\circ} \mathrm{W}\right)$ at $3.15 \mathrm{~m} /$ pixel scale. Some layers appear to be only a few meters thick and are rhythmic, while other layers appear more resistant and massive in appearance. Image is $1.61 \mathrm{~km}$ across. 
and were therefore likely formed in a lacustrine environment, or if the layers form a blanket that covers preexisting uneven topography, which would favor an airfall (volcanic or aeolian) origin. HiRISE may be able to detect large-scale depositional structures such as cross-bedding, which has already been suggested from MOC images [Komatsu et al., 2004].

[116] Results from the Opportunity Rover at Meridiani Planum also shed new insight into layering and stratigraphy on Mars. Images returned from the rover show cm-scale cross-laminations interpreted as evidence for flowing water at the site [Squyres et al., 2004b] as well as stratigraphic exposures of multiple layers of sulfur-rich sedimentary rocks along the walls of larger impact craters [Grotzinger et al., 2005]. Orbital images and OMEGA spectra of the Meridiani Planum region suggest the light-toned layered units may extend over a large area [Hynek, 2004; Arvidson et al., 2005]. The ability to tie the rover images from the ground to orbital images has greatly aided in deciphering the geologic history of this particular area on Mars. HiRISE images of the Opportunity landing site will provide an intermediate resolution between the rover images and the current orbital data sets to further elucidate how layering and stratigraphy appear at different scales.

[117] In addition to the fine-layered deposits, much of the upper Martian crust appears more coarsely layered. Such crustal layering is especially well exposed in the outer "walls" of Valles Marineris, where it has been interpreted as primarily volcanic lavas [McEwen et al., 1999], sedimentary rocks [Malin and Edgett, 2001], and/or layered intrusives [Williams et al., 2003]. The layers in Valles Marineris are not of uniform strength, but consist of rare strong layers, perhaps dense lavas, separated by thick stacks of much weaker layers, perhaps volcanic ash or other sedimentary deposits [Beyer and McEwen, 2005]. Some exposures of the Martian crust, especially in the ancient highlands and a few deep portions of Valles Marineris, appear to lack layering in MOC images, consistent with megaregolith. Higher-resolution images may help resolve these debates if we can locate structures diagnostic of origin such as the characteristic internal stratigraphy of lava flows (Figure 20), or the block and boulder size-frequency distributions characteristic of megaregolith.

\subsection{Landscape Evolution}

[118] Landscape evolution refers to the overall changes in a region's shape and elevation through time. As such, it reflects the imprint and heritage of all the geological processes combined that have operated on the surface since its formation. Often, separate endogenic and/or exogenic processes contribute to evolution of either degradational or aggradational landforms whose overall form is similar and difficult to distinguish [Easterbrook, 1993, Ritter et al., 1995]. In other cases, sequential or competing processes create "hybrid" landforms where deconvolving the processes responsible for their appearance may be difficult, especially where no one process may dominate. Nevertheless, the ability to resolve the specific signatures related to individual geomorphic processes is crucial for understanding the geologic evolution of a planetary surface.

[119] For Mars, existing image resolution is often sufficient to identify general processes contributing to large- scale components of landscapes, but leaves many details literally unresolved [Greeley and Guest, 1987; Scott and Tanaka, 1986]. For example, at the regional scale, it is obvious that volcanic activity has dominated the evolution of the Tharsis region, but any component of more silicic activity contributing to structures there and elsewhere often remains uncertain [Mouginis-Mark et al., 1992]. Similarly, impact cratering has played a large role in sculpting the surface [Strom et al., 1992], but it is unclear whether subtle differences in pristine morphology may reflect the influence of the atmosphere and/or subsurface volatiles during formation [Schultz and Gault, 1979; Schultz, 1992; Barlow, 2005]. The source(s) of water responsible for shaping portions of the surface at different times during Martian history is even less constrained and may include the subsurface, atmosphere, or both [Baker et al., 1992; Carr, 1996; Squyres et al., 2004a]. Comparison with landforms on the Earth suggests that the morphologies required for resolving such ambiguities in process often occur at scales too small to be resolved in existing orbital data sets for Mars.

[120] Similarly, the relative contributions of volcanic versus impact versus alluvial/lacustrine versus aeolian processes in formation of widespread deposits on Mars [Malin and Edgett, 2000b] are also not completely understood. In some instances, structure and stratigraphy (e.g., occurrence of aeolian cross-bedding or finely laminated beds extending for kilometers) that may hold the key to completely evaluating the role of these and other processes occur at scales too small to be resolved in existing imagery.

[121] The submeter to meter views of the surface coupled with meter-scale knowledge of surface relief and slope afforded by HiRISE images and derived DEMs of any location on Mars should resolve morphology, structure, and stratigraphy needed to quantitatively evaluate the role of various aqueous versus nonaqueous processes in past and ongoing modification of the surface. For example, evaluation of many morphometric parameters associated with basins encompassing gullies to those associated with large integrated valley systems on Mars requires detailed knowledge of across and down-slope relief. These data record important information regarding the relative role of fluvial denudation versus mass wasting versus impact cratering in shaping associated basin surfaces [Howard, 1994]. Detailed knowledge of gradient across depositional surfaces is also useful in determining whether mass-wasting or alluvial processes dominated emplacement [e.g., Grant, 1999] and can distinguish whether a deposit drapes relief and is a candidate for airfall or lacustrine deposition or is confined to local depressions and more likely the result of volcanic or fluvial infilling. Determining whether along valley profiles are concave up or more variably shaped can help distinguish associated valley segments and whether incisement was due to surface runoff versus subsurface discharge of water, whereas information on how the elevation of valley floors compares with adjacent deposits can help identify terraces, how base level may have changed over time, and constrain the duration, number and magnitude of valley forming events [Howard et al., 2005, Irwin et al., 2005a, 2005b]. A combination of high-resolution HiRISE image and DEM data and with the lower-resolution context imagery provided by CTX, mineralogic data from CRISM, and other existing 

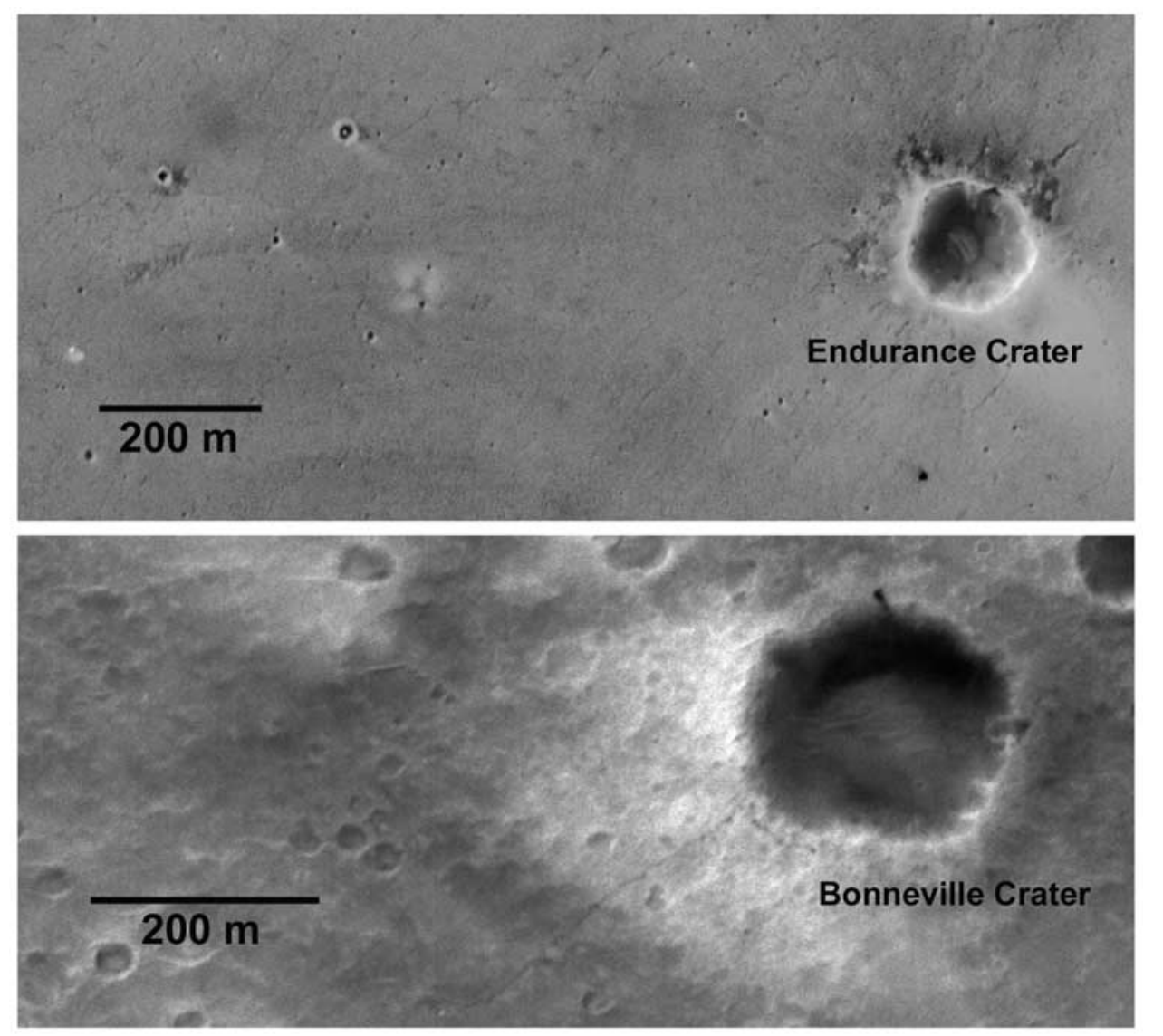

Figure 24. MOC c-proto images [Malin and Edgett, 2005] of (top) the approximately $150 \mathrm{~m}$ diameter Endurance crater in Meridiani Planum and surfaces to the west and (bottom) the $210 \mathrm{~m}$ diameter crater Bonneville and surfaces to the west. In Meridiani, MOC images do not easily distinguish widespread aeolian bedforms on the plains or the widely varying states of crater preservation that include the mistaken suggestion of widespread ejecta around Endurance crater. Images from the Opportunity rover highlight the dominant role played by aeolian processes in shaping the present landscape and confirm a paucity of ejecta around Endurance. In Gusev, MOC images of Bonneville crater reveal a subdued form and crenulations in the southeast wall that might be interpreted as debris chutes. Images from the Spirit rover, however, confirm the crater is a relatively pristine crater and that crenulations on southeast rim are due to superposition of small, younger craters. HiRISE images will be capable of resolving morphology at scales overlapping with that observed by the rovers and necessary for accurate interpretation of geologic setting. Top image is MOC R1602188; bottom image is MOC R1502643. In both cases the original data have a scale of $\sim 1.5 \mathrm{~m} / \mathrm{pixel}$, but with 3 times oversampling in the downtrack direction, so the images are assembled at $0.5 \mathrm{~m} / \mathrm{pixel}$ to show all of the data at a correct aspect ratio.

image orbital data sets should enable better interpretation of how Martian landscapes evolved over time.

[122] The potential for HiRISE to provide new insight into the evolution of Martian landscapes is borne out by comparisons between orbital and surface views of Gusev crater and Meridiani Planum (Figure 24). Images from the Mars Exploration Opportunity Rover reveal plains mostly buried by a thin mantle of sediments that are swept into bedforms tens of centimeters high and meters to tens of meters wide and long [Sullivan et al., 2005]. The plains are punctuated by small craters of widely varying preservation state that are being stripped and buried by wind transported sediments from the surrounding plains [Grant et al., 2006]. The widespread aeolian bedforms and variable appearance of craters are not well detected in the best possible MOC images (Figure 24) and results in an incomplete understand- ing of the importance of aeolian processes in shaping the presently exposed surface [Golombek et al., 2003b]. At Gusev crater, the Mars Exploration Spirit Rover imaged a basaltic plain covered by relatively pristine (for diameters $>100 \mathrm{~m}$ ) mostly secondary craters dominated by limited aeolian and impact modification [Squyres et al., 2004b; Grant et al., 2006]. By contrast, the subdued appearance of the craters in MOC images (Figure 24) suggests a paucity of ejecta. Interpretation of gradation based only on the MOC images could lead to the erroneous conclusion that there has been significant modification by aeolian and mass-wasting processes [Grant et al., 2006]. HiRISE will provide color and stereo images at meter resolutions that can detect morphology visible to the rovers (e.g., aeolian bedforms, small craters, and meter-sized ejecta rocks) that is required 
for complete and accurate determination of gradation state and processes.

\subsection{Aeolian Processes}

[123] Aeolian activity, that is, the interaction of wind and the near surface layer, is the most dynamic geologic process on Mars in nonpolar areas [Greeley et al., 1992]. Numerous depositional and erosional landforms attributable to wind activity are present. On a large scale seen from orbiters these include dunes, ripples, yardangs, wind tails, and dust devil tracks. At the small scale seen from landers and rovers, drifts, erosional moats, wind tails, ripples, and ventifacts are found. HiRISE, with its high resolution, color imaging, and ability to produce precise DEMs at small scales, should significantly advance our understanding of Martian aeolian processes.

[124] There are 4 subthemes of aeolian studies amenable to study by HiRISE.

\subsubsection{Dust: Storms, Removal, and Deposition}

[125] Large dust storms occur virtually every Martian year during southern spring or summer, when the planet is near perihelion. The storms commonly envelope a large fraction of the planet, settling down over time periods of a few weeks or months [Briggs et al., 1979; Greeley and Iversen, 1985]. High and low albedo features on Mars have fairly constant locations, but their extent and boundaries are highly variable from one year to the next [Geissler, 2005]. HiRISE will be able to monitor brightness changes at small scales. Dust loading in the atmosphere (derived from MCS or MARCI) will be tracked for operational purposes in order to make targeting decisions and determine which binning and TDI combinations are best for the current conditions.

\subsubsection{Dust Devils and Wind Streaks}

[126] Dust devils occur when the surface is heated appreciably such that convective heat transfer to the atmosphere takes place, and have been observed from orbit [Thomas and Gierasch, 1985; Edgett and Malin, 2000]. They have been seen on a variety of surfaces, including rock-strewn plains, hills, and dunes. HiRISE images may catch some in action. Repeat imaging of documented dust track areas, such as the Spirit landing site in Gusev, will document the formation and decay of tracks over time.

[127] Bright and dark streaks that change their albedo, size, shape, and orientation with time were one of the first, and the most abundant, aeolian features identified by the Mariner 9 mission [Sagan et al., 1972, 1973]. They are generally associated with topographic obstacles, commonly exhibiting streak-like morphologies downwind [Thomas et al., 1981; Greeley et al., 1992]. All of these streaks serve as wind vanes and provide insight into Mars' current climate. HiRISE will be able to detect very small streaks, down to the submeter scale, in order to document wind direction and shear that is influenced by topography and surface roughness not seen by MOC and other imaging systems.

\subsubsection{Bedforms}

[128] Dunes, bedforms from saltation, and ripples formed from surface creep, have been well documented on Mars, although the origin of some features identified as "ripples" is uncertain [Malin and Edgett, 2001]. The resolution of HiRISE, and the ability to produce DEMs with $25 \mathrm{~cm}$ or better vertical precision, will provide the ability to measure changes in dune position with time. This is an important measurement, as it quantifies the rates of deposition of sand into topographic lows and the fraction of time that surfaces are covered by sand. Observations using MOC and other images show evidence of modification of dune slip faces, but no net migration [Edgett and Malin, 2000; Zimbelman, 2000; Malin and Edgett, 2001]. Other HiRISE investigations will be to help determine the origin of bright versus dark bedforms and, through stratigraphic relationships, determine the relative ages of lithified dunes.

\subsubsection{Yardangs and Removal of Mantled Material}

[129] Yardangs, remnant landforms that have been sculpted by wind and saltating sand, are a common aeolian feature on Mars. At maximum size, they are as long as $50 \mathrm{~km}$, with $1 \mathrm{~km}$ widths and $200 \mathrm{~m}$ deep troughs $[A . W$. Ward, 1979; Ward et al., 1985]. They are commonly made up of arrayed linear ridges or knobs. One of the largest areas of yardangs on Mars occurs in outcrops of the Medusae Fossae formation. In addition to yardangs, pits and grooves in equatorial regions and pits and grooves in the southern polar regions have been attributed to aeolian erosion [Sharp, 1973; A. W. Ward, 1979; Ward et al., 1985; Howard, 2000; Bridges and Herkenhoff, 2002]. Evidence for exhumation of buried craters and other topography is found in the northern plains, in craters with remnant mounds, and elsewhere [Malin and Edgett, 2001]. This process is probably dominated by aeolian erosion. HiRISE should make fundamental contributions to the study of yardangs and removal of mantling material. Detailed morphometry from highresolution images and stereo DEMs may reveal notches in yardangs, forms that on Earth are attributable to the height of peak abrasion by saltating sand. Fluting in mantled material seen at small scales should reveal the direction of winds that caused removal.

\subsection{Glacial and Periglacial Processes}

[130] The climate of Mars is presently cold and dry, with a surface layer dominated by permafrost [e.g., Leighton and Murray, 1966; Fanale et al., 1986; Mellon and Jakosky, 1993], but extensive glaciation may have occurred in the past [Kargel and Strom, 1992; Kargel et al., 1995; Kargel, 2004]. Ice-rich permafrost and surficial ice deposits can have a pronounced effect on the morphology of the Martian surface [e.g., Squyres, 1989, Carr, 1986; 1996; Kargel, 2004; Mangold, 2005] as they do on Earth [e.g., Péwé, 1974; Sugden and John, 1976; Washburn, 1980; Williams and Smith, 1989]. Indeed, large deposits of subsurface hydrogen (presumably water ice) have been observed in the Martian high latitudes [Boynton et al., 2002; Feldman et al., 2002]. While there are many similarities between the Martian cold climate and terrestrial polar deserts, differences in their relative climatic conditions raise questions about the dominant geologic processes and the characteristics of the resulting landforms. In the absence of freeze/ thaw cycles, which landforms dominate the Martian surface and can these specific landforms provide us with evidence of liquid water? Can differences between short-lived and long-lived landforms provide clues about the Martian climate history with respect to water and temperature? A general understanding of glacial and periglacial landforms and their specific morphological characteristics will aid in developing a broader understanding of the climate history of Mars and the history of water. 


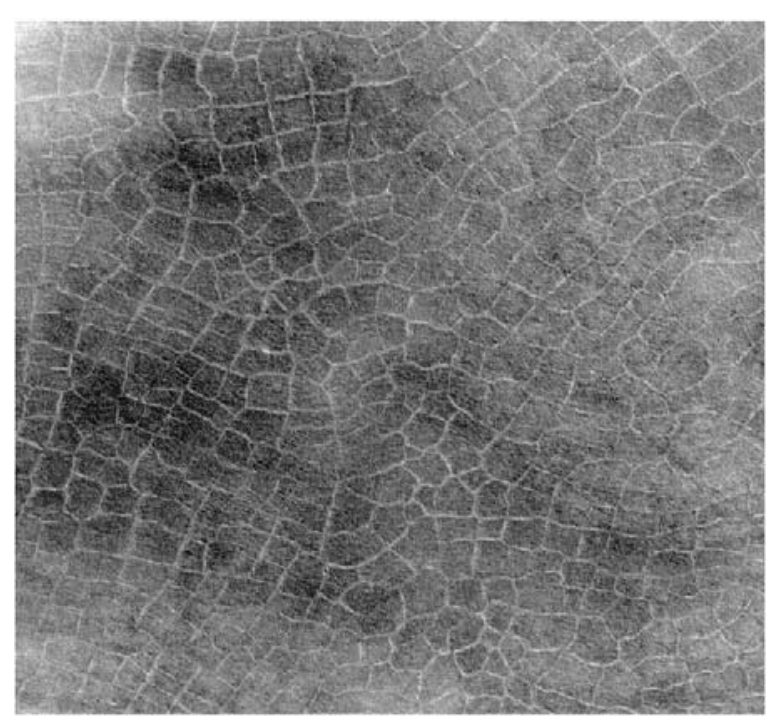

Figure 25. Polygonal patterns in the northern high latitudes. Such patterns on Earth form from seasonal thermal-contraction cracking of ice-rich permafrost. A wide range of sizes and shapes of polygonal patterns are observed on Mars down to and presumably below the resolution of existing images. Subframe of MGS MOC image E0300299. Scene width is $3.2 \mathrm{~km}$.

[131] A wide range of landforms occur in terrestrial cold climates and polar deserts [Washburn, 1980; Sugden and John, 1976]. Active glaciers form characteristic topography, flow fronts, and streamlines as evidence of movement and direction under the influence of gravity. Rock glaciers and debris-covered glaciers form many diagnostic features without any expression of exposed surface ice. Past glacial flow can leave characteristic landforms such as moraines, eskers, and kettles long after the ice has been lost to melting or sublimation. The occurrence of such features and their morphological details (including boulder distributions) not only provide evidence for the existence of past ice deposits, but also the climate conditions under which the ice occurred and was eventually lost. Periglacial landforms are perhaps the most common in Earth's cold regions. Solifluction lobes and stone circles can be diagnostic of freeze thaw cycles. Larger polygonal patterns can indicate permanently frozen, ice-rich soil deposits (see Figure 25). Characteristics such as the spatial distribution of rocks, plan view patterns, and micro-topography can help distinguish process and history. Many of these periglacial and glacial landforms exhibit morphology on small, frequently submeter, length scales. HiRISE provides a unique opportunity to resolve microtopographic characteristics diagnostic of the formation processes.

\subsection{Regolith Characteristics}

[132] The surface layer of Mars is globally dominated by soil deposits [Palluconi and Kieffer, 1981; Christensen and Moore, 1992; Mellon et al., 2000]. The physical characteristics of these soils are strongly related to the processes of the breakdown of underlying bedrock along with erosion and deposition that have occurred throughout Martian history. Thermal measurements provide some information about the global nature of these soils; the physical structure of the soil layer strongly influences the thermal inertia and seasonal temperatures. However, ground truth for interpretation of these thermal measurements is limited to a few select landing sites [e.g., Jakosky and Mellon, 2001] and landing sites are chosen for safe thermal characteristics, among other reasons, biasing our sampling of Martian surface types. From lander images the Martian surface is dominated by rocks, sand, dust, and weakly cemented soils (duricrust) in various proportions. Other regions of Mars are likely considerably different from these local examples. Indeed, thermal inertia values of the Martian surface range widely indicating some areas are dominated by thick dust deposits and others by complex rocky and mixed materials. In general, Mars is covered by diverse surface soil types. Ground truth to understand many of these regions is lacking and HiRISE provides a unique ability to image the surface at horizontal length scales approaching the characteristic thermal length scales. Being able to directly observe and measure rock populations, surface roughness, reflectance, and color variations on these small length scales will enable interpretation of the wide range of surface types indicated by thermal measurements.

\subsection{Polar Geology}

[133] It is widely believed that the Martian polar layered deposits (PLD) record climate variations over at least the last 10 to 100 million years [Murray et al., 1972; Cutts et al., 1976, 1979; Squyres, 1979; Toon et al., 1980; Carr, 1982; Howard et al., 1982b; Plaut et al., 1988; Herkenhoff and Plaut, 2000], but the details of the processes involved and their relative roles in layer formation and evolution remain obscure [Thomas et al., 1992]. Variations in axial obliquity and orbital eccentricity are thought to influence the climates of both Earth and Mars, but are of greater amplitude in the Martian case [Ward, 1974; W. R. Ward, 1979; Bills, 1990; Touma and Wisdom, 1993; Mellon and Phillips, 2001]. A common presumption among Mars researchers has been that the polar layered deposits (PLD) are the result of variations in the proportions of dust and water ice deposited over many climate cycles [Cutts et al., 1979; Squyres, 1979; Toon et al., 1980; Mellon and Jakosky, 1995; Tanaka, 2000; Laskar et al., 2002]. Results from the GRS experiment on Mars Odyssey are consistent with abundant water ice in the near subsurface of both polar regions [Boynton et al., 2003]. Aeolian erosion is likely the dominant process that has exposed the layers [Cutts, 1973; Howard, 2000]. Blasius et al. [1982] presented evidence for both topographic and albedo variations between layers in the north polar layered deposits, based on analysis of springtime images [Howard et al., 1982a]. By combining stereophotogrammetry and photoclinometry, Herkenhoff and Murray [1990] showed that the layered appearance of an exposure of the south polar deposits is due both to "staircase" topography and albedo variations caused by differential frost retention rather than compositional variations between layers. The expression of layers is highly variable [Malin and Edgett, 2001], further complicating separation of topographic and albedo effects on their appearance.

[134] HiRISE is capable of observing the topography and stratigraphy of the Martian PLD at meter-scale resolution. 


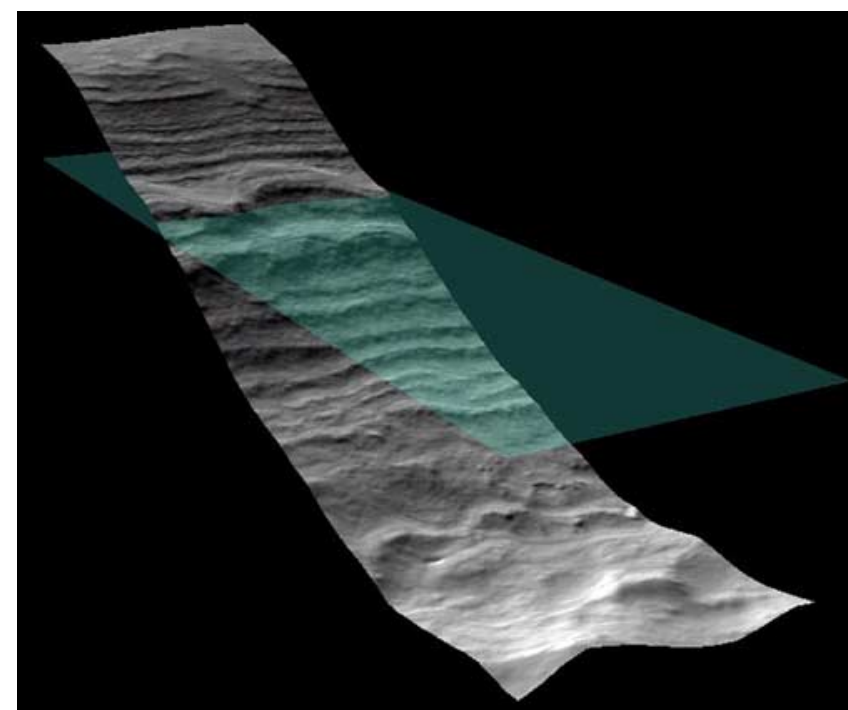

Figure 26. Oblique shaded relief view of digital elevation model of exposure of south polar layered deposits, generated from MOC image M0905983 using two-dimensional photoclinometry. Green plane is horizontal reference; note folding and truncation of layers, suggesting flow and faulting.

Such observations can be used to determine whether the PLD contain fine laminae at the limit of HiRISE resolution, which would indicate that even thinner layers may be present. Alternatively, HiRISE images of massive layering would suggest that the stratigraphy of the PLD is adequately resolved. In either case, HiRISE observations of the PLD during the winter and spring seasons, when the surface is covered by seasonal $\mathrm{CO}_{2}$ frost, may be used to derive topography with submeter resolution using two-dimensional photoclinometric techniques (Figure 26). When the resulting high-resolution topography is combined with HiRISE images of the same exposures of PLD taken during the summer, albedo and color variations between layers can be quantified at finer spatial scales than previously possible. By repeating these types of observations and analysis in various locations, regional stratigraphic correlations can be made. Thus the stratigraphy of the PLD can be measured with submeter precision and compared to theoretical models of PLD deposition and evolution. These types of studies will help to assess the importance of global climate changes in the geologic history of the PLD.

\subsection{Seasonal Processes}

[135] The polar caps of Mars are a reservoir for Mars' volatiles $\mathrm{CO}_{2}$ and $\mathrm{H}_{2} \mathrm{O}$. In 1966 Leighton and Murray published their theory that Mars' $\mathrm{CO}_{2}$ atmosphere is in vapor pressure equilibrium with its polar caps. Atmospheric pressure changes by $\sim 25 \%$ seasonally as frost condenses at the poles in the fall and sublimes in the spring. This global picture serves well as a high-level description of the state of Mars' volatiles, however in detail there are numerous questions to address regarding the condensation and sublimation processes.

[136] A number of exotic features have been observed in the seasonal polar caps that HiRISE is well suited to study.
Although MOC coverage of the polar regions is substantial, HiRISE offers higher resolution and greater sensitivity. Improvements in sensitivity enable more detailed study of the inherently low light level regions at high latitudes. The MRO capability to frequently turn off nadir enables repeat coverage of specific sites to monitor change as well as stereo.

[137] The process of spring sublimation is particularly interesting on a local level. The seasonal $\mathrm{CO}_{2}$ frost exhibits a wide variety of enigmatic phenomena. One intriguing feature found in groups in some areas of the cryptic region in the southern hemisphere has been termed "spiders." These features are hypothesized to form from geysers, which may develop as $\mathrm{CO}_{2}$ gas is trapped under pressure below seasonal ice, then released through cracks in the ice [Piqueux et al., 2003]. Geysers have not actually been observed on Mars, however analogies have been drawn to the geysers observed on Neptune's moon Triton by Voyager [Smith and the Voyager Imaging Team, 1989]. The brief observation period available to image Triton left more questions than answers on the actual eruption process. HiRISE observations may catch a geyser in the process of eruption, confirming their existence and increasing our understanding of geyser mechanics on both Mars and Triton.

[138] Other HiRISE images of the subliming seasonal cap may shed light on the evolution of the $\mathrm{CO}_{2}$ seasonal frost coverage. Does $\mathrm{CO}_{2}$ start as a bright frost from winter snows, then change to slabs of clear ice? Is this the reason for the cryptic terrain [e.g., Titus et al., 2001; Kieffer et al., 2000]? How do cracks in the ice affect the albedo? Figure 27 shows one example of a MOC image of a strange area on the southern seasonal cap in the process of defrosting in the spring.

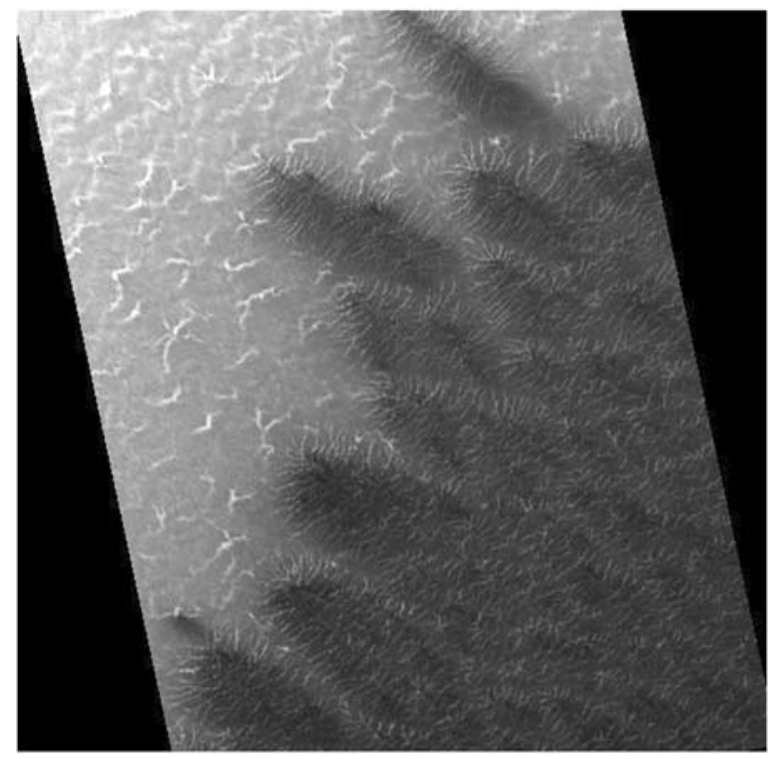

Figure 27. This cropped version of MOC image M0305635 shows one of the more enigmatic areas of the southern seasonal cap in southern spring. Regions like this will be imaged repeatedly by HiRISE to study the sublimation process and its interaction with underlying terrain. 
[139] Polar terrain in the process of defrosting exhibits multiple dark spots that gradually grow. Apparently the positive feedback as the dark spot warms and grows enhances sublimation of frost in that spot. The loss of ice frees the loose dust originally entrained and deposited as the frost condensed, allowing it to be lofted by local winds and create a wind streak. The fields of streaks can be used as a snapshot of local wind conditions and compared to the Mars GCM for polar meteorology studies. The streaks imply a certain ease of lofting materials, which gives us insight into the dust available to form layers.

\subsection{Nonaeolian Surface Changes and Potential Climate Change}

[140] We will be keenly interested in dynamic processes and changing features on the Martian surface and implications for current processes. Aeolian and seasonal changes are well documented, but many nonaeolian changes have also been detected by MOC. The higher spatial resolution of MOC has enabled detection of new types of variable features, and we expect that trend to continue with HiRISE.

[141] MOC images of the south residual polar cap "Swiss cheese" terrain, composed of roughly circular pits, ridges and mounds, are suggestive of recent climate change. The escarpments in this unit have been observed by MOC to retreat 1-4 m over one Mars year [Malin et al., 2001], with older materials eroding more quickly than younger units [Thomas et al., 2005]. HiRISE images will extend the temporal coverage of these units and address whether the erosion is consistent with a longer-term trend in climate change (if they continue to retreat) or represents year-toyear variability. HiRISE stereo will enable accurate measurement of the mass flux.

[142] There has been recent interest in evidence for late Amazonian climate change on Mars, as evidenced by a midlatitude debris mantle that appears to be sublimating [Mustard et al., 2001] and possible young glacial activity [Hauber et al., 2005; Head et al., 2003b]. The mantle has been suggested to be less than 100,000 years old based on the lack of small impact craters [Mustard et al., 2001; Head et al., 2003b], but McEwen et al. [2005] suggested that $10 \mathrm{Ma}$ is a more realistic upper limit given the large uncertainties in the small-crater production function on Mars. Direct observation of changes in various features is probably our best hope for quantitative constraints on rates of change in very recent features and extrapolation to estimate absolute ages. Nevertheless, the features are geologically young and well preserved at the meter scale, so HiRISE images are sure to be interesting. High-resolution DEMs should enable detailed modeling of ice stability with topography [Russell et al., 2005].

[143] Dark slope streaks have been observed to be currently forming on Mars [Malin and Edgett, 2001; Sullivan et al., 2001]. These streaks form exclusively in regions of low thermal inertia and steep slopes, consistent with dust avalanches [Sullivan et al., 2001]. They also form only where peak temperatures exceed $275 \mathrm{~K}$, so phase transition of small amounts of water may trigger the mass movements [Schorghofer et al., 2002]. In spite of the strong correlation with recent dust deposits, some workers have proposed that a few of the streaks could be due to currently active fluvial processes [Ferris et al., 2002; Miyamoto et al., 2004].
HiRISE will take a closer look at some of these features and may improve our understanding of the processes. Other forms of active mass wasting have been observed by MOC, including new rock slides and boulder tracks (see image releases at http://www.msss.com).

[144] Van Gasselt et al. [2005] have documented evidence for changing and evolving patterned ground in a South Polar trough over three years, which they interpret as due to thermal contraction. These results suggest that major climate change may not be needed to explain the presence of patterned ground on Mars.

\section{Imaging of Past, Present, and Future Landing Sites}

[145] An important function of HiRISE will be to image all past landing (or attempted landing) sites and candidate future landing sites. We will be very interested in imaging successful past landing sites (Viking 1 and 2, Pathfinder, MER Spirit and Opportunity) because observations from the landers and rovers provide "ground truth" for interpretation of HiRISE images. Our images may also help to address continuing scientific debates by providing a larger-scale perspective at the resolution needed to see key features. One example is whether the rocks at the Pathfinder landing site were emplaced directly from ancient catastrophic floods or as more recent impact ejecta, which in turn is key to questions such as estimation of long term average erosion rates [Golombek and Bridges, 2000]. For the currently active Mars Exploration Rovers (MER), HiRISE may influence decisions about where to drive the rovers. Even if the missions of Spirit and Opportunity end before HiRISE can image Mars, they will have returned the most detailed and extensive "ground truth" for HiRISE interpretations.

[146] Imaging past attempted landing sites is also important for making engineering evaluations of how and why failures occurred. If we can locate the spacecraft hardware in HiRISE images and answer key questions such as whether or not the parachute was released or whether there may have been previously undetected hazards it could contribute to enabling future successful landings. High on the list of attempted landing sites will be the 1999 Mars Polar Lander (MPL) from NASA and the 2003 Beagle 2 led by the United Kingdom [Bridges et al., 2003]. Attempts to locate MPL and Beagle 2 with MOC are described at http:// www.msss.com. The MPL landing error ellipse is of order $500 \mathrm{~km} 2$, which could be completely covered in about 10 large HiRISE images. Although we can probably resolve the landers or parachutes or unopened airbags, it is not certain that we can distinguish these man-made objects from natural objects on Mars' surface. MOC images of the Pathfinder and Viking 1 landers look like bumps that are indistinguishable from natural features, but the bumps can be determined to be the landers by triangulation on surrounding features imaged both by MOC and by the landers. By contrast, triangulation cannot be used to help identify the failed landers since no images from the surface were returned. We might be able to detect unusual colors if the man-made objects are not yet dust-covered. Other failed landers of potential interest are the 1971 Mars 2 and Mars 3 and 1974 Mars 6 landers from the former Soviet Union [Snyder and Moroz, 1992]. Only Mars 3 actually landed 
successfully; the other two are probably crash sites. These were large landers, but we have very poor information about where to look for them on Mars.

[147] The future landing site of most immediate concern to MRO and HiRISE will be that for the 2007 Phoenix mission [Smith and the Phoenix Science Team, 2004]. The Phoenix team presently has one large candidate region [Arvidson et al., 2006], and the HiRISE strategy will be to sample the range of morphologic units identified in these regions from previous imaging, to aid the final choice. In particular there is interest in identifying meter-scale hazards such as boulders and in characterizing periglacial landforms to aid in assessment of potential sites for meeting the Phoenix mission science objectives. Once the final landing site has been selected, we will image as much of the highprobability error ellipse as possible, so that before-and-after comparisons may be used to search for the lander, if necessary. Stereo coverage will include samples of different terrains and the final landing site. We will also monitor the landing site over time to evaluate changes such as frost deposition and sublimation.

[148] The MRO project expects to make a major contribution to the landing site decision for the 2009 Mars Science Laboratory (MSL). MSL will have the potential to land over a large fraction of the Martian surface and to pursue a wide range of science investigations, so a large fraction of HiRISE images may be relevant to MSL studies. We expect HiRISE will play a key role in a lengthy and comprehensive community and MSL process geared toward identification and evaluation of the best candidate landing sites, similar to the process followed for MER [Golombek et al., 2003a]. HiRISE images and DEMs will also be key in evaluation of MSL mission engineering constraints.

[149] Finally, Mars exploration plans by NASA and ESA beyond 2009 are still in flux, but may include sample return or other landed missions. If so, we expect HiRISE color imaging to be of particular value, so that interesting compositional units identified by CRISM can be precisely located for identification of specific outcrops of interest.

\section{Education and Public Outreach (E/PO)}

[150] The HiRISE team is planning an innovative education and public outreach program with a variety of formal and informal educational activities and materials [Gulick et $a l ., 2003]$. These include educator workshops, large-scale displays of HiRISE images at museums and planetariums, and opportunities for students and the general public to suggest HiRISE image observations and to participate in data analysis via HiRISE's intuitive Web site called HiWeb (http://marsoweb.nas.nasa.gov/hirise). Additionally, HiRISE team members have committed to spending at least $5 \%$ of their time in outreach activities and to coordinating local E/PO activities in their regions.

\subsection{Education Material and Partnerships}

[151] HiRISE will provide curriculum materials and activities to educators via publications, workshops, and the Internet that will draw upon existing classroom-tested, standards-based, Mars and space science lesson plans. Modified or new lesson plans created after the start of the PSP will be able to draw upon a wealth of new data, including high-resolution color images of the surface of Mars. New data and images will allow us to bring the excitement of an active spacecraft mission and its discoveries into classrooms and informal settings. Technologybased activities will be published through JPL's Space Place alliance with the International Technology Education Association's (ITEA's) Technology Teacher magazine. Several activities will be developed during the mission. NASA Quest will support HiRISE sponsored Web events. Educator workshops using HiRISE and Mars Educational Program products will be held each year at or near the institution of a HiRISE team member. Workshop background materials and instructions for all hands-on activities will also be placed on the HiWeb E/PO site. This will facilitate the sharing of information with the general public and other educators who are unable to attend a workshop. We will also provide materials and speakers to a number of existing educator workshop programs including MarsQuest, and the JPL Solar System Educators and Ambassadors Programs.

\subsection{Public Target Suggestions}

[152] The HiRISE team plans to cast a wide net to collect suggestions for the $\sim 10,000$ high-resolution images expected from the PSP. Images will be selected from suggestions submitted by the science team, the Mars Exploration Program Office, the Mars science community, students, and the general public. Approximately one image per week will be targeted based on suggestions from students. The Web-based interface for image suggestion input (HiWeb) is based upon Marsoweb, the Mars Landing Site Selection Studies Web environment (http://marsoweb.nas. nasa.gov/landingsites) [Deardorff and Gulick, 2003; Gulick and Deardorff, 2003]. In addition to browsing HiRISE and various other Mars data sets, users are able to input suggestions, specify special constraints (e.g., season, resolution), and upload short science justifications. HiWeb will also serve as a Web facility for displaying and distributing HiRISE images.

[153] Input from students will be motivated and filtered in part by NASA Quest, the Web-based K-12 education portal based at NASA Ames Research Center (http://quest.arc. nasa.gov). To inform students and educators, in particular, about the capabilities of HiRISE, Mars science and the plethora of potential targets, Quest will host Web events, on-line chats and Webcasts that will link science team members with students at numerous schools, and will provide access to other on-line E/PO material. To select image suggestions from students, Quest will advertise and conduct on-line polls, where needed to help prioritize and filter student suggestions. Student image suggestions will be selected through the polling, chats, and Webcasts hosted by Quest. We expect student suggestions to produce an interesting and diverse set of targets that will then enter the usual image selection stream at a prioritized level. Once obtained, the resulting student-motivated images will be highlighted on HiWeb at a rate of at least one image per week

\subsection{Public Science Analysis}

[154] The public will also have the opportunity to participate in HiRISE data analysis. This effort will be based on the "Clickworkers" project that explored the production of 
science data products from images by harnessing public interest in planetary missions. The proof-of-concept effort involved having the public look at images of Mars and identify the locations and diameters of impact craters in each image. Over 85,000 individuals visited the site (http:// clickworkers.arc.nasa.gov) and submitted over 1.9 million crater location/diameter entries and a quarter million crater classification entries [Kanefsky et al., 2001]. Results from the prototype Clickworkers study show that the accuracy of volunteer inputs, when appropriately tested and filtered, is comparable to that of existing crater databases.

[155] The Clickworker's project will work with the HiRISE team to develop similar analysis modules to harness the enthusiasm of the public while educating them about Mars, mission goals, accomplishments, and resulting science. For example volunteers could quickly establish a database of features (e.g., craters, boulders, gullies, polygons, wind streaks) imaged by HiRISE. Clickworkers also demonstrated that there is strong interest generated by direct public participation in science. By empowering the public with user-friendly Web tools, timely access to data and unique opportunities to participate not only in the discovery process, but also in the actual science as well, we hope to make the dream of exploring Mars a virtually real experience for all.

\section{Summary Comment}

[156] MRO and HiRISE stand poised to contribute our next major advance in understanding Mars. However, this will be a quiet revolution because the data volumes will be very large and take considerable time to analyze. Understanding the significance of new results will take even longer. HiRISE will reveal many strange landscapes that defy initial understanding, but should eventually be understood via study of Earth analogs, physical models, co-analysis with other Martian data sets, and continued surface exploration.

[157] Acknowledgments. We thank the entire HiRISE crew at Ball Aerospace, under the management of Paul Volmer and Charlie Van Houten, especially Dennis Gallagher (optics), Tom Ebben (FPS), Ed Bortolini (Xilincs FPGA code), Jeff Lasco (thermal), Steve Tarr (flight software), and Dino Rossetti (integration and testing). Many thanks also to the MRO crew at JPL, especially Jim Graf, Rich Zurek, Bill Mateer, Fred Vescelus, and Carl Kloss, and to the crew working with Lockheed-Martin on the MRO spacecraft, especially Steve Bailey. Special thanks are due to Hugh Kieffer and Gentry Lee for their support of HiRISE at the many project reviews, and to Peter Smith for his contributions before the Phoenix Mission. Jim Bell (Cornell Univ.) and Ray Arvidson (Washington Univ.) provided important reviews of this manuscript. Finally, we thank the HiROC staff at the University of Arizona, especially Linda Hickcox and Joe Plassmann, as well as LPL Director Mike Drake and College of Science Dean Joaquin Ruiz for their support.

\section{References}

Allen, C. C. (1979), Volcano-ice interactions on Mars, J. Geophys. Res., 84, $8048-8059$

Arvidson, R. E., F. Poulet, J.-P. Bibring, M. Wolff, A. Gendrin, R. V. Morris, J. J. Freeman, Y. Langevin, N. Mangold, and G. Bellucci (2005), Spectral reflectance and morphologic correlations in eastern Terra Meridiani, Mars, Science, 307, 1576-1581.

Arvidson, R. E., et al. (2006), Overview of Mars Exploration Program 2007 Phoenix mission landing site selection, Lunar Planet. Sci., XXXVII, Abstract 1328.

Baker, V. R., R. G. Strom, V. C. Gulick, J. S. Kargel, and G. Komatsu (1991), Ancient oceans, ice sheets and the hydrological cycle on Mars, Nature, 352, 584-589.
Baker, V. R., M. H. Carr, V. C. Gulick, C. R. Williams, and M. S. Marley (1992), Channels and valley networks, in Mars, edited by H. H. Kieffer et al., pp. 493-522, Univ. of Ariz. Press, Tucson.

Baker, V. R., G. Benito, and A. N. Rudoy (1993), Paleohydrology of late Pleistocene superflooding, Altay Mountains, Siberia, Science, 259, $348-$ 350.

Barlow, N. G. (2004), Martian subsurface volatile concentrations as a function of time: Clues from layered ejecta craters, Geophys. Res. Lett., 31, L05703, doi:10.1029/2003GL019075.

Barlow, N. G. (2005), A review of Martian impact crater ejecta structures and their implications for target properties, in Large Meteorite Impacts III, edited by T. Kenkmann et al., Spec. Pap. Geol. Soc. Am., 384, 433442 .

Bart, G. D., and H. J. Melosh (2005), Ejected boulders: Implications for secondary craters and the age dating of surfaces, Lunar Planet. Sci., XXXVI, Abstract 2022.

Bergstrom, J. W., W. A. Delamere, and A. S. McEwen (2004), MRO High Resolution Imaging Science Experiment (HiRISE): Instrument test, calibration, and operating constraints, paper presented at 55th International Astronautic Federation Congress, Int. Astron. Congr., Vancouver, B.C., Canada.

Beyer, R. A., and A. S. McEwen (2005), Layering stratigraphy of eastern Coprates and northern Capri Chasmata, Mars, Icarus, 179, 1-23.

Bhattacharya, J. P., T. H. D. Payenberg, S. C. Lang, and M. Bourke (2005), Dynamic river channels suggest a long-lived Noachian crater lake on Mars, Geophys. Res. Lett., 32, L10201, doi:10.1029/2005GL022747.

Bibring, J. P., et al. (2005), Mars surface diversity as revealed by the OMEGA/Mars Express observations, Science, 307, 1591-1595.

Bills, B. G. (1990), The rigid body obliquity history of Mars, J. Geophys. Res., 95, 14,137-14,153.

Blasius, K. R., J. A. Cutts, and A. D. Howard (1982), Topography and stratigraphy of Martian polar layered deposits, Icarus, 50, 140-160.

Boynton, W. V., et al. (2002), Distribution of hydrogen in the near surface of Mars: Evidence for subsurface ice deposits, Science, 297, 81-85.

Boynton, W. V., M. Chamberlain, W. C. Feldman, T. Prettyman, D. Hamara, D. Janes, K. Kerry, and the GRS Team (2003), Abundance and distribution of ice in the polar regions of Mars: More evidence for wet periods in the recent past, in Sixth International Conference on Mars [CD-ROM], Abstract 3259, Lunar and Planet. Inst., Houston, Tex.

Brakenridge, G. R., H. E. Newsom, and V. R. Baker (1985), Ancient hot springs on Mars: Origins and paleoenvironmental significance of small Martian valleys, Geology, 13, 859-862.

Bridges, J. C., et al. (2003), Selection of the landing site in Isidis Planitia of Mars probe Beagle 2, J. Geophys. Res., 108(E1), 5001, doi:10.1029/ 2001JE001820.

Bridges, N. T., and K. E. Herkenhoff (2002), Topography and geologic characteristics of eolian grooves in the south polar layered deposits, Icarus, 156, 387-398.

Briggs, G. A., W. A. Baum, and J. Barnes (1979), Viking Orbiter imaging observations of dust in the Martian atmosphere, J. Geophys. Res., 84, $2795-2820$.

Burr, D. M., J. A. Grier, A. S. McEwen, and L. P. Keszthelyi (2002), Repeated aqueous flooding from the Cerberus Fosssae: Evidence for very recently extant, deep groundwater on Mars, Icarus, 159, 53-73.

Burr, D. M., P. A. Carling, R. A. Beyer, and N. Lancaster (2004), Floodformed dunes in Athabasca Valles, Mars: Morphology, modeling, and implications, Icarus, 171, 68-83.

Burr, D. M., R. J. Soare, J.-M. Wan Bun Tseung, and J. P. Emery (2005), Young (late Amazonian) near-surface, ground ice features near the equator, Athabasca Valles, Mars, Icarus, 178, 56-73.

Carr, M. H. (1973), Volcanism on Mars, J, Geophys. Res., 78, 4049-4062.

Carr, M. H. (1979), Formation of Martian flood features by release of water from confined aquifers, J. Geophys. Res., 84, 2995-3007.

Carr, M. H. (1982), Periodic climate change on Mars: Review of evidence and effects on distribution of volatiles, Icarus, 50, 129-139.

Carr, M. H. (1986), Mars: A water-rich planet?, Icarus, 68, 187-216.

Carr, M. H. (1996), Water on Mars, 229 pp., Oxford Univ. Press, New York.

Carr, M. H., and J. W. Head III (2003), Oceans on Mars: An assessment of the observational evidence and possible fate, J. Geophys. Res., 108(E5), 5042, doi:10.1029/2002JE001963.

Carr, M. H., and M. C. Malin (2000), Meter-scale characteristics of Martian channels and valleys, Icarus, 146, 366-386.

Carr, M. H., L. S. Crumpler, J. A. Cutts, R. Greeley, J. E. Guest, and H. Masursky (1977a), Martian impact craters and emplacement of ejecta by surface flow, J. Geophys. Res., 82, 4055-4065.

Carr, M. H., R. Greeley, K. R. Blasius, J. E. Guest, and J. B. Murray (1977b), Some Martian volcanic features as viewed from the Viking orbiters, J. Geophys. Res., 82, 3985-4015. 
Chapman, M. G. (2003), Sub-ice volcanoes and ancient oceans/lakes: A Martian challenge, Global Planet. Change, 35, 185-198.

Chapman, M. G., and K. L. Tanaka (2001), Interior trough deposits on Mars: Subice volcanoes?, J. Geophys. Res., 106, 10,087-10,100.

Chappelow, J. E., and V. L. Sharpton (2005), Influences of atmospheric variations on Mars' record of small craters, Icarus, 178, 40-55.

Christensen, P. R. (2003), Formation of recent Martian gullies through melting of extensive water-rich snow deposits, Nature, 422, 45-48.

Christensen, P. R., and H. J. Moore (1992), The Martian surface layer, Mars, edited by H. H. Kieffer et al., pp. 686-729, Univ. of Ariz. Press, Tucson.

Christensen, P. R., et al. (2001), Mars Global Surveyor Thermal Emission Spectrometer experiment: Investigation description and surface science results, J. Geophys. Res., 106, 23,823-23,871.

Christensen, P. R., et al. (2004), The Thermal Emission Imaging System (THEMIS) for the Mars 2001 Odyssey Mission, Space Sci. Rev., 110, $85-130$.

Christensen, P. R., et al. (2005), Evidence for magmatic evolution and diversity on Mars from infrared observations, Nature, 436, 504-509.

Clark, R. N., G. A. Swayze, R. Wise, K. E. Livo, T. M. Hoefen, R. F. Kokaly, and S. J. Sutley (2003), USGS Digital Spectral Library splib05a, U.S. Geol. Surv. Open File Rep., 03-395.

Clow, G. D. (1987), Generation of liquid water on Mars through melting of a dusty snowpack, Icarus, 72, 95-127.

Coffin, M. F., et al. (2000), Proceedings of the Ocean Drilling Program, Initial Reports, vol. 183, Kerguelen Plateau-Broken Ridge, Sites $1135-$ 1142, 7 December 1998-11 February 1999, 101 pp. + CD-ROM, Ocean Drill. Program, College Station, Tex.

Costard, F. M. (1989), The spatial distribution of volatiles in the Martian hydro-lithosphere, Earth Moon Planets, 45, 265-290.

Craddock, R. A., and R. Greeley (1995), Estimates of the amount and timing of gases released into the Martian atmosphere from volcanic eruptions, Lunar Planet. Sci., XXVI, 287.

Craddock, R. A., and A. D. Howard (2002), The case for rainfall on a warm, wet early Mars, J. Geophys. Res., 107(E11), 5111, doi:10.1029/ 2001JE001505.

Crown, D. A., and R. Greeley (1993), Volcanic geology of Hadriaca Patera and the eastern Hellas region of Mars, J. Geophys. Res., 98, 3431-3451.

Cutts, J. A. (1973), Nature and origin of layered deposits of the Martian polar regions, J. Geophys. Res., 78, 4231-4249.

Cutts, J. A., K. R. Blasius, G. A. Briggs, M. H. Carr, R. Greeley, and H. Masursky (1976), North polar region of Mars: Imaging results from Viking 2, Science, 194, 1329-1337.

Cutts, J. A., K. R. Blasius, and W. J. Roberts (1979), Evolution of Martian polar landscapes: Interplay of long-term variations in perennial ice cover and dust storm intensity, J. Geophys. Res., 84, 2975-2994.

Deardorff, G., and V. Gulick (2003), Marsoweb: A collaborative web facility for Mars landing site and global data studies, in Visual and Data Exploration 2003, edited by R. F. Erbacher et al., Proc. SPIE Int. Soc. Opt. Eng., $5009,248-259$

Delamere, A. W., I. Becker, J. Begstrom, J. Burkepile, J. Day, D. Dorn, D. Gallagher, C. Hamp, J. Lasco, B. Beies, A. Sievers, S. Streetman, S. Tarr, M. Tommeraasen, and Pl. Volmer (2003), MRO High Resolution Imaging Science Experiment (HiRISE): Instrument development, in Sixth International Conference on Mars [CD-ROM], Abstract 3260, Lunar and Planet. Inst., Houston, Tex.

Dorn, D. A., W. Meiers, J. Burkepile, E. D. Freymiller, A. W. Delamere, A. S. McEwen, P. Maggs, P. J. Pool, and I. Wallace (2004), HiRISE focal plane for use on the Mars Reconnaissance Orbiter, in Focal Plane Arrays for Space Telescopes, edited by T. J. Grycewicz and C. R. McCreight, Proc. SPIE Int. Soc. Opt. Eng., 5167, 63-71.

Easterbrook, D. J., (Ed.) (1993), Surface Processes and Landforms, Macmillan, New York.

Edgett, K. S., and M. C. Malin (2000), New views of Mars eolian activity, materials, and surface properties: Three vignettes from the Mars Global Surveyor Mars Orbiter Camera, J. Geophys. Res., 105, 1623-1650.

Edgett, K. S., B. J. Butler, J. R. Zimbelman, and V. E. Hamilton (1997), Geologic context of the Mars radar "Stealth" region in southwestern Tharsis, J. Geophys. Res., 102, 21,545-21,568.

Eliason, E. M., et al. (2003), Operation of MRO's High Resolution Imaging Science Experiment (HiRISE): Maximizing science participation, in Sixth International Conference on Mars [CD-ROM], Abstract 3212, Lunar and Planet. Inst., Houston, Tex.

Fagents, S. A., and L. Wilson (1996), Numerical modeling of ejecta dispersal from transient volcanic explosions on Mars, Icarus, 123, 284-295.

Fanale, F. P., J. R. Salvail, A. P. Zent, and S. E. Postawko (1986), Global distribution and migration of subsurface ice on Mars, Icarus, 67, 1-18.

Feldman, W. C., et al. (2002), Global distribution of neutrons from Mars: Results from Mars Odyssey, Science, 297, 75-78.
Ferris, J. C., J. M. Dohm, V. R. Baker, and T. Maddock III (2002), Dark slope streaks on Mars: Are aqueous processes involved?, Geophys. Res. Lett., 29(10), 1490, doi:10.1029/2002GL014936.

Gaidos, E., and G. Marion (2003), Geological and geochemical legacy of a cold early Mars, J. Geophys. Res., 108(E6), 5055, doi:10.1029/ 2002JE002000

Gallagher, D., J. Bergstrom, J. Day, B. Martin, T. Reed, P. Spuhler, S. Streetman, and M. Tommeraasen (2005), Overview of the optical design and performance of the High Resolution Imaging Science Experiment (HiRISE), Proc. SPIE Int. Soc. Opt. Eng., 5874, 198-207.

Geissler, P. E. (2005), Three decades of Martian surface changes, J. Geophys. Res., 110, E02001, doi:10.1029/2004JE002345.

Gendrin, A., et al. (2005), Sulfates in Martian layered terrains: The OMEGA/Mars Express view, Science, 307, 1587-1591.

Golombek, M. P., and N. T. Bridges (2000), Erosion rates on Mars and implications for climate change: Constraints from the Pathfinder landing site, J. Geophys. Res., 105, 1841-1853.

Golombek, M., et al. (1999), Constraints, approach, and status of Mars Surveyor '01 landing site selection, in Fifth International Conference on Mars, Abstract 6068, Lunar and Planet. Inst., Houston, Tex.

Golombek, M. P., et al. (2003a), Selection of the Mars Exploration Rover landing sites, J. Geophys. Res., 108(E12), 8072, doi:10.1029/ 2003JE002074.

Golombek, M. P., A. F. C. Haldemann, N. K. Forsberg-Taylor, E. N. DiMaggio, R. D. Schroeder, B. M. Jakosky, M. T. Mellon, and J. R. Matijevic (2003b), Rock size-frequency distributions on Mars and implications for Mars Exploration Rover landing safety and operations, J. Geophys. Res., 108(E12), 8086, doi:10.1029/2002JE002035. Grant, J. A. (1999), Evaluating the evolution of process specific degradation signatures around impact craters, Int. J. Impact Eng., 23, 331-340.

Grant, J. A., et al. (2006), Crater gradation in Gusev crater and Meridiani Planum, Mars, J. Geophys. Res., 111, E02S08, doi:10.1029/2005JE002465. Greeley, R., and S. A. Fagents (2001), Icelandic pseudocraters as analogs to some volcanic cones on Mars, J. Geophys. Res., 106, 20,527-20,546.

Greeley, R., and J. E. Guest (1987), Atlas of Mars: Eastern region, U.S. Geol. Surv. Misc. Invest. Ser., Map I-1802-B.

Greeley, R., and J. D. Iversen (1985), Wind as a Geological Process on Earth, Mars, Venus, and Titan, 333 pp., Cambridge Univ. Press, New York.

Greeley, R., and B. D. Schneid (1991), Magma generation on Mars: Amounts, rates, and comparisons with Earth, Moon, and Venus, Science, 254, 996-998.

Greeley, R., and P. D. Spudis (1981), Volcanism on Mars, Rev. Geophys., $19,13-41$.

Greeley, R., N. Lancaster, S. Lee, and P. Thomas (1992), Martian eolian processes, sediment, and features, Mars, edited by H. H. Kieffer et al., pp. 730-766, Univ. of Ariz. Press, Tucson.

Greeley, R., D. J. McCleese, and J. Garvin (2001), The Mars Exploration Program: Scientific goals, objectives, investigations, and priorities, Eos Trans. $A G U, 82(47)$, Fall Meet. Suppl., Abstract P41A-01.

Gregg, T. K. P., and S. N. Williams (1996), Explosive mafic volcanoes on Mars and Earth: Deep magma sources and rapid rise rate, Icarus, 122 , $397-405$.

Grotzinger, J. P., et al. (2005), Stratigraphy and sedimentology of a dry to wet eolian depositional esystem, Burns Formation, Meridiani Planum, Mars, Earth Planet. Sci. Lett., 240, 11-72.

Gulick, V. C. (1993), Magmatic intrusions and hydrothermal systems: Implictions for the formation of Martian fluvial valleys, $\mathrm{Ph} . \mathrm{D}$. thesis, Univ. of Ariz., Tucson.

Gulick, V. C. (1997), Episodic ocean-induced $\mathrm{CO}_{2}$ greenhouse on Mars: Implicatons for fluvial valley formation, Icarus, 130, 68-86.

Gulick, V. C. (1998), Magmatic intrusions and a hydrothermal origin for fluvial valleys on Mars, J. Geophys. Res., 103, 19,365-19,387.

Gulick, V. C. (2001a), Origin of the valley networks on Mars: A hydrological perspective, Geomorphology, 37, 241-268.

Gulick, V. C. (2001b), Some ground water considerations regarding the formation of small Martian gullies, Lunar Planet. Sci., XXXII, Abstract 2193

Gulick, V. C., and V. R. Baker (1989), Fluvial valleys and Martian paleoclimates, Nature, 341, 514-516.

Gulick, V. C., and V. R. Baker (1990), Origin and evolution of valleys on Martian volcanoes, J. Geophys. Res., 95, 14,325-14,344.

Gulick, V. C., and D. G. Deardorff (2003), Mars data visualization and E/PO with Marsoweb, Lunar Planet. Sci., XXXIV, Abstract 2081.

Gulick, V. C., et al. (2003), MRO's High Resolution Imaging Science Experiment (HiRISE): Education and public outreach plans, in Sixth International Mars Conference, Abstract 3260, Lunar and Planet. Inst., Houston, Tex.

Hartmann, W. K., and G. Neukum (2001), Cratering chronology and the evolution of Mars, Space Sci. Rev., 96, 94-165. 
Hauber, E., et al. (2005), Discovery of a flank caldera and very young glacial activity at Hecates Tholus, Mars, Nature, 434, 356-361.

Head, J. W., L. Wilson, and K. L. Mitchell (2003a), Generation of recent massive water floods at Cerberus Fossae, Mars by dike emplacement, cryospheric cracking, and confined aquifer groundwater release, Geophys. Res. Lett., 30(11), 1577, doi:10.1029/2003GL017135.

Head, J. W., J. F. Mustard, M. A. Kreslavsky, R. E. Millikan, and D. R. Marchant (2003b), Recent ice ages on Mars, Nature, 426, 797-802.

Heldmann, J. L., and M. T. Mellon (2004), Observations of Martian gullies and constraints on potential formation mechanisms, Icarus, 168, 285 304.

Herkenhoff, K. E., and B. C. Murray (1990), High resolution-topography and albedo of the south polar layered deposits on Mars, J. Geophys. Res., 95, 14,511-14,529.

Herkenhoff, K. E., and J. J. Plaut (2000), Surface ages and resurfacing rates of the polar layered deposits on Mars, Icarus, 144, 243-253.

Herkenhoff, K. E., et al. (2006), Overview of the Microscopic Imager Investigation during Spirit's first 450 sols in Gusev crater, J. Geophys. Res., 111, E02S04, doi:10.1029/2005JE002574.

Hodges, C. A., and H. J. Moore (1978), Table Mountains of Mars (abstract), Lunar Planet. Sci., IX, 523-525.

Hon, K., J. Kauahikaua, R. Denlinger, and K. Mackay (1994), Emplacement and inflation of pahoehoe sheet flows: Observations and measurements of active lava flows on Kilauea Volcano, Hawaii, Geol. Soc. Am. Bull., 106, 351-370.

Hort, M., and C. M. Weitz (2001), Theoretical modeling of eruption plumes on Mars under current and past climates, J. Geophys. Res., 106, 20,54720,562 .

Howard, A. D. (1994), A detachment-limited model of drainage basin evolution, Water Resour. Res., 30, 2261-2285.

Howard, A. D. (2000), The role of eolian processes in forming surface features of the Martian polar layered deposits, Icarus, 144, 267-288.

Howard, A. D., K. R. Blasius, and J. A. Cutts (1982a), Photoclinometric determination of the topography of the Martian north polar cap, Icarus, $50,245-258$

Howard, A. D., J. A. Cutts, and K. R. Blasius (1982b), Stratigraphic relationships within Martian polar cap deposits, Icarus, 50, 161-215.

Howard, A. D., J. M. Moore, and R. P. Irwin III (2005), An intense terminal epoch of widespread fluvial activity on early Mars: 1. Valley network incision and associated deposits, J. Geophys. Res., 110, E12S14 doi:10.1029/2005JE002459.

Howard, P. G., and J. S. Vitter (1993), Fast and efficient lossless image compression, in Proceedings of the IEEE Data Compression Conference, edited by J. Storer and M. Cohn, pp. 351-360, IEEE Comput. Soc. Press, New York.

Hynek, B. M. (2004), Implications for hydrologic processes on Mars from extensive bedrock outcrops throughout Terra Meridiani, Nature, 431, $156-159$.

Hynek, B. M., R. J. Phillips, and R. E. Arvidson (2003), Explosive volcanism in the Tharsis region: Global evidence in the Martian geologic record, J. Geophys. Res., 108(E9), 5111, doi:10.1029/2003JE002062.

Irwin, R. P., III, A. D. Howard, and T. A. Maxwell (2004), Geomorphology of Ma'adim Vallis, Mars, and associated paleolake basins, J. Geophys. Res., 109, E12009, doi:10.1029/2004JE002287.

Irwin, R. P., R. A. Craddock, and A. D. Howard (2005a), Interior channels in Martian valley networks: Discharge and runoff production, Geology, 33(6), 489-492.

Irwin, R. P., III, A. D. Howard, R. A. Craddock, and J. M. Moore (2005b), An intense terminal epoch of widespread fluvial activity on early Mars: 2. Increased runoff and paleolake development, J. Geophys. Res., 110, E12S15, doi:10.1029/2005JE002460.

Jakosky, B. M., and M. T. Mellon (2001), Thermal inertia of Mars: Sites of exobiological interest, J. Geophys. Res., 106, 23,887-23,908.

Kanefsky, B., N. Barlow, and V. Gulick (2001), Can distributed volunteers accomplish massive data analysis tasks?, Lunar Planet. Sci., XXXII, Abstract 1272

Kargel, J. S. (2004), Mars: A Warmer and Wetter Planet, 557 pp., Springer, New York.

Kargel, J. S., and R. G. Strom (1992), Ancient glaciation on Mars, Geology, $20,3-7$

Kargel, J. S., V. R. Baker, J. E. Begét, J. F. Lockwood, T. L. Péwé, J. S Shaw, and R. G. Strom (1995), Evidence of ancient continental glaciation in the Martian northern plains, J. Geophys. Res., 100(E3), 5351-5368.

Keszthelyi, L. (2002), Classification of the mafic lava flows from ODP Leg 183 [online], Proc. Ocean Drill. Program Sci. Results, 183, 28 pp. (Available at http://www-odp.tamu.edu/publications/183_SR/012/012.htm)

Keszthelyi, L., and A. S. McEwen (2007), Comparison of flood lavas on Earth and Mars, in The Geology of Mars: Evidence From Earth-Based Analogs, edited by M. Chapman, pp. 126-150, Cambridge Univ. Press, New York.
Keszthelyi, L., A. S. McEwen, and T. Thordarson (2000), Terrestrial analogs and thermal models for Martian flood lavas, J. Geophys. Res., 105 , $15,027-15,050$

Keszthelyi, L., T. Thordarson, A. McEwen, H. Haack, M.-N. Guilbaud, S. Self, and M. J. Rossi (2004), Icelandic analogs to Martian flood lavas, Geochem. Geophys. Geosyst., 5, Q11014, doi:10.1029/2004 GC000758.

Kieffer, H. H., T. N. Titus, K. F. Mullins, and P. R. Christensen (2000), Mars south polar spring and summer behavior observed by TES: Seasonal cap evolution controlled by frost grain size, J. Geophy. Res., 105, 9653-9699

Kirk, R. L., et al. (1999), Digital photogrammetric analysis of the IMP camera images: Mapping the Mars Pathfinder landing site in three dimensions, J. Geophys. Res., 104(E4), 8868-8888.

Kirk, R. L., E. Howington-Kraus, B. Redding, D. Galuszka, T. M. Hare, B. A. Archinal, L. A. Soderblom, and J. M. Barrett (2003), Highresolution topomapping of candidate MER landing sites with Mars Orbiter Camera narrow-angle images, J. Geophys. Res., 108(E12), 8088, doi:10.1029/2003JE002131.

Kirk, R. L., E. Howington-Kraus, L. A. Soderblom, B. Giese, and J. Oberst (2004), Comparison of USGS and DLR topographic models of Comet Borrelly and photometric applications, Icarus, 167, 54-69, doi:10.1016/ j.icarus.2003.07.009.

Kirk, R. L., J. M. Barrett, E. Howington-Kraus, B. A. Archinal, T. M. Hare, G. Neukum, and the HRSC Team (2005), USGS topomapping with Mars Express HRSC and SRC images, paper presented at Second Annual Asia Oceanic Geosciences Society Conference, Singapore, 20-24 June.

Komatsu, G., G. Ori, P. Ciarcaelluti, and Y. D. Litasiv (2004), Interior layered deposits of Valles Marineris, Mars: Analogous subice volcanism related to Baikal rifting, southern Siberia, Planet. Space Science, 52, $167-187$.

Lanagan, P. D., A. S. McEwen, L. P. Keszthelyi, and T. Thordarson (2001), Rootless cones on Mars indicating the presence of shallow equatorial ground ice in recent times, Geophys. Res. Lett., 28, 2365-2367.

Laskar, J., B. Levrard, and J. F. Mustard (2002), Orbital forcing of the Martian polar layered deposits, Nature, 419, 375-377.

Lee, S. W., E. D. Skulsky, J. Chapel, D. Cwynar, R. Gehling, and A. Delamere (2001), Mars Reconnaissance Orbiter design approach for high-resolution surface imaging, paper presented at 26th Annual AAS Guidance and Control Conference, Am. Astron. Soc., Breckenridge, Colo., Feb.

Leighton, R. B., and B. C. Murray (1966), Behavior of carbon dioxide and other volatiles on Mars, Science, 153, 136-144.

Leovy, C. B. (2000), An evolving perspective on the atmosphere and surface of Mars, Bull. Am. Astron. Soc., 32, 1054.

Leverington, D. W. (2004), Volcanic rilles, streamlined islands, and the origin of outflow channels on Mars, J. Geophys. Res., 109, E10011, doi:10.1029/2004JE002311

Lucchitta, B. K., A. S. McEwen, G. D. Clow, P. E. Geissler, R. B. Singer, R. A. Schultz, and S. W. Squyres (1992), The canyon system on Mars, in Mars, edited by H. H. Kieffer et al., pp. 453-492, Univ. of Ariz. Press, Tucson

Lucchitta, B. K., N. K. Isbell, and A. Howington-Kraus (1994), Topography of Valles Marineris: Implications for erosional and structural history, J. Geophys. Res., 99, 3783-3798.

Macdonald, G. A. (1953), Pahoehoe, aa, and block lava, Am. J. Sci., 251, $169-191$.

Malin, M. C., and K. Edgett (2000a), Evidence for recent groundwater seepage and surface runoff on Mars, Science, 288, 2330-2335.

Malin, M. C., and K. S. Edgett (2000b), Sedimentary rocks of early Mars, Science, 290, 1927-1937.

Malin, M. C., and K. S. Edgett (2001), Mars Global Surveyor Mars Orbiter Camera: Interplanetary cruise through primary mission, J. Geophys. Res., $106,23,429-23,570$

Malin, M. C., and K. S. Edgett (2003), Evidence for persistent flow and aqueous sedimentation on early Mars, Science, 302, 1931-1934.

Malin, M. C., and K. E. Edgett (2005), First views of Mars at sub-meter resolutions from orbit, Lunar Planet. Sci., XXXVI, Abstract 1172.

Malin, M. C., G. E. Danielson, A. P. Ingersoll, H. Masursky, J. Veverka, M. A. Ravine, and T. A. Soulanille (1992), The Mars Observer Camera, J. Geophys. Res., 97, 7699-7718.

Malin, M. C., M. A. Caplinger, and S. D. Davis (2001), Observational evidence for an active surface reservoir of solid carbon dioxide on Mars, Science, 294, 2146-2148.

Malin, M. C., et al. (2007), Context Camera Investigation on board the Mars Reconnaissance Orbiter, J. Geophys. Res., doi:10.1029/2006JE002808, in press.

Mangold, N. (2005), High latitude patterned ground on Mars: Classification, distribution, and climatic control, Icarus, 174, 336-359. 
Mangold, N., F. Costard, and F. Forget (2003), Debris flows over sand dunes on Mars: Evidence for liquid water, J. Geophys. Res., 108(E4), 5027, doi:10.1029/2002JE001958.

Mars Channel Working Group (1983), Channels and valleys on Mars, Geol. Soc. Am. Bull., 94, 1035-1054.

Mars Exploration Program Analysis Group (2001), Scientific goals, objectives, investigations, and priorities, in Science Planning for Exploring Mars, JPL Publ. 01-7, pp. 9-38, Jet Propul. Lab., Pasadena, Calif. (Available at http://mepag.jpl.nasa.gov/reports/index.html)

McCauley, J. F. (1978), Geologic map of the Coprates quadrangle of Mars, U.S. Geol. Surv. Misc. Invest. Ser., Map I-897.

McCleese, D. J., J. T. Schofield, F. W. Taylor, S. B. Calcutt, M. C. Foote, D. M. Kass, C. B. Leovy, D. A. Paige, P. L. Read, and R. W. Zurek (2007), Mars Climate Sounder: An investigation of thermal and water vapor structure, dust and condensate distributions in the atmosphere, and energy balance of the polar regions, J. Geophys. Res., doi:10.1029/ 2006JE002790, in press.

McConnochie, T. H., J. F. Bell III, D. Savransky, G. Mehall, M. Caplinger, P. R. Christensen, L. Cherednik, K. Bender, and A. Dombovari (2006), Calibration and in-flight performance of the Mars Odyssey Thermal Emission Imaging System visible imaging subsystem (THEMIS VIS), J. Geophys. Res., 111, E06018, doi:10.1029/2005JE002568.

McEwen, A. S., and E. B. Bierhaus (2006), The importance of secondary cratering to age constraints on planetary surfaces, Annu. Rev. Earth Planet. Sci., 34, 535-567.

McEwen, A. S., M. C. Malin, M. H. Carr, and W. K. Hartmann (1999), Voluminous volcanism on early Mars revealed in Valles Marineris, Nature, 397, 584-586.

McEwen, A. S., B. S. Preblich, E. P. Turtle, N. A. Artemieva, M. P. Golombek, M. Hurst, R. L. Kirk, D. M. Burr, and P. R. Christensen (2005), The rayed crater Zunil and interpretations of small impact craters on Mars, Icarus, 176, 351-381.

McKenzie, D., and F. Nimmo (1999), The generation of Martian floods by melting permafrost above dykes, Nature, 397, 231-233.

Mellon, M. T., and B. M. Jakosky (1993), Geographic variations in the thermal and diffusive stability of ground ice on Mars, J. Geophys. Res, 98, 3345-3364.

Mellon, M. T., and B. M. Jakosky (1995), The distribution and behavior of Martian ground ice during past and present epochs, J. Geophys. Res. 100, 11,781-11,799.

Mellon, M. T., and R. J. Phillips (2001), Recent gullies on Mars and the source of liquid water, J. Geophys. Res., 106, 23,165-23,180.

Mellon, M. T., B. M. Jakosky, H. H. Kieffer, and P. R. Christensen (2000), High-resolution thermal inertia mapping from the Mars Global Surveyor Thermal Emission Spectrometer, Icarus, 148, 437-455.

Melosh, H. J. (1984), Impact ejection, spallation, and the origin of meteorites, Icarus, 59, 234-260

Melosh, H. J. (1989), Impact Cratering: A Geologic Process, 253 pp., Oxford Univ. Press, New York.

Miller, S. B., and A. S. Walker (1993), Further developments of Leica digital photogrammetric systems by Helava, in ACSM/ASPRS Annual Convention and Exposition Technical Papers, vol. 3, pp. 256-263, American Congress on Surveying and Mapping, Gaithersburg, Md.

Miller, S. B., and A. S. Walker (1995), Die Entwicklung der digitalen photo-grammetrischen Systeme von Leica und Helava, Z. Photogramm. Fernerkundung, 1(95), 4-16.

Miyamoto, H., J. M. Dohm, R. A. Beyer, and V. R. Baker (2004), Fluid dynamical implications of anastomosing slope streaks on Mars, J. Geophys. Res., 109, E06008, doi:10.1029/2003JE002234.

Moore, J. M., and A. D. Howard (2005), Large alluvial fans on Mars, J. Geophys. Res., 110, E04005, doi:10.1029/2004JE002352.

Mouginis-Mark, P. (1979), Martian fluidized crater morphology: Variations with crater size, latitude, altitude, and target material, J. Geophys. Res., 84, 8011-8022

Mouginis-Mark, P. J., and P. R. Christensen (2005), New observations of volcanic features on Mars from the THEMIS instrument, J. Geophys. Res., 110, E08007, doi:10.1029/2005JE002421.

Mouginis-Mark, P. J., L. Wilson, and M. T. Zuber (1992), The physical volcanology of Mars, in Mars, edited by H. H. Kieffer et al., pp. 424 453, Univ. of Ariz. Press, Tucson.

Murchie, S., et al. (2007), Compact Reconnaissance Imaging Spectrometer for Mars on Mars Reconnaissance Orbiter, J. Geophys. Res., doi:10.1029 2006JE002682, in press.

Murray, B. C., L. A. Soderblom, J. A. Cutts, R. P. Sharp, D. J. Milton, and R. B. Leighton (1972), Geological framework of the south polar region of Mars, Icarus, 17, 328-345.

Mustard, J. F., C. D. Cooper, and M. K. Rifkin (2001), Evidence for recent climate change on Mars from the identification of youthful near-surface ground ice, Nature, 412, 411-414.
Nedell, S. S., S. W. Squyres, and D. W. Anderson (1987), Origin and evolution of the layered deposits in the Valles Marineris, Mars, Icarus, 70, 409-441.

Neukum, G., and R. Jaumann (2004), The High Resolution Stereo Camera of Mars Express, in Mars Express: The Scientific Payload, edited by A. Wilson, Eur. Space Agency Spec. Publ., ESA-SP 1240, 17-35.

Neumann, G. A., D. D. Rowlands, F. G. Lemoine, D. E. Smith, and M. T. Zuber (2001), The crossover analysis of MOLA altimetric data, J. Geophy. Res., 106(E10), 23,753-23,768.

Nimmo, F. (2005), Tectonic consequences of Martian dichotomy modification by lower-crustal flow and erosion, Geology, 3(7), 533-536.

Nyquist, L. E., D. D. Bogard, C.-Y. Shih, A. Greshake, D. Stoffler, and O. Eugster (2001), Ages and geologic histories of Martian meteorites, Space Sci. Rev., 96, 105-164.

Okubo, C. H. (2005), Assessing fault-controlled volatile migration in sedimentary rock, Geol. Soc. Am. Abstr. Programs, 37, 513.

Okubo, C. H., and R. A. Schultz (2005), Evolution of damage zone geometry and intensity in porous sandstone: Insight gained from strain energy density, J. Geol. Soc., 162, 939-950.

Okubo, C. H., and R. A. Schultz (2006), Variability in Early Amazonian Tharsis stress state based on wrinkle ridges and strike-slip faulting, J. Struct. Geol., 28, 2169-2181.

Palluconi, F. D., and H. H. Kieffer (1981), Thermal inertia mapping of Mars from $60 \mathrm{~S}$ to $60 \mathrm{~N}$, Icarus, 45, 415-426.

Parker, T. J., R. S. Saunders, and D. M. Schneeberger (1989), Transitional morphology in the west Deuteronilus Mensae region of Mars: Implications for modification of the lowland/upland boundary, Icarus, 82, $111-$ 145 .

Parker, T. J., D. S. Gorsline, R. S. Saunders, D. C. Pieri, and D. M. Schneeberger (1993), Coastal geomorphology of the Martian northern plain, J. Geophys. Res., 98, 11,061-11,078.

Pathare, A. V., D. A. Paige, and E. Turtle (2005), Viscous relaxation of craters within the Martian south polar layered deposits, Icarus, 174, 396418

Péwé, T. L. (1974), Geomorphic processes in polar deserts, in Polar Deserts and Modern Man, edited by T. L. Smiley and J. H. Zumberge, pp. 33-52, Univ. of Ariz. Press, Tucson.

Piqueux, S., S. Byrne, and M. I. Richardson (2003), Sublimation of Mars's southern seasonal $\mathrm{CO}_{2}$ ice cap and the formation of spiders, J. Geophys. Res., 108(E8), 5084, doi:10.1029/2002JE002007.

Plaut, J. J., R. Kahn, E. A. Guinness, and R. E. Arvidson (1988), Accumulation of sedimentary debris in the south polar region of Mars and implications for climate history, Icarus, 75, 357-377.

Quantin, C., P. Allemand, N. Mangold, G. Dromart, and C. Delacourt (2005), Fluvial and lacustrine activity on layered deposits in Melas Chasma, Valles Marineris, Mars, J. Geophys. Res., 110, E12S19, doi:10.1029/ 2005JE002440.

Rice, J. W., Jr., T. J. Parker, A. J. Russel, and O. Knudsen (2002), Morphology of fresh outflow channel deposits on Mars, Lunar Planet. Sci. XXXIII, Abstract 2026

Ritter, D. F., R. C. Kochel, and J. R. Miller (Eds) (1995), Process Geomorphology, 540 pp. Wm. C. Brown, Dubuque, Iowa.

Rosiek, M. R., R. L. Kirk, B. A. Archinal, E. Howington-Kraus, T. Hare, D. Galuszka, and B. Redding (2005), Utility of Viking Orbiter images and products for Mars mapping, Photogramm. Eng. Remote Sens., 71, $1187-1196$

Russell, P. S., A. Lefort, and N. Thomas (2005), Modeling ice stability with topography on a local scale, Lunar Planet. Sci., XXXVI, Abstract 15554.

Sagan, C., J. Veverka, P. Fox, R. Dubisch, J. Ledberg, E. Levinthal, L. Quam, R. Tucker, J. B. Pollack, and B. A. Smith (1972), Variable features in Mars: Preliminary Mariner 9 television results, Icarus, 17, $346-372$.

Sagan, C., et al. (1973), Variable features in Mars: 2. Mariner 9 global results, J. Geophys. Res., 78, 4163-4196.

Schaller, C. J. (2006), Automated HiRISE data processing: Conductor in action, Lunar Planet. Sci., XXXVII, Abstract 2134.

Schorghofer, N., O. Aharonson, and S. Khatiwala (2002), Slope streaks on Mars: Correlations with surface properties and the potential role of water, Geophys. Res. Lett., 29(23), 2126, doi:10.1029/ 2002GL015889.

Schultz, P. H. (1992), Atmospheric effects on ejecta emplacement, J. Geophys. Res., 97, 11,623-11,662.

Schultz, P. H., and D. E. Gault (1979), Atmospheric effects on Martian ejecta emplacement, J. Geophys. Res., 84, 7669-7687.

Schultz, P. H., and A. B. Lutz (1988), Polar wandering of Mars, Icarus, 73, 91-141.

Scott, D. H., and T. L. Tanaka (1986), Atlas of Mars: Western region, U.S. Geol. Surv. Misc. Invest. Ser, Map I-1802-A. 
Settle, M. (1979), Formation and deposition of volcanic sulfate aerosols on Mars, J. Geophys. Res., 84, 8343-8354.

Seu, R., D. Biccardi, R. Orsei, L. V. Lorenzoni, R. J. Phillips, L. Marinangeli, G. Picardi, A. Masdea, and E. Zampolini (2004), SHARAD: The MRO 2005 shallow radar, Planet. Space Sci., 52, $157-166$.

Seu, R., et al. (2007), SHARAD sounding radar on the Mars Reconnaissance Obiter, J. Geophys. Res., doi:10.1029/2006JE002745, in press.

Sharp, R. P. (1973), Mars: South polar pits and etched terrain, J. Geophys. Res., 78, 4222-4230.

Smith, B. A., and the Voyager Imaging Team (1989), Voyager 2 at Neptune: Imaging science results, Science, 246, 1422-1450.

Smith, P. H., and the Phoenix Science Team (2004), The Phoenix mission to Mars, Lunar Planet. Sci., XXXV, Abstract 2050.

Snyder, C. W., and V. I. Moroz (1992), Spacecraft exploration of Mars, in Mars, edited by H. H. Kieffer et al., pp. 71-119, Univ. of Ariz. Press, Tucson.

Squyres, S. W. (1979), The evolution of dust deposits in the Martian north polar region, Icarus, 40, 244-261.

Squyres, S. W. (1989), Urey prize lecture: Water on Mars, Icarus, 79, $229-$ 288

Squyres, S. W., and M. H. Carr (1986), Geomorphic evidence for the distribution of ground ice on Mars, Science, 231, 249-252.

Squyres, S. W., and J. F. Kasting (1994), Early Mars: How warm and how wet?, Science, 265, 744-748.

Squyres, S. W., et al. (2004a), In situ evidence for an ancient aqueous environment at Meridiani Planum, Mars, Science, 306, 1709-1714.

Squyres, S. W., et al. (2004b), The Spirit rover's Athena science investigation at Gusev Crater, Mars, Science, 305, 794-799.

Stewart, S. T., T. J. Ahrens, and J. D. O'Keefe (2004), Impact-induced melting of near-surface water ice on Mars: Shock compression of condensed matter, in Proceedings Conference of the American Physical Society Topical Group on Shock Compression of Condensed Matter, AIP Conf. Proc., 706, 1484-1487.

Strom, R. G., S. K. Croft, and N. G. Barlow (1992), The Martian impact cratering record, in Mars, edited by H. H. Kieffer et al., pp. 383-424, Univ. of Ariz. Press, Tucson.

Sugden, D. E., and B. S. John (Eds.) (1976), Glaciers and Landscape: A Geomorphological Approach, 376 pp., John Wiley, Hoboken, N. J.

Sullivan, R., P. Thomas, J. Veverka, M. Malin, and K. Edgett (2001), Mass movement slope streaks imaged by Mars Orbiter Camera, J. Geophys. Res., 106, 23,607-23,633.

Sullivan, R., et al. (2005), Eolian processes at the Mars Exploration Rover Meridiani Planum landing site, Nature, 436, 58-61.

Tanaka, K. L. (2000), Dust and ice deposition in the Martian geologic record, Icarus, 144, 254-266.

Tanaka, K. L., J. A. Skinner Jr., T. M. Hare, T. Joyal, and A. Wenker (2003), Resurfacing history of the northern plains of Mars based on geologic mapping of Mars Global Surveyor data, J. Geophys. Res., 108(E4), 8043, doi:10.1029/2002JE001908.

Thomas, N., L. Jorda, and W. Markiewicz (2000), Effect of diffuse sky brightness on the spectrophotometry of rough Martian surfaces, J. Geophys. Res., 105, 26,739-26,744.

Thomas, P., S. Squyres, K. Herkenhoff, A. Howard, and B. Murray (1992), Polar deposits on Mars, in Mars, edited by H. H. Kieffer et al., pp. $767-$ 795, Univ. of Ariz. Press, Tucson.

Thomas, P. C., and P. J. Gierasch (1985), Dust devils on Mars, Science, 230, $175-177$.

Thomas, P. C., J. Veverka, S. Lee, and A. Bloom (1981), Classification of wind streaks on Mars, Icarus, 45, 124-153.

Thomas, P. C., M. C. Malin, P. B. James, B. A. Cantor, R. M. E. Williams, and P. Gierasch (2005), South polar residual cap of Mars: Features, stratigraphy, and changes, Icarus, 174, 535-559.

Thordarson, T. (1995), Volatile release and atmospheric effects of basaltic fissure eruptions, Ph.D. thesis, 570 pp., Univ. of Hawaii at Manoa, Manoa.

Thordarson, T. (2000), Rootless eruptions and cone groups in Iceland: Products of authentic explosive water to magma interactions, in Volcano/Ice Interactions on Earth and Mars, edited by V. C. Gulick and M. T. Gudmundsson, 48 pp., Univ. of Iceland, ReykjavIk.

Thordarson, T., and S. Self (1993), The Laki (Skaftár Fires) and Grímsvötn eruptions in 1783-1785, Bull. Volcanol., 55, 233-263.

Thordarson, T., and S. Self (1998), The Roza Member, Columbia River Basalt Group: A gigantic pahoehoe lava flow field formed by endogenous processes?, J. Geophys. Res., 103, 27,411-27,445.

Titus, T. N., H. H. Kieffer, K. F. Mullins, and P. R. Christensen (2001), TES premapping data: Slab ice and snow flurries in the Martian north polar night, J. Geophys. Res., 106, 23,181-23,196.
Toon, O. B., J. B. Pollack, W. Ward, J. A. Burns, and K. Bilski (1980), The astronomical theory of climatic change on Mars, Icarus, 44, 552-607.

Touma, J., and J. Wisdom (1993), The chaotic obliquity of Mars, Science, 259, 1294-1297.

van Gasselt, S., D. Reiss, A. K. Thorpe, and G. Neukum (2005), Seasonal variations of polygonal thermal contraction crack patterns in a south polar trough, Mars, J. Geophys. Res., 110, E08002, doi:10.1029/2004JE002385.

Ward, A. W. (1979), Yardangs on Mars: Evidence of recent wind erosion, J. Geophys. Res., 84, 8147-8166.

Ward, A. W., K. B. Doyle, P. J. Helm, M. K. Weisman, and N. E. Witback (1985), Global map of eolian features on Mars, J. Geophys. Res., 90 2038-2056.

Ward, W. R. (1974), Climatic variations on Mars: 1. Astronomical theory of insolation, J. Geophys. Res., 79, 3375-3386.

Ward, W. R. (1979), Present obliquity oscillations of Mars: Fourth-order accuracy in orbital e and I, J. Geophys. Res., 84, 237-241.

Washburn, A. L. (Eds.) (1980), Geocryology: A Survey of Periglacial Processes and Environments, John Wiley, Hoboken, N. J.

Weitz, C. M., T. J. Parker, F. S. Anderson, and J. A. Grant (2001), The interior layered deposits of Valles Marineris: Layering, erosional processes, and age relationships, Lunar Planet. Sci. [CD-ROM], XXXII, Abstract 1629.

Williams, J.-P., D. A. Paige, and C. E. Manning (2003), Layering in the wall rock of Valles Marineris: intrusive and extrusive magmatism, Geophys. Res. Lett., 30(12), 1623, doi:10.1029/2003GL017662.

Williams, P. J., and M. W. Smith (Eds.) (1989), The Frozen Earth, Cambridge Univ. Press, New York.

Williams, R. M., and K. S. Edgett (2004), MGS MOC perspectives on the role of fluids in impact crater formation and modification, Eos Trans. $A G U, 85(47)$, Fall Meet. Suppl., Abstract P33B-03.

Williams, R. M., M. C. Malin, and K. S. Edgett (2005), Remnants of the courses of fine-scale, precipitation-fed runoff streams preserved in the Martian rock record, Lunar Planet. Sci., XXVVI, Abstract 1173.

Wilson, L., and J. W. Head (1994), Mars: Review and analysis of volcanic eruption theory and relationships to observed landforms, Rev. Geophys., $32,221-263$.

Wu, G. K., M. J. Gormish, and M. P. Boliek (2000), New compression paradigms on JPEG 2000, Proc. SPIE Int. Soc. Opt. Eng., 4115, $418-$ 429 .

Zimbelman, J. R. (2000), Non-active dunes in the Acheron Fossae region of Mars between the Viking and Mars Global Surveyor eras, Geophys. Res. Lett., 27, 1069-1072.

Zuber, M. T., and D. E. Smith (1997), Mars without Tharsis, J. Geophys. Res., 102, 28,673-28,686.

Zuber, M. T., et al. (2000), Internal structure and early thermal evolution of Mars from Mars Global Surveyor topography and gravity, Science, 287, $1788-1793$

Zurek, R. W., and S. E. Smrekar (2007), An overview of the Mars Reconnaissance Orbiter (MRO) science mission, J. Geophys. Res., doi:10.1029/ 2006JE002701, in press.

J. W. Bergstrom, Ball Aerospace \& Technologies Corp., 1600 Commerce Street, Boulder, CO 80301, USA.

N. T. Bridges and C. J. Hansen, Jet Propulsion Laboratory, 4800 Oak Grove Drive, Pasadena, CA 91109, USA.

W. A. Delamere, Delamere Support Systems, 525 Mapleton Avenue, Boulder, CO 80304, USA.

E. M. Eliason and A. S. McEwen, Lunar and Planetary Laboratory, University of Arizona, Tucson, AZ 85721, USA. (mcewen@pirl.lpl. arizona.edu)

J. A. Grant, Smithsonian Institution, National Air and Space Museum, 6th at Independence SW, Washington, DC 20560, USA.

V. C. Gulick, NASA Ames Research Center and SETI Institute, Moffett Field, CA 94035, USA.

K. E. Herkenhoff, L. Keszthelyi, and R. L. Kirk, U.S. Geological Survey, 2255 North Gemini Drive, Flagstaff, AZ 86001, USA.

M. T. Mellon, Laboratory for Atmospheric and Space Physics, University of Colorado, 392 UCB, Boulder, CO 80309, USA.

S. W. Squyres, Department of Astronomy, Cornell University, 428 Space Sciences Building, Ithaca, NY 14853, USA.

N. Thomas, Physikalisches Institut, University of Bern, Sidlerstr. 5, CH-3012, Bern, Switzerland.

C. M. Weitz, Planetary Science Institute, 1700 East Ft. Lowell, Tucson, AZ 85719, USA. 